\title{
Effects of herbivory by white -tailed deer (Odocoileus virginianus Zimm.) on the population ecology and conservation biology of American ginseng (Panax quinquefolius L.)
}

\author{
Mary Ann Furedi \\ West Virginia University
}

Follow this and additional works at: https://researchrepository.wvu.edu/etd

\section{Recommended Citation}

Furedi, Mary Ann, "Effects of herbivory by white -tailed deer (Odocoileus virginianus Zimm.) on the population ecology and conservation biology of American ginseng (Panax quinquefolius L.)" (2004). Graduate Theses, Dissertations, and Problem Reports. 2138.

https://researchrepository.wvu.edu/etd/2138

This Dissertation is protected by copyright and/or related rights. It has been brought to you by the The Research Repository @ WVU with permission from the rights-holder(s). You are free to use this Dissertation in any way that is permitted by the copyright and related rights legislation that applies to your use. For other uses you must obtain permission from the rights-holder(s) directly, unless additional rights are indicated by a Creative Commons license in the record and/ or on the work itself. This Dissertation has been accepted for inclusion in WVU Graduate Theses, Dissertations, and Problem Reports collection by an authorized administrator of The Research Repository @ WVU.

For more information, please contact researchrepository@mail.wvu.edu. 
Effects of herbivory by white-tailed deer (Odocoileus virginianus Zimm.) on the population ecology and conservation biology of American ginseng (Panax quinquefolius L.)

\author{
Mary Ann Furedi \\ Dissertation submitted to the \\ Eberly College of Arts and Sciences \\ at West Virginia University \\ in partial fulfillment of the requirements \\ for the degree of \\ Doctor of Philosophy \\ in \\ Biology \\ James B. McGraw, Ph.D. Chair \\ James Anderson Ph.D. \\ Jonathan Cumming Ph.D. \\ Donna Ford-Werntz Ph.D. \\ Richard Thomas Ph.D. \\ Department of Biology \\ Morgantown, West Virginia \\ 2004
}

Keywords: American ginseng, demographic matrix modeling, herbivory, plant-animal interactions, white-tailed deer, wild-harvested plants

Copyright 2004 Mary Ann Furedi 


\title{
ABSTRACT \\ Effects of herbivory by white-tailed deer (Odocoileus virginianus Zimm.) on the population ecology and conservation biology of American ginseng (Panax quinquefolius L.)
}

\begin{abstract}
Mary Ann Furedi
American ginseng (Panax quinquefolius L.) is a long-lived understory herb considered rare within its range. Harvesting pressures and habitat degradation/destruction are thought to be the primary causes of population decline although others factors such as browsing by white-tailed deer (Odocoileus virginianus Zimm.) have not yet been explored. To understand the effects of deer browsing on natural ginseng populations, my research focused on four specific objectives. First, I investigated how plant characteristics and microsite conditions influence the susceptibility to being browsed. I found that apparency plays a role in influencing browse selection, such that large, reproductive plants in visible and accessible areas are more prone to browse than smaller, protected plants. The second study addressed the effects of deer browsing on individual plant growth, reproduction, and fate. Complete browsing terminated growth and reproduction in the season that it occurred. Carryover effects such as reductions in sizerelated measures, bud number, alteration of reproductive status, and reemergence were seen in the season following the browsing event. Consecutive years of browsing magnified these effects. The third study examined the role of deer as possible dispersers of ginseng seeds. The results of feeding trials using captive deer revealed that seeds are destroyed during the processes of mastication and digestion. Thus, deer are predators and not dispersers of ginseng seeds. Loss of seeds can negatively impact the seed bank and ultimately population growth and viability. The fourth study investigated the effects of deer browsing on population growth $(\lambda)$ using demographic matrix models. The general effect of deer browsing was a decline in $\lambda$. These reductions in $\lambda$ are most likely due to selective browsing, carryover effects, and seed destruction. The overall conclusion from these studies is that overabundant white-tailed deer are negatively impacting natural ginseng populations. Due to current browse pressures, natural ginseng populations may be unable to support both deer and harvest. A plausible solution to this problem is the reduction of deer herds.
\end{abstract}




\section{ACKNOWLEDGMENTS}

Many individuals have been instrumental in helping me complete this research.

First and foremost, I must recognize the support and guidance given to me by my advisor, Dr. James B. McGraw. I sincerely thank him for his continuous help with this project. I am also grateful to my committee members, Jim Anderson, Jonathan Cumming, Donna Ford-Werntz, and Richard Thomas, for their critiques throughout this process.

I thank Beth Adams and the staff at the Fernow Experimental Forest in Parsons, WV for not only the use of the forest in my studies but also for the use of the bunkhouse. Although I do enjoy camping, after a long day in the field, it is always a pleasure to take a hot shower and have a bed to sleep in. I thank Bob Driscoll at the West Virginia University Forest for his help over the last five years.

I am eternally grateful to all of my field assistants, Gera Jochum, Rebecca Kenyon, Nathan Kota, Sara Lightner, Rick May, Emily Mooney, Mary Olive, and Chris Packert, for their enthusiasm and willingness to work under ALL conditions. Without their help, I would probably still be in the field. I would like to thank my fellow graduate students, faculty, and staff in the Department of Biology at West Virginia University for all of their support over the last five years. My family and friends must also be recognized for their continual support in my endeavors. Finally, I must thank my fiancé, Rick May. Thank you for understanding my goals in life and giving me the freedom and emotional support to achieve them.

This research was supported by the National Science Foundation grant DEB 0212411 to J. B. McGraw. 


\section{TABLE OF CONTENTS}

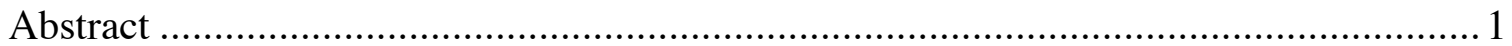

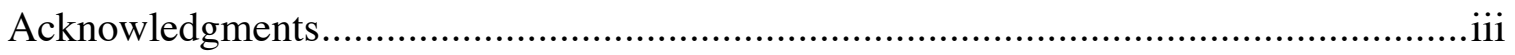

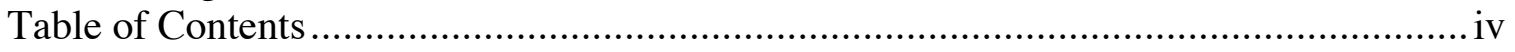

List of Figures ................................................................................................. vi

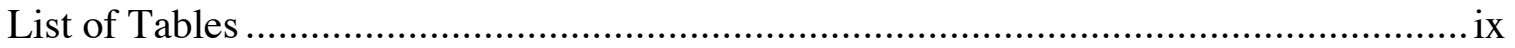

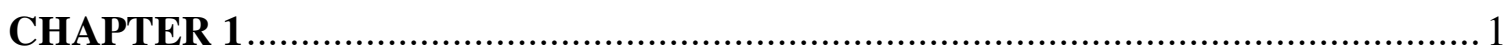

General Introduction .................................................................................. 1

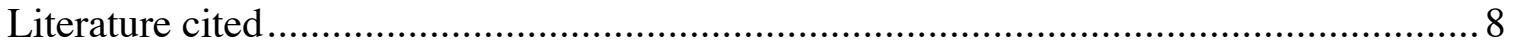

CHAPTER 2

Conservation biology of American ginseng (Panax quinquefolius L.): The influence of plant characteristics and microsite conditions on herbivory by white-tailed deer

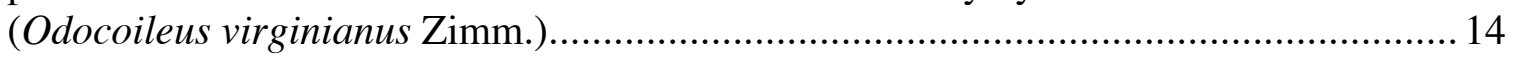

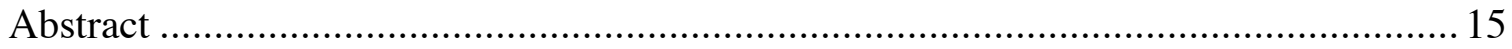

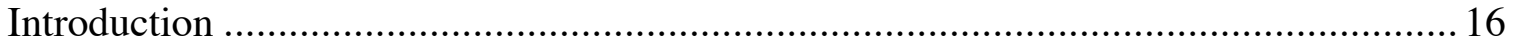

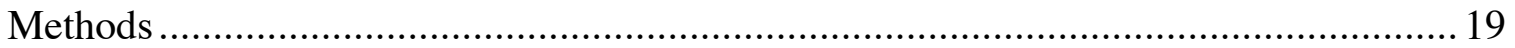

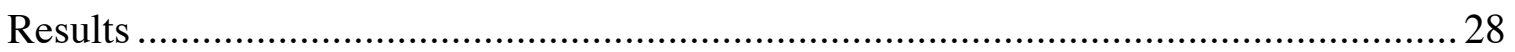

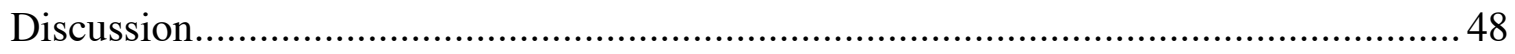

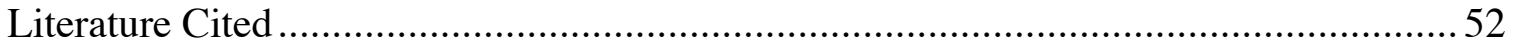

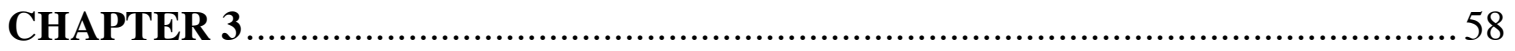

Effects of browsing by white-tailed deer (Odocoileus virginianus Zimm.) on growth, reproduction, and survival of American ginseng, (Panax quinquefolius L.) .................. 58

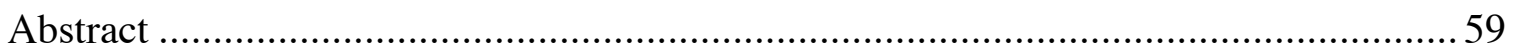

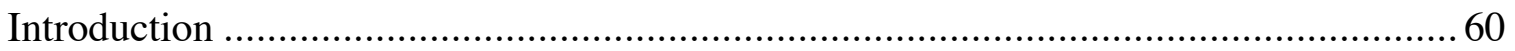

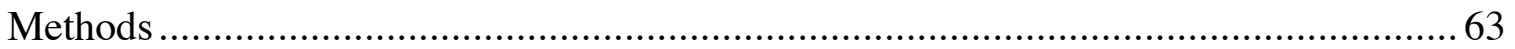

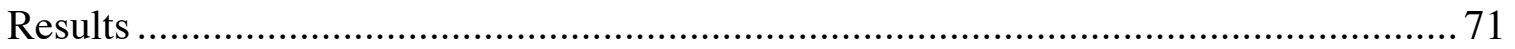

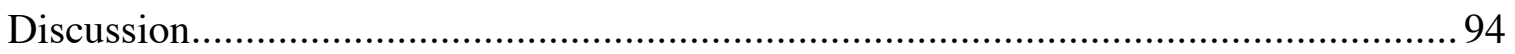

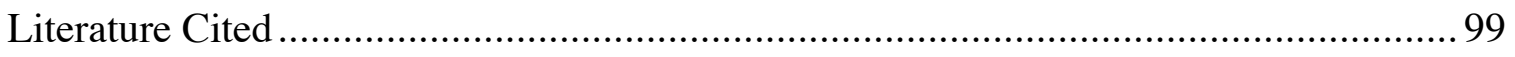

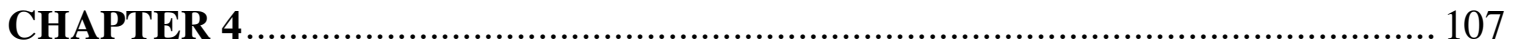

White-tailed deer: Dispersers or predators of American ginseng seeds?..................... 107

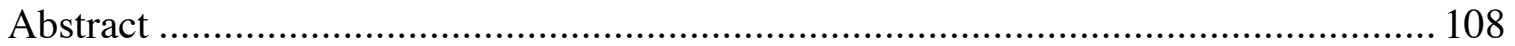

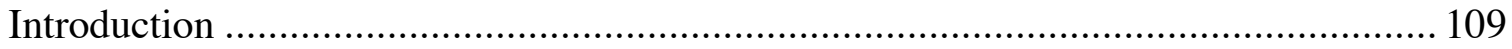

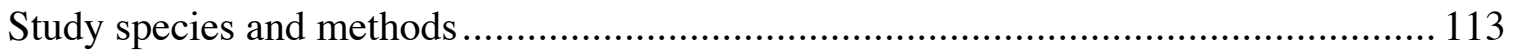

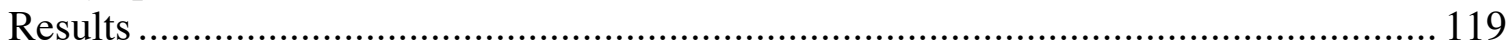




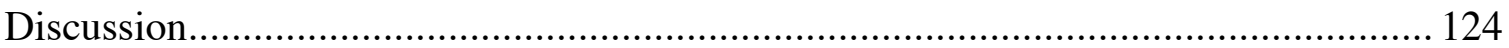

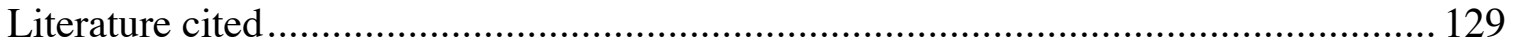

CHAPTER 5

Demography of American ginseng: effects of herbivory by white-tailed deer ............. 135

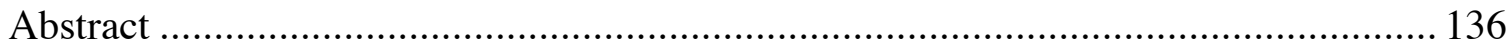

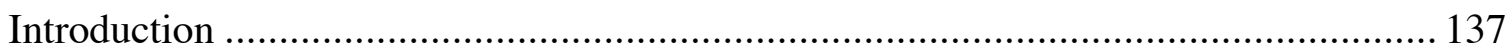

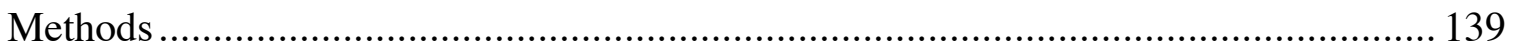

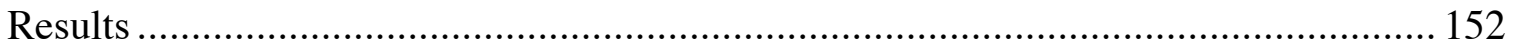

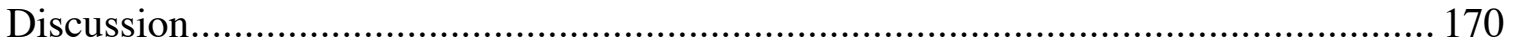

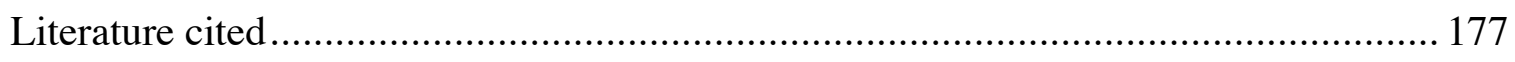

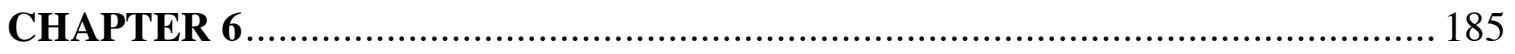

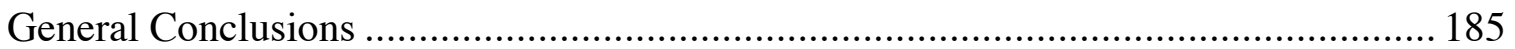

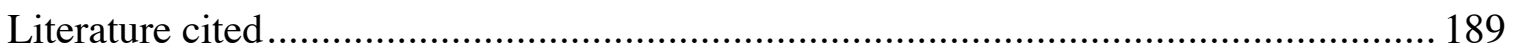

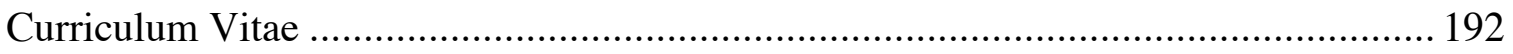




\section{LIST OF FIGURES}

Figure 2.1. The relationship between deer browsing rates and deer density estimates in six natural populations of American ginseng in West Virginia.

Figure 2.2. The proportion of ginseng plants browsed by deer in population $\mathrm{W} 2$ as a function of (a) leaf number, and (b) reproductive status. (c) The relationship between the probability of being browsed by deer and leaf area of ginseng plants in population $\mathrm{W} 2$.

Figure 2.3. (a) The relationship between the probability of being browsed by deer and sympodium height of ginseng plants in the pooled populations (BG, BN, CR, and W4). (b) The proportion of ginseng plants browsed in the pooled populations as a function of reproductive status. (c) The relationship between the probability of being browsed and fruit number in the pooled populations

Figure 2.4. The proportion of ginseng plants browsed in: (a) the natural populations as a function of height compared to neighboring species, (b) population W2 as a function of distance from deer paths, and (c) population $\mathrm{P} 4$ as a function of microsite location.

Figure 2.5. The proportion of browsed plants in population $\mathrm{P} 5$ as a function of distance from deer paths $(\mathrm{N}=$ within $2 \mathrm{~m}, \mathrm{~F}=$ greater than $2 \mathrm{~m})$, plant density $(\mathrm{S}=$ single plant, $\mathrm{C}=$ cluster $)$, and microsite location $(\mathrm{O}=$ open areas, $\mathrm{S}=$ under shrubs, $\mathrm{R}=$ other areas of refugia)

Figure 2.6. The proportion of ginseng plants browsed in the experimental populations as a function of: (a) distance from deer paths, (b) microsite locations, and (c) plant density

Figure 3.1. Comparisons of the mean relative growth rates of ginseng plants in the simulated browse experiment exposed to three browse treatments (a) on a leaf area basis, and (b) on a sympodium height basis (means $\pm 1 \mathrm{SE}$ ). Means with the same letters are not significantly different.

Figure 3.2. Comparison of the mean relative growth rate on a bud number basis of 3and 4-leaf plants in the simulated browse experiment exposed to three browse treatments (means $\pm 1 \mathrm{SE}$ ). Means with the same letters are not significantly different

Figure 3.3. Comparisons of the mean relative growth rates of ginseng plants exposed to three levels of natural deer browsing (a) on a leaf area basis, and (b) on a sympodium height basis (means $\pm 1 \mathrm{SE}$ ) 
Figure 3.4. Comparisons of the mean relative growth rate on a bud number basis of 3and 4-leaf plants experiencing natural rates of deer browsing (means $\pm 1 \mathrm{SE}$ ). Means with the same letters are not significantly different.

Figure 3.5. Proportion of browsed ginseng plants not emerging in the spring census 2003 as a function of browse occurrence.

Figure 3.6. Proportion of browsed ginseng plants in the natural populations as a function of the time interval when browsing occurred (Julian day) in: (a) 2000, (b) 2001, (c) 2002, and (d) 2003 .

Figure 3.7. Mean change in leaf area occurring from (a) 2001 to 2002, and (b) 2002 to 2003 as a function of the time interval when browsing occurred (Julian day).

Figure 4.1. Browsing effects in seven natural populations of American ginseng over three growing seasons, including: (a) the proportion of fruiting plants that were either partially or completely browsed by deer, (b) the proportion fruiting plants whose fruits were consumed by deer, and (c) the proportion of all forming or ripe seeds that were consumed by deer.

Figure 5.1. Life cycle diagram of American ginseng showing the five classes (seeds, 1leaf plants, 2-leaf plants, small adults, and large adults) and all possible transitions between the classes (s) when all plants were included in the calculation of the mean matrix $\left(\mathbf{A}_{\mathbf{H}}\right)$ and (b) when only unbrowsed plants were included in the calculation of the mean matrix $\left(\mathbf{A}_{\mathrm{NH}}\right)$. The mean probabilities of transitioning from one class to another $\left(a_{i j}\right)$ are indicated with numbers above each arrow. The dotted arrows below each class represent the proportion of plants that died

Figure 5.2. The population growth rate $(\lambda)$ of seven natural populations of American ginseng and the combined populations for the following one-year intervals: (a) the mean $\lambda$ for each population, (b) 2000-01, (c) 2001-02, (d) 2002-03, and (e) 2003-04 (includes $\pm 1 \mathrm{SE}$ ).

Figure 5.3. The sample influence function (SIF) of individuals in the combined population with herbivory $(\mathrm{H})$ and in the combined population without herbivory (NH) undergoing all possible transitions within (a) class 1, (b) class 2, (c) class 3, (d) class 4, and (e) class 5. The class transitions represent a plant going from one class to another in a one-year interval $\left(a_{i j}\right)$. Plants transitioning from class $j$ to class 6 have died. 
Figure 5.4. (a) The relationship between the mean sample influence function (SIF) of individuals and the number of seeds produced in all possible reproductive transitions both when deer browsing is included and when it is excluded. The dotted regression line represents the relationship when deer browsing is included. The solid line represents the relationship when browsing is excluded. (b) The mean residuals around the deer browsing regression line for each reproductive class transition

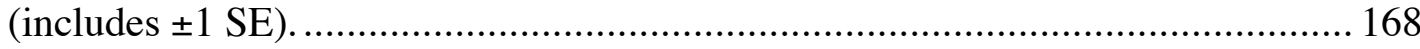




\section{LIST OF TABLES}

Table 2.1. Site characteristics, deer density estimates from pellet counts, and the proportion of plants browsed in seven natural populations of American ginseng found in north-central West Virginia.

Table 2.2. The effects of several plant characteristics on susceptibility to deer browsing occurring in natural populations of American ginseng. The table includes the likelihood ratio chi-square values for each effect along with their associated $\mathrm{P}$ values in parentheses.

Table 2.3. The effects of several microsite characteristics on deer browsing occurring in natural populations of American ginseng. The table includes the likelihood ratio chi-square values for each effect along with the associated $\mathrm{P}$ values in parentheses.

Table 2.4. The effects of distance from a deer path, microsite location, and plant density on whether or not ginseng plants in two experimental populations are browsed by deer. The table includes the likelihood ratio chi-square values for each effect along with the associated $\mathrm{P}$ values in parentheses.

Table 3.1. Site characteristics of eight natural populations of American ginseng studied in north-central West Virginia, 2000-2003.

Table 3.2. Proportion of ginseng plants browsed in seven natural populations showing the overall browse rates for 2000-2003 and the proportion of plants browsed in each size class. (No data are available for W4 in 2000. Censusing of this population began in 2001.)

Table 3.3. The effect of the time interval when browsing occurred (Julian day) on the change in sympodium height, change in leaf area, and bud number over three oneyear intervals (200-2001, 2001-2002, and 2002-2003). The table includes F-values and their associated $p$-values in parentheses.

Table 4.1. The population size, number of reproductive individuals, and the deer browsing rates of reproductive plants found in seven natural populations of American ginseng from 2001-2003

Table 5.1. Transition matrix model (A) for American ginseng. Each matrix element $\left(a_{i j}\right)$ represents the probability that an individual of stage $i$ will be derived from an individual stage $j$ in one time interval. 
Table 5.2. Proportion of ginseng plants deer browsed in seven natural populations showing the proportion of plants browsed in each size class and the total browse rate per population for 2000-2003. (No data is available for W4 in 2000. Monitoring of this population began in 2001.)

Table 5.3. Elasticities $\left(e_{i j}\right)$ corresponding to the mean herbivory matrix $\left(\mathrm{A}_{\mathrm{H}}\right)$ and the mean no herbivory matrix $\left(\mathrm{A}_{\mathrm{NH}}\right)$. The matrix elements having the greatest effect on $\lambda$ are in bold.

Table 5.4. Results of a life table response experiment (LTRE) for American ginseng showing how the two components responsible for changing $\lambda\left(\Delta a_{i j}\right.$ and $\left.s_{i j}\right)$ varied among the possible life-stage transitions observed. Those transitions with the greatest contributions are shown in bold. The $a_{i j}$ values are from the mean no herbivory matrix $\left(\mathrm{A}_{\mathrm{NH}}\right)$ and the mean herbivory matrix $\left(\mathrm{A}_{\mathrm{H}}\right)$. The $s_{i j}$ values of each matrix element are from the average matrix of $A_{\mathrm{NH}}$ and $A_{H}$ 


\section{CHAPTER 1}

General Introduction 
American ginseng (Panax quinquefolius L.) is a long-lived perennial herb found in the deciduous forests of the northeastern United States and southern Canada. The range of this species extends from southern Quebec to northern Georgia and from the east coast states to Missouri (Anderson et al. 1984; Robbins 1998). In the central Appalachian region, American ginseng is usually associated with rich, north-facing forest coves although McGraw et al. (2003) found that ginseng occupies a broader niche than previously thought.

American ginseng consists of a thick taproot attached to a narrow rhizome (Charron and Gagnon 1991). An aerial stem or sympodium arises from the rhizome. One to several leaves (prongs), consisting of three to seven leaflets, are located at the summit of the sympodium. Leaf number is a rough indicator of age (i.e., a three-leaf plant is typically at least five years old), although variation in growth rates is high such that plants may remain as subadults for many years (Carpenter and Cottam 1982). Newly emerged seedlings have one leaf with three leaflets. In subsequent years, a young plant will develop four or five leaflets and eventually two or more leaves (Lewis and Zenger 1982). If damage occurs, a plant may revert back to a smaller size class in the following season. Flower development does not occur until a plant has produced at least two leaves. Charron and Gagnon (1991) and Nantel et al. (1996) used these discrete size classes to examine population dynamics and population viability of four populations in southern Quebec.

Growth of American ginseng begins each spring after tree canopy closure (Lewis and Zenger 1982). Plants emerge from winter dormancy in late April to early May 
(Hackney and McGraw 2001). Anthesis is reached in mid-May and continues until late July. Berry development and maturation begins in late June and continues until October (Carpenter and Cottam 1982). Fruit maturation is marked by the bright red color of the exocarp. Mature berries contain one to three seeds (Lewis and Zenger 1982; Anderson et al. 1984). Once dispersed, a seed germination period of 18 months or more is required (Hackney and McGraw 2001). The formation of a seed bank aids in population restoration after disturbance (Lewis 1984; Van der Voort et al. 2003).

Despite being a long-lived perennial and occupying such a broad distribution, American ginseng populations are becoming increasingly rare. This rarity has been thought to be associated with the harvesting of American ginseng to supply the global demands of the herbal market (Charron and Gagnon 1991; Robbins 1998; McGraw 2001). Anecdotal evidence in the form of export records (Carlson 1986; Robbins 1998), distribution (McGraw et al. 2003), and a reduction in size-related plant traits (McGraw 2001) have suggested that natural populations are in decline. As a result this evidence suggesting declining natural populations in the United States, ginseng was listed in 1973 as an Appendix II species of the Convention on International Trade in Endangered Species of Wild Fauna and Flora (CITES) (Robbins 1998). The U.S. Office of Scientific Authority is required to issue a "no-detriment" finding on a state-by-state basis if harvesting is to continue.

Another pressure that has not been investigated but may also be contributing to the rarity of American ginseng is herbivory by white-tailed deer (Odocoileus virginianus Zimm.). As a result of strict hunting regulations, land-use changes, and loss of top predators, white-tailed deer are now the most abundant wild ungulate in North America. 
According to archeological evidence of deer consumption rates made by native Americans and early European settlers (McCabe and McCabe 1997), deer densities are currently two to four times higher than pre-settlement densities in some areas of the United States (Alverson et al. 1988; Van Deelen et al. 1996). As keystone herbivores in the eastern deciduous forests, large deer herds can alter biotic communities within forest ecosystems (Waller and Alverson, 1997; Rooney 2001; Gill and Beardall 2001; Rooney and Waller 2003). The building body of evidence suggests that deer are negatively impacting many aspects of the forest community. Studies have shown that deer browsing not only depresses the growth of valuable tree species (Russell et al. 2001; Horsley et al. 2003; Rooney and Waller 2003) and several herbaceous species (Anderson 1994; Rooney and Dress 1997; Augustine and Frelich 1998; Fletcher et al. 2001; Rooney and Gross 2003; Knight 2004) but also decreases species richness and abundance (Hough 1965; Horsley and Marquis 1983; Van Deelen et al. 1996; Rooney and Dress 1997; Russell et al. 2001; Horsley et al. 2003) and has contributed to the local extirpation of some rare plant species (Miller et al. 1992). In addition, overabundant deer populations have been associated with indirect negative impacts on bird (deCalesta 1994; McShea and Rappole 1997; Fuller 2001) and small mammal populations (Flowerdew and Ellwood 2001). Although no studies have focused directly on the effects of deer browsing on American ginseng, two studies suggest that deer are negatively impacting ginseng. A review of rare and threatened vascular plants by Miller et al. (1992) listed ginseng as a plant species disturbed by deer. Furthermore, a study of size-related morphometric traits of American ginseng by McGraw (2001) suggested that deer could be responsible in part for size declines seen in herbarium specimens over the past century. This time period 
over which the decline occurred corresponds roughly with the time when deer herds began to grow to densities large enough to be damaging to forest vegetation in the eastern United States (Porter 1994). Based on these studies, the growing body of evidence showing deer damage to forest ecosystems, anecdotal evidence suggesting ginseng declines, and personal observations of deer browsing occurring in ginseng populations, the overall goal of my dissertation work was to examine the effects of deer browsing on individual plant growth, reproduction, and survival and to understand how these effects alter population growth.

To understand the influence and effects of browsing by white-tailed deer on American ginseng, my research was focused on four specific objectives. First, I investigated how plant characteristics and microsite conditions influenced susceptibility to browsing by white-tailed deer. This objective was achieved by measuring plant characteristics and microsite conditions of individual plants in seven natural populations of American ginseng and monitoring which plants were browsed by deer. From these measurements and observations, I developed a set of inferences about characteristics that influence plant susceptibility to browsing. The validity of these inferences was further tested in two experimental populations. The results of this study are presented in Chapter 2 and have been submitted to Journal of the Torrey Botanical Society.

The second objective addressed the potential effects of deer browsing on individual plant growth, reproduction, and survival in the year that browsing occurred and subsequent years. This objective was met by using both multi-year observational studies of seven natural populations and experimental studies where browsing was simulated. After determining the effects of deer browsing, I further examined whether 
the timing of browse occurrence during a growing season impacted the overall effects of deer browsing. The combined results of these studies are reported in Chapter 3 and has been submitted to American Journal of Botany.

The purpose of the third objective was to examine the role of deer as possible dispersal agents of American ginseng seeds. I quantified the frequency of frugivory by white-tailed deer in natural ginseng populations. Feeding trials were then conducted using captive white-tailed deer to determine the fate of consumed ginseng seeds. The details of this study are found in Chapter 4 and have been published in The American Midland Naturalist (Furedi and McGraw 2004).

The fourth objective was to investigate the effects of deer browsing on population growth using demographic matrix models. Demographic data from seven natural populations of ginseng was gathered over a five-year period (2000-2004) along with the incidence of deer browsing for individual plants in each population. Two sets of population matrix models were constructed, one containing all plants whether browsed or unbrowsed and one containing only unbrowsed plants. Population growth rate $(\lambda)$ was calculated using MATLAB (1993) and several analyses were conducted to examine the change in vital rates due to browsing (life table response experiment) and how the contribution of individuals to $\lambda$ is altered by deer browsing (sample influence function analysis). These results are addressed in Chapter 5 and will be submitted to Conservation Biology.

As suggested by Schemske et al. (1994), effective management of a species is built on an understanding of that species' demography, important life history stages, and how biological processes affect life stages. All of these elements are investigated in this 
dissertation work. The results of these studies can be applied to the management of ginseng since they provide new information on the demography of American ginseng in the range center. Both managers of ginseng and wildlife can benefit from the understanding that another pressure besides human harvesting is affecting ginseng populations. The impacts of deer browsing must be considered in combination with human harvesting if ginseng populations are to persist. 


\section{Literature cited}

Alverson, W. S., D. M. Waller, and S. L. Solheim. 1988. Forest too edge: edge effects in northern Wisconsin. Conservation Biology 2: 348-358.

Anderson, R. C., F. S. Fralish, J. Armstrong, and P. Benjamin. 1984. Biology of ginseng (Panax quinquefolium) in Illinois. Department of Conservation, Division of Forest Resources and Natural Heritage, Springfield, Illinois.

Anderson, R. C. 1994. Height of white-flowered trillium (Trillium grandiflorum) as an index of deer browsing intensity. Ecological Applications 4: 104-109.

Augustine, D. J. and L. E. Frelich. 1998. Effects of white-tailed deer on populations of an understory forb in fragmented deciduous forests. Conservation Biology 12: 995-1004.

Carlson, A. W. 1986. Ginseng - America's botanical drug connection to the Orient. Economic Botany 40: 233-249.

Carpenter, S. G. and G. Cottam. 1982. Growth and reproduction of American ginseng (Panax quinquefolius) in Wisconsin. Canadian Journal of Botany 60: 2692-2696. 
Charron, D. and D. Gagnon. 1991. The demography of northern populations of Panax quinquefolius (American ginseng). Journal of Ecology 79: 431-445.

deCalesta, D. S. 1994. Effects of white-tailed deer on songbirds within managed forests in Pennsylvania. Journal of Wildlife Management 58: 711-718.

Fletcher, J. D., L. A. Shipley, W. J. McShea, and D. L. Shumway. 2001. Wildlife herbivory and rare plants: the effects of white-tailed deer, rodents, and insects on growth and survival of Turk's cap lily. Biological Conservation 101: 229-238.

Flowerdew, J. R. and S. A. Ellwood. 2001. Impacts of woodland deer on small mammal ecology. Forestry 74: 278-287.

Fuller, R. J. 2001. Responses of woodland birds to increasing numbers of deer: a review of evidence and mechanisms. Forestry 74: 290-298.

Furedi, M. and J. B. McGraw. 2004. White-tailed deer: dispersers or predators of American ginseng seeds? American Midland Naturalist 152: 268-276.

Gill, R. M. A. and V. Beardall. 2001. The impact of deer on woodlands: the effects of browsing and seed dispersal on vegetation structure and composition. Forestry 74: 209-218. 
Hackney, E. E. and J. B. McGraw. 2001. Experimental demonstration of an Allee effect in American ginseng. Conservation Biology 15: 129-136.

Horsley, S. B. and D. A. Marquis. 1983. Interference by weeds and deer with Allegheny hardwood reproduction. Canadian Journal of Forest Resources 13: 61-69.

Horsley, S. B., S. L. Stout, and D. S. deCalesta. 2003. White-tailed deer impact on the vegetation dynamics of a northern hardwood forest. Ecological Applications 13: 98-118.

Hough, A. F. 1965. A twenty year record of understory vegetational change in a virgin Pennsylvania forest. Ecology 46: 370-373.

Knight, T. M. 2004. The effects of herbivory and pollen limitation on a declining population of Trillium grandiflorum. Ecological Applications 14: 915-928.

Lewis, W. H. and V. E. Zenger. 1982. Population dynamics of the American ginseng Panax quinquefolium (Araliaceae). American Journal of Botany 69: 1483-1490.

Lewis, W. H. 1984. Population structure and environmental corollaries of Panax quinquefolium in Delaware County, New York. Rhodora 86: 431-437.

MATLAB. 1993. MathWorks. Version 4.0. Natick, Massachusetts, USA. 
McCabe, R. E. and T. R. McCabe. 1997. Recounting whitetails past. In: W. J. McShea, H. B. Underwood and J. H. Rappole (eds), The science of overabundance: deer ecology and population management. Smithsonian Institution Press, Washington D. C., pp. 11-26.

McGraw, J. B. 2001. Evidence for decline in stature of American ginseng plants from herbarium specimens. Biological Conservation 98: 25-32.

McGraw, J. B., S. M. Sanders, and M. Van der Voort. 2003. Distribution and abundance of Hydrastis canadensis L. (Ranunculaceae) and Panax quinquefolius L. (Araliaceae) in the central Appalachian region. Journal of the Torrey Botanical Society 130: 62-69.

McShea, W. J. and J. H. Rappole. 1997. Herbivores and the ecology of forest understory birds. In: W. J. McShea, H. B. Underwood, and J. H. Rappole (eds), The science of overabundance: deer ecology and population management. Smithsonian Institution Press, Washington D. C., pp. 298-309.

Miller, S. G., S. P. Bratton, and J. Hadidian. 1992. Impacts of white-tailed deer on endangered and threatened vascular plants. Natural Areas Journal 12: 67-74. 
Nantel, P., D. Gagnon, and A. Nault. 1996. Population viability analysis of American ginseng and wild leek harvested in stochastic environments. Conservation Biology 10: 608-621.

Porter, W. F. 1994. Burgeoning ungulate populations in national parks: is intervention warranted? In: D. R. McCullough and R. H. Barret (eds), Wildlife 2001: populations. Elsevier, New York, New York, USA, pp. 304-312.

Robbins, C. S. 1998. American ginseng: the root of North America's medicinal herb trade. TRAFFIC North America, Washington, D. C.

Rooney, T. P. and W. J. Dress. 1997. Species loss over sixty-six years in the ground layer vegetation of Heart's Content, an old growth forest in Pennsylvania, USA. Natural Areas Journal 17: 297-305.

Rooney, T. P. 2001. Deer impacts on forest ecosystems: a North American perspective. Forestry 74: 201-208.

Rooney, T. P. and K. Gross. 2003. A demographic study of deer browsing impacts on Trillium grandiflorum. Plant Ecology 168: 267-277.

Rooney, T. P. and D. M. Waller. 2003. Direct and indirect effects of white-tailed deer in forest ecosystems. Forest Ecology and Management 181: 165-176. 
Russell, F. L., D. B. Zippin, and N. L. Fowler. 2001. Effects of white-tailed deer (Odocoileus virginianus) on plants, plant populations, and communities: a review. American Midland Naturalist 146: 1-26.

Schemske, D. W., B. C. Husband, M. H. Ruckelshaus, C. Goodwillie, I. M. Parker, and J. G. Bishop. 1994. Evaluating approaches to the conservation of rare and endangered plants. Ecology 75: 584-606.

Van Deelen, T. R., K. S. Pregitzer, and J. B. Haulfer. 1996. A comparison of presettlement and present-day forests in northern Michigan deer yards. American Midland Naturalist 135: 181-194.

Van der Voort, M. E., B. Baily, D. E. Samuel, and J. B. McGraw. 2003. Recovery of populations of goldenseal (Hydrastis canadensis L.) and American ginseng (Panax quinquefolius L.) following harvest. American Midland Naturalist 149: 282-292.

Waller, D. M. and W. S. Alverson. 1997. The white-tailed deer: a keystone herbivore. Wildlife Society Bulletin 25: 217-226. 


\section{CHAPTER 2}

Conservation biology of American ginseng (Panax quinquefolius L.): The influence of plant characteristics and microsite conditions on herbivory by white-tailed deer (Odocoileus virginianus Zimm.) 


\begin{abstract}
Food choices by herbivores are often influenced by the apparency of plants to potential consumers. To understand the role that apparency plays in influencing browsing by white-tailed deer (Odocoileus virginianus Zimm.), I examined five plant characteristics and four microsite conditions of individual American ginseng (Panax quinquefolius L.) plants in seven natural populations in West Virginia. All individuals were monitored for evidence of deer browsing during the 2002 growing season. Based on these measurements, I developed inferences about which microsite characteristics influence browsing and tested them in two experimental populations. I found that apparencyrelated characteristics (e.g., plant size, distances from deer paths, microsite location) influenced browsing by white-tailed deer, although the influence of apparency on browsing was far greater in the experimental populations than in the natural populations. These differences may be the result of past browsing pressure by deer such that, over time, deer have selectively browsed highly visible and accessible plants, thus modifying the spatial arrangement and apparency of plants remaining in natural populations. Knowledge of characteristics that influence deer browsing can aid in restoration and management efforts. As long as deer densities remain high, understory species like American ginseng are at risk.
\end{abstract}




\section{Introduction}

Food choices by herbivores can potentially alter the structure of plant populations (Huntly, 1991). To better understand this effect, one important question is, what are the characteristics that influence whether or not a plant is consumed? In the context of studying the relationship between insect herbivory and plant defenses, Feeny (1976) suggested that one of the most important factors determining the susceptibility to discovery by herbivores is how "visible" a plant is to a consumer. Apparency of a plant to herbivores can depend on phenotypic characteristics, chemical composition, and various microsite conditions (Feeny, 1976). Since the inception of this concept, much research has focused on the role of apparency as either an attractant or a deterrent to invertebrate herbivores (see reviews by Belsky, 1986; Marquis, 1992; also see Crawley, 1989; Alonso and Herrera, 1996; Schädler et al., 2003). Although the effects of apparency on invertebrate herbivory have been widely researched, less focus has been placed on applying this concept to food choice by mammalian herbivores (but see Jenkins, 1980; Belovsky, 1981; Robbins et al., 1987; Spalinger et al., 1988; Saunders and Puettmann, 1999). The studies that do examine the role of apparency in herbivore food selection seldom take into account both physical attributes of the plant and surrounding environmental conditions.

For rare plant species that are food targets of herbivores, conservation efforts can be improved by understanding the influence that plant and microsite characteristics have on whether or not a plant is consumed. The focus of this research is American ginseng (Panax quinquefolius L.), an Appendix II listed species in the Convention on International Trade of Endangered Species of Wild Fauna and Flora (CITES). American 
ginseng is considered rare in part due to annual harvesting of natural populations for medicinal sales on the Asian market and also loss of suitable habitat (Charron and Gagnon, 1991). White-tailed deer (Odocoileus virginianus Zimm.) may be exacerbating the rarity of ginseng, as herbivory occurs at high rates and deer are seed predators of ginseng (Furedi and McGraw, 2004). Loss of large carnivores and fragmentation of the landscape, coupled with effective game management practices, have led to dramatic increases in herd numbers of white-tailed deer in the northeastern United States. An increase in edge habitat due to landscape fragmentation has not only created more ideal feeding areas for white-tailed deer, but has also opened otherwise protected parcels of forested areas to browsing. Thus, once inaccessible understory herbs are now more vulnerable to browsing (Miller et al., 1992). I have observed that American ginseng is often browsed while known palatable species were not. In fact, in some populations, browsing rates are so intense that nearly all of the plants, with the exception of seedlings, were browsed during a growing season (Furedi and McGraw, 2004). However, in most populations, deer browse a fraction of the plants. If nonrandom browsing occurs, deer may serve as agents of selection against plant characteristics that confer high apparency and at the same time alter microsite conditions where ginseng is found.

One potential long-term effect of selective browsing of apparent ginseng plants in visible and accessible areas may be that the actual role of apparency becomes obscured in natural populations. Through plastic responses to browsing, apparent plants may become less so over time. Likewise, if browsing pressure is high, mortality of frequently browsed plants may alter the dispersion pattern within populations, such that only relatively inaccessible plants remain. Both of these mechanisms are a form of "ecological escape", 
analogous to the "evolutionary escape through ecological disappearance" described by Chew and Courtney (1991).

The purpose of this study was to investigate the influence of plant characteristics and microsite conditions on susceptibility to browsing by white-tailed deer. Specifically, my research objectives were to: 1) determine deer density estimates and deer browsing rates in seven naturally occurring populations of American ginseng, 2) measure plant characteristics and microsite conditions of individual plants in these populations and monitor which plants were browsed by deer, 3) develop a set of inferences concerning apparency-related factors based on the plants that were browsed and their physical and microsite characteristics, and 4) test these inferences in experimental populations by controlling for plant phenotype while placing plants in specific microsite conditions. I hypothesized that browsing rates would be positively related to deer densities and that larger, reproductive plants found in clusters would be more apparent to deer and thus would be more susceptible to browsing. I also hypothesized that certain microsite conditions, such as isolation from deer paths and obstruction from view due to vegetation or an elevated location (i.e., on rocks), would serve as refugia from browsing. 


\section{Methods}

\section{Study species}

American ginseng is a long-lived perennial herb found in the herbaceous layer of deciduous forests in the eastern United States and southern Canada (Charron and Gagnon, 1991). The range of American ginseng extends from southern Quebec to northern Georgia and from the east coast states to Missouri (Anderson et al., 1993). In the central Appalachian region, ginseng is often associated with rich, moist, well-drained soils in north-facing coves (Anderson et al., 1993; Van der Voort et al., 2003;), although McGraw et al. (2003) found that ginseng occupies a broader niche than previously assumed, including what could be considered 'suboptimal' habitat.

The seasonal phenological progression of American ginseng begins each spring with the onset of tree canopy closure in the eastern deciduous forests (Lewis and Zenger, 1982). During late April and early May, the ginseng rhizome gives rise to an aerial "stem" or sympodium (Charron and Gagnon, 1991). Arising from the summit of the sympodium are one or more palmately compound leaves consisting of three to five leaflets (Lewis and Zenger, 1982). Newly emerged seedlings have one leaf with three leaflets. In subsequent years, a young plant may develop four or five leaflets and eventually two or more leaves (Lewis and Zenger, 1982, Anderson et al., 1993). Flowering occurs in June and July and is virtually assured when a plant reaches the 3-leaf stage, although some 2-leaf plants develop an inflorescence as well (Charron and Gagnon, 1991). Fruit development and maturation begins in late June and ends by October (Carpenter and Cottam, 1982). Fruit maturation is marked by the bright red color of the exocarp. 


\section{Study sites}

Seven naturally occurring populations of American ginseng were used to develop inferences about what plant and microsite characteristics influence browsing by whitetailed deer. These populations were located in second growth mixed mesophytic stands in north-central West Virginia. Although most populations were found in stands dominated by sugar maple (Acer saccharum Marshall) and tulip-poplar (Liriodendron tulipifera Linneaus), they differed in other general site characteristics (Table 2.1).

\section{Estimates of deer densities}

Pellet-group surveys along belt transects were used to estimate deer densities in 2002 (Eberhardt and Van Etten, 1956; Neff, 1968). All old pellet groups were cleared from each population in mid-May, approximately $65 \mathrm{~d}$ before surveys were conducted in mid-July. Ten, $4 \mathrm{~m} \times 100 \mathrm{~m}$ transects, were established in six of the seven natural populations. Due to the steep terrain and small geographic area of population CR, I was unable to obtain accurate deer estimates for this population. In mid-July, the number of pellet groups found along transects was recorded. A pellet-group was defined as a group of $\geq 10$ fecal pellets (Longhurst and Connolly, 1982). Deer density estimates were calculated using the following equation, modified from Davis (1982):

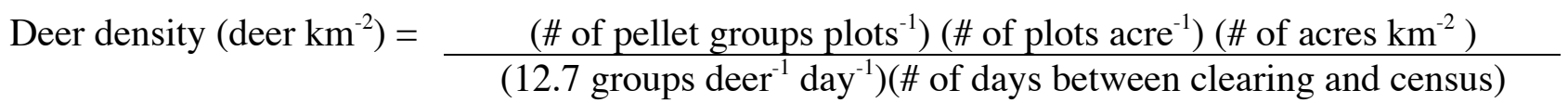
A frequently cited defecation rate of 12.7 pellet-groups per deer per day was used in the density calculations (Eberhardt and Van Etten, 1956; Longhurst and Connolly, 1982). A regression analysis was used to determine the relationship between deer densities and 
Table 2.1. Site characteristics, deer density estimates from pellet counts, and the proportion of plants browsed in seven natural populations of American ginseng found in north-central West Virginia. 


\begin{tabular}{|c|c|c|c|c|c|}
\hline Population & $\begin{array}{l}\text { Elevation } \\
(\mathrm{m})\end{array}$ & $\begin{array}{c}\text { Aspect } \\
\text { (degrees) }\end{array}$ & Number of plants & $\begin{array}{c}\text { Deer density } \\
\left(\text { deer } \mathrm{km}^{-2}\right)\end{array}$ & Deer browse rates \\
\hline BG & 722 & 146 & 64 & 15 & 0.229 \\
\hline $\mathrm{BN}$ & 695 & 20 & 43 & 49 & 0.489 \\
\hline CR & 616 & 54 & 6 & NA & 0.833 \\
\hline $\mathrm{P} 4$ & 475 & 24 & 129 & 47 & 0.407 \\
\hline P5 & 536 & 15 & 352 & 48 & 0.525 \\
\hline W2 & 810 & 3 & 110 & 33 & 0.417 \\
\hline W4 & 806 & 336 & 31 & 22 & 0.152 \\
\hline
\end{tabular}


deer browsing rates in each of the six natural populations (SAS JMP, V.5.0, SAS, Inc., 2002).

\section{Measurements of plant and microsite characteristics}

In May 2000, all individuals in the seven populations were located and marked. Each ginseng plant was cryptically tagged with an engraved aluminum nail placed at the base of the sympodium, just below the soil surface. If the plant senesced early or was completely deer browsed, the tag was relocated using a metal detector. In addition to tagging individual plants, maps were constructed for each population using a 'photo-trail' approach. The location of each plant within a population was digitally photographed along with compass bearings and distances to neighboring plants. The photographs and related details were then compiled to create a photographic path through the population. The tagging system and 'photo-trail' maps facilitated the relocation of plants during the growing season with very little disturbance to the surrounding vegetation and no obvious aboveground markers that could attract unwanted attention.

Once all individuals had been tagged and photographed, plant characteristics related to apparency were measured. These characteristics included sympodium height (distance from the soil surface to the summit of the sympodium), leaf number, the length and width of the longest leaflet per leaf (used to calculate leaf area), and reproductive status. If a plant was reproductive, the number of fruits produced was also recorded. To derive the equation for leaf area, I randomly selected 102 intact leaves. For each leaf, the length and width of the longest leaflet per leaf was measured along with the area of the entire leaf using a portable leaf area meter (Li-Cor Model Li-3000A). A multiple linear 
regression with leaf length (LL), leaf width (LW), and the cross-product as effects in the model (intercept constrained to zero) was used to derive the following equation for leaf area $(\mathrm{LA})\left(\mathrm{r}^{2}=0.95, \mathrm{~N}=102\right)$ :

$\mathrm{LA}=4.03(\mathrm{LL})+5.17(\mathrm{LW})+1.38(\mathrm{LL} * \mathrm{LW})$.

Plant size-related traits and reproductive status were measured in late May 2002, while the number of fruits was recorded in mid-August and again in mid-September. In addition to those times designated for taking measurements, all plants within the seven populations were censused every three weeks for evidence of deer browsing starting in June and continuing until early October. Damage due to deer browsing was identified by the partial or entire loss of aboveground biomass and the rough cut on the sympodium or petiole (Augustine and Frelich, 1998). In total, 735 ginseng plants were monitored during the 2002 growing season.

Microsite characteristics related to apparency were also measured in 2002. These characteristics included the height of ginseng plants compared to adjacent species (taller or shorter than neighbors), density of ginseng plants (single plant vs. a cluster), the distance from known deer paths, and the general microsite location of plants within a population. The height of ginseng plants compared to neighbors was scored using a qualitative classification system: (a) represented ginseng plants that were shorter than neighbors $(>2 \mathrm{~cm}),(\mathrm{b})$ represented plants that were of equal height $(+/-2 \mathrm{~cm})$, and $(\mathrm{c})$ represented plants that were taller than their neighbors $(<2 \mathrm{~cm})$. A qualitative classification system was also used for density with (a) representing solitary plants (no other ginseng plant within $0.46 \mathrm{~m}$ ) and (b) representing those found in clusters ( 2 or more ginseng plants). The distance from known deer paths was scored based on a qualitative 
classification system: (a) represented plants within $2 \mathrm{~m}$ of a deer path, and (b) represented plants located at a distance greater than $2 \mathrm{~m}$ from a deer path. A distance of $2 \mathrm{~m}$ was chosen based on the findings of Shipley et al. (1996) that the maximum encounter rate of forage for white-tailed deer occurred between 0 and $2 \mathrm{~m}$. The microsite location of plants within each population was scored based on the following qualitative classification system: (a) represented plants located in open, unobstructed areas easily accessible to deer, (b) represented plants found under low shrub cover, and (c) represented plants located on rocks elevated above the forest floor, adjacent to fallen trees, or some other obstructions.

\section{Development of inferences}

Two statistical analyses were used to develop inferences about plant and microsite characteristics that might influence a plant's susceptibility to being browsed by deer. Separate log-likelihood analyses were used to determine if each of the variables (leaf number, reproductive status, height compared to neighboring species, distance, density, and microsite location) influenced the chance of being browsed by deer (SAS JMP, V.5.0, SAS, Inc., 2002). Logistic regressions were used to determine the individual effects of sympodium height, leaf area, and fruit number on whether or not a plant was browsed (SAS JMP, V.5.0, SAS, Inc., 2002). Since only a small proportion of 1-leaf plants were browsed (8.6\%) and because these plants differed in many of the characteristics measured compared to larger size classes, all 1-leaf plants were excluded from the statistical tests. Populations P4, P5, and W2 were analyzed individually. Due to small population size, data from $\mathrm{BN}, \mathrm{BG}, \mathrm{CR}$, and $\mathrm{W} 4$ were pooled, then analyzed with 
population as an additional fixed effect to account for some of the variation existing among populations.

\section{Testing of inferences}

The inferences about environmental (microsite) characteristics that influence deer browsing were tested in two experimental populations. The locations for these populations were determined between May and September of 2002. Three criteria were used to determine placement of the populations. First, sites had to be located in what would be considered suitable ginseng habitat (i.e. closed canopy and indicator herbaceous species). Second, sites had to be located at a great enough distance from other known natural populations to avoid pathogen transmission: since the plants used to create the experimental populations were from a cultivated source, I wanted to ensure that pathogens often associated with high density cultivation were not introduced to natural populations. Third, physical evidence in the form of traveled deer paths, pellets, and browsing was required to show that deer actively travel through an area. The sites chosen for the experimental populations were on north facing slopes in $2^{\text {nd }}$ growth stands dominated by sugar maple and tulip poplar. The elevations for the two sites were $480 \mathrm{~m}$ and $824 \mathrm{~m}$.

After site selection, creation of experimental populations began in March 2003. To create each population, 7y old dormant, 'woods-grown' ginseng roots were obtained from a ginseng cultivator in Preston County, West Virginia. These roots were chosen because they would give rise to relatively uniform, large, reproductive individuals, 
allowing me to focus the study on the influence of microsite characteristics on deer browsing.

The two experimental populations were established on March 29-31, 2003. All roots were randomly assigned to treatment groups based on a $3 \times 2 \times 2$ full factorial design with microsite location (open areas, under shrubs, and on rocks or other forms of protection), density (single and a cluster of three plants), and distance from deer paths (between 0 and $2 \mathrm{~m}$ and greater than $2 \mathrm{~m}$ ) as fixed main effects. Each treatment group contained 15 ginseng plants for a total of 180 plants per site. The roots were placed in each experimental population in such a manner as to utilize the natural microsites and deer paths already present in the area. Once planted, all roots were tagged with engraved aluminum nails. Photo-trail maps for these populations were made in May once the plants had fully emerged from winter dormancy. Also beginning in May, all plants were censused every three weeks for deer browsing. The deer browse census continued until early October 2003.

To determine if browsing by white-tailed deer depended on microsite location, density, and distance from deer paths, I performed a three-way factorial log-likelihood analysis on the pooled data from the two experimental populations with microsite location, density, and distance as fixed main effects (SAS JMP, V.5.0, SAS, Inc., 2002). 


\section{Results}

\section{Deer densities and browsing rates in natural populations}

Deer densities and browsing rates differed among the six natural populations. Deer density estimates ranged from $8 \mathrm{~km}^{-2}$ to $49 \mathrm{~km}^{-2}$ (Table 2.1). Browsing rates ranged from $15.2 \%$ to $83.3 \%$ (Table 2.1 ). Although there were only six data points, deer density was significantly positively related to browsing rates in the six populations $\left(r^{2}=0.80, P=\right.$ 0.02; Fig. 2.1).

\section{Apparency in natural populations}

I did not find a consistent relationship between plant characteristics and the risk of being browsed for all seven populations. However, my hypothesis that certain plant characteristics influence browsing was supported in $\mathrm{W} 2$ and the pooled populations (BN, $\mathrm{BG}, \mathrm{CR}$, and W4). In population $\mathrm{W} 2$, leaf number and reproductive status had a significant effect on being browsed (Table 2.2). A greater proportion of 3-and 4-leaf plants were browsed compared to 2-leaf plants (Fig. 2.2a). Reproductive individuals were browsed in higher proportions than non-reproductive plants (Fig. 2.2b). I also noted a trend towards the risk of being browsed increasing with increasing leaf area consistent with the other size effects (Table 2.2). From the lowest to the highest leaf area, I saw a doubling in the probability of being browsed (Fig. 2.2c).

For the pooled populations, sympodium height, reproductive status, and fruit number all influenced browsing (Table 2.2). Susceptibility to browsing increased with sympodium height (Fig. 2.3a). Similar to population W2, more reproductive individuals

Figure 2.1. The relationship between deer browsing rates and deer density estimates in six natural populations of American ginseng in West Virginia. 


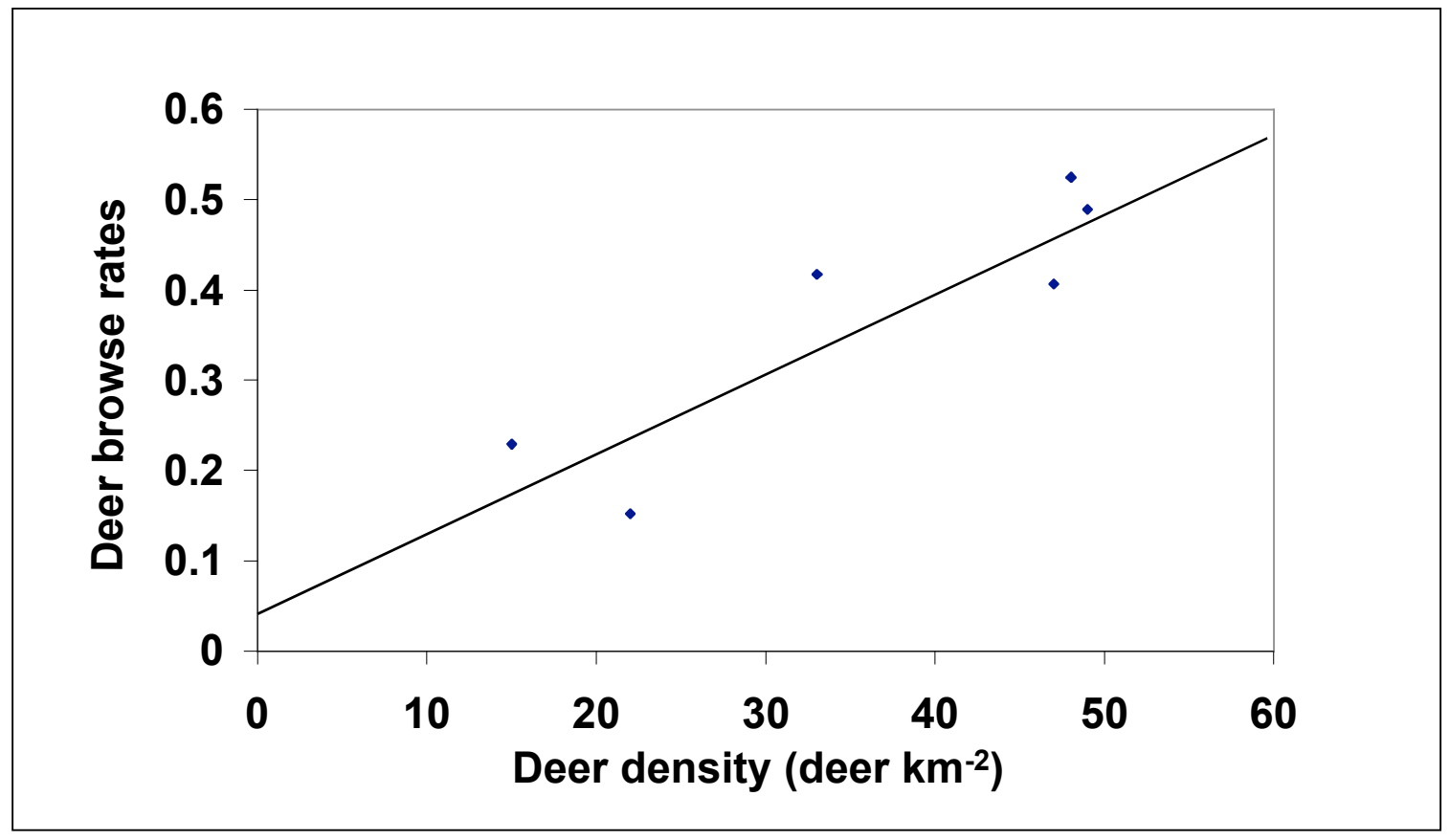


Table 2.2. The effects of several plant characteristics on susceptibility to deer browsing occurring in natural populations of American ginseng. The table includes the likelihood ratio chi-square values for each effect along with their associated $\mathrm{P}$ values in parentheses. 


\begin{tabular}{lcccccc}
\hline Population & $\begin{array}{c}\text { Leaf } \\
\text { number }\end{array}$ & $\begin{array}{c}\text { Sympodium } \\
\text { height }(\mathrm{cm})\end{array}$ & $\begin{array}{c}\text { Leaf area } \\
\left(\mathrm{cm}^{2}\right)\end{array}$ & $\begin{array}{c}\text { Reproductive } \\
\text { status }\end{array}$ & $\begin{array}{c}\text { Fruit } \\
\text { number }\end{array}$ & $\begin{array}{c}\text { Height to } \\
\text { neighbors }\end{array}$ \\
\hline Pooled, small & 1.731 & $5.757^{*}$ & 2.684 & $16.559^{*}$ & $7.929 *$ & $42.190^{*}$ \\
P4 & $(0.421)$ & $\mathbf{( 0 . 0 1 6 )}$ & $(0.101)$ & $(<\mathbf{0 . 0 0 1})$ & $\mathbf{( 0 . 0 0 5 )}$ & $(<\mathbf{0 . 0 0 1})$ \\
& 0.073 & 0.839 & 1.274 & 1.077 & 1.391 & $16.941^{*}$ \\
P5 & $(0.788)$ & $(0.360)$ & $(0.259)$ & $(0.299)$ & $(0.238)$ & $(<\mathbf{0 . 0 0 1})$ \\
& 2.805 & 0.180 & 2.223 & 0.473 & 2.512 & $8.750^{*}$ \\
W2 & $(0.246)$ & $(0.671)$ & $(0.136)$ & $(0.492)$ & $(0.113)$ & $(\mathbf{0 . 0 1 3})$ \\
& $5.350^{*}$ & 2.194 & $3.646 \dagger$ & $4.287^{*}$ & 0.004 & $17.024^{*}$ \\
& $(\mathbf{0 . 0 2 1})$ & $(0.139)$ & $(0.056)$ & $\mathbf{( 0 . 0 3 8 )}$ & $(0.950)$ & $(<\mathbf{0 . 0 0 1})$ \\
\hline
\end{tabular}

$*$ denotes a significant effect if $\mathrm{P}<0.05$ 
Figure 2.2. The proportion of ginseng plants browsed by deer in population W2 as a function of (a) leaf number, and (b) reproductive status. (c) The relationship between the probability of being browsed by deer and leaf area of ginseng plants in population W2. 

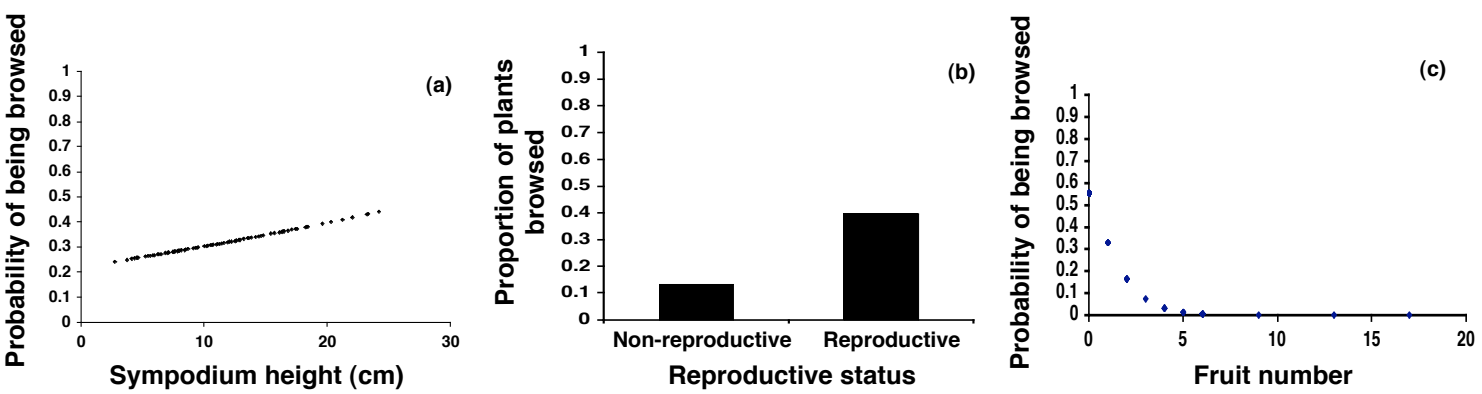
Figure 2.3. (a) The relationship between the probability of being browsed by deer and sympodium height of ginseng plants in the pooled populations $(\mathrm{BG}, \mathrm{BN}, \mathrm{CR}$, and W4). (b) The proportion of ginseng plants browsed in the pooled populations as a function of reproductive status. (c) The relationship between the probability of being browsed and fruit number in the pooled populations. 

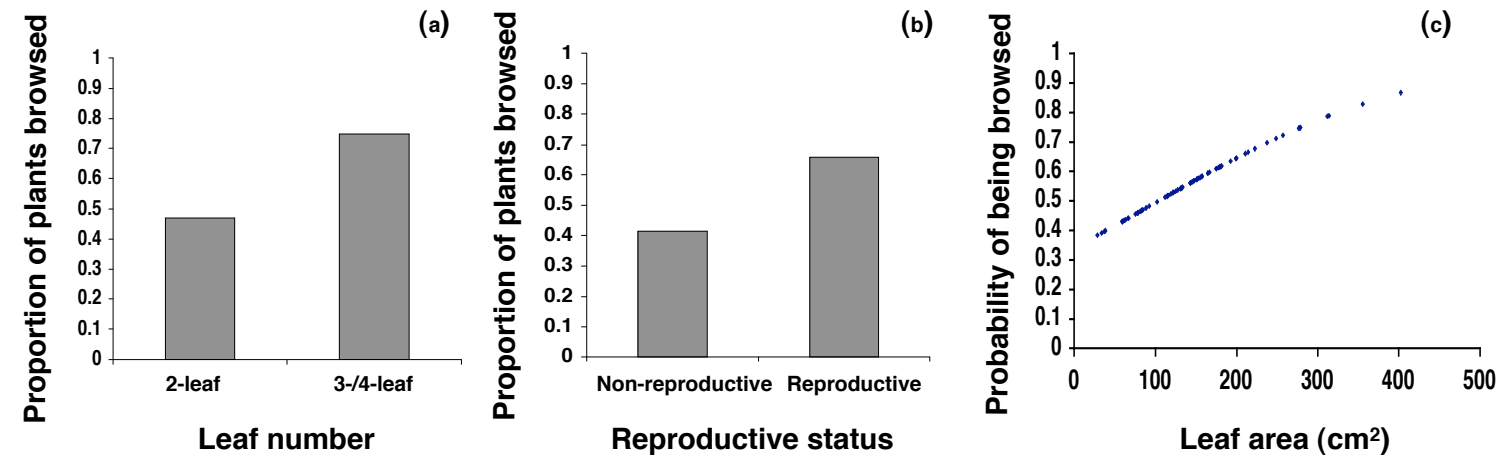
were browsed than non-reproductive ones (Fig. 2.3b). In contrast to my hypothesis, the probability of being browsed in populations BG and W4 declined as the number of fruits present on a plant increased (Fig. 2.3c). However, those plants that produced larger amounts of fruit were found in well-protected areas.

All seven populations shared one microsite characteristic that significantly affected whether or not a plant was browsed: the height of a ginseng plant compared to neighboring species (Table 2.2). The probability of a plant being browsed increased as its height relative to other plants increased (Fig. 2.4a). Surprisingly, I found that local plant density did not influence browsing (Table 2.3). Single plants were browsed as often as plants in clusters. Population W2 was the only population where browsing was influenced by a plant's distance from a deer path (Table 2.3). Plants located closer to deer paths were browsed more than those found farther from deer paths (Fig. 2.4b). Unlike the other populations, Population P4 was unique in that deer browsing was influenced by microsite location (Table 2.3). The greatest rate of browsing occurred on plants located in open, unprotected areas (Fig. 2.4c).

To better understand the occurrence of browsing under specific microsite characteristics, I examined the proportion of plants browsed in all possible microsite combinations in population P5 (Fig. 2.5). Clustered plants under shrubs near deer paths experienced the greatest browsing (83\%), followed closely by single plants in open areas near deer paths (80\%) (Fig. 2.5). In contrast, those plants escaping herbivory by deer were protected by fallen trees and rocks, regardless of distance from deer paths and density (Fig. 2.5). 
Figure 2.4. The proportion of ginseng plants browsed in: (a) the natural populations as a function of height compared to neighboring species, (b) population W2 as a function of distance from deer paths, and (c) population P4 as a function of microsite location. 

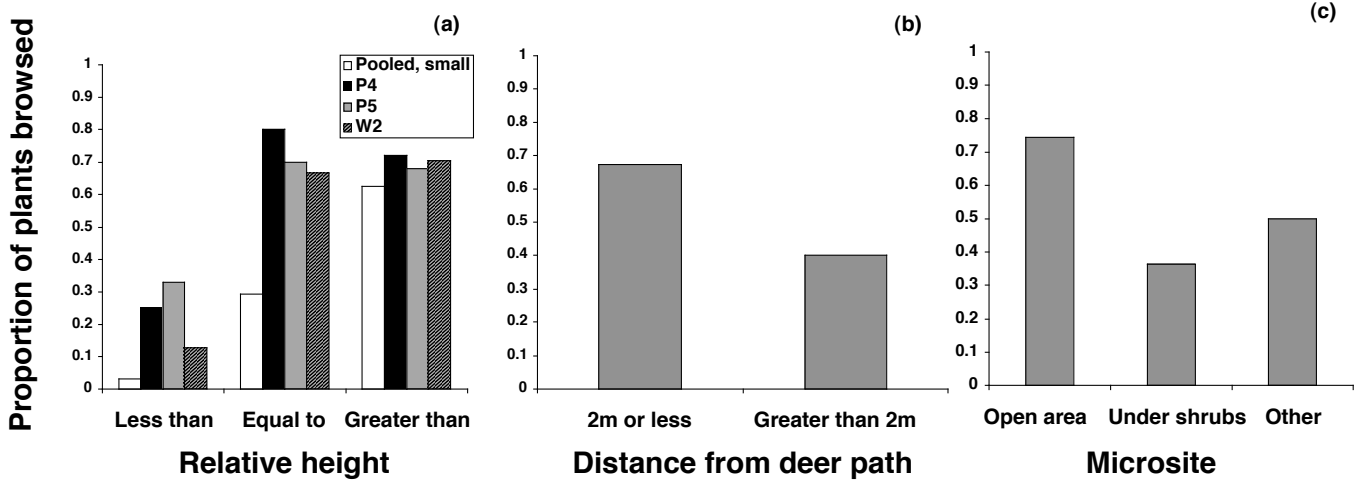
Table 2.3. The effects of several microsite characteristics on deer browsing occurring in natural populations of American ginseng. The table includes the likelihood ratio chi-square values for each effect along with the associated $\mathrm{P}$ values in parentheses. 


\begin{tabular}{lccc}
\hline Population & $\begin{array}{c}\text { Distance from } \\
\text { deer paths }\end{array}$ & $\begin{array}{c}\text { Microsite } \\
\text { location }\end{array}$ & Density \\
\hline Pooled, small & 0.412 & 0.020 & 1.937 \\
P4 & $(0.521)$ & $(0.990)$ & $(0.164)$ \\
& 2.386 & $9.591^{*}$ & 0.579 \\
P5 & $(0.122)$ & $\mathbf{( 0 . 0 0 8 )}$ & $(0.447)$ \\
& 0.065 & 2.242 & 0.007 \\
W2 & $(0.7982)$ & $(0.326)$ & $(0.934)$ \\
& $5.440 *$ & 0.014 & 0.130 \\
& $(\mathbf{0 . 0 2 0})$ & $(0.907)$ & $(0.719)$ \\
\hline
\end{tabular}

$*$ denotes a significant effect if $\mathrm{P}<0.05$ 
Figure 2.5. The proportion of browsed plants in population P5 as a function of distance from deer paths $(\mathrm{N}=$ within $2 \mathrm{~m}, \mathrm{~F}=$ greater than $2 \mathrm{~m})$, plant density $(\mathrm{S}=$ single plant, $\mathrm{C}=$ cluster $)$, and microsite location $(\mathrm{O}=$ open areas, $\mathrm{S}=$ under shrubs, $\mathrm{R}=$ other areas of refugia). 


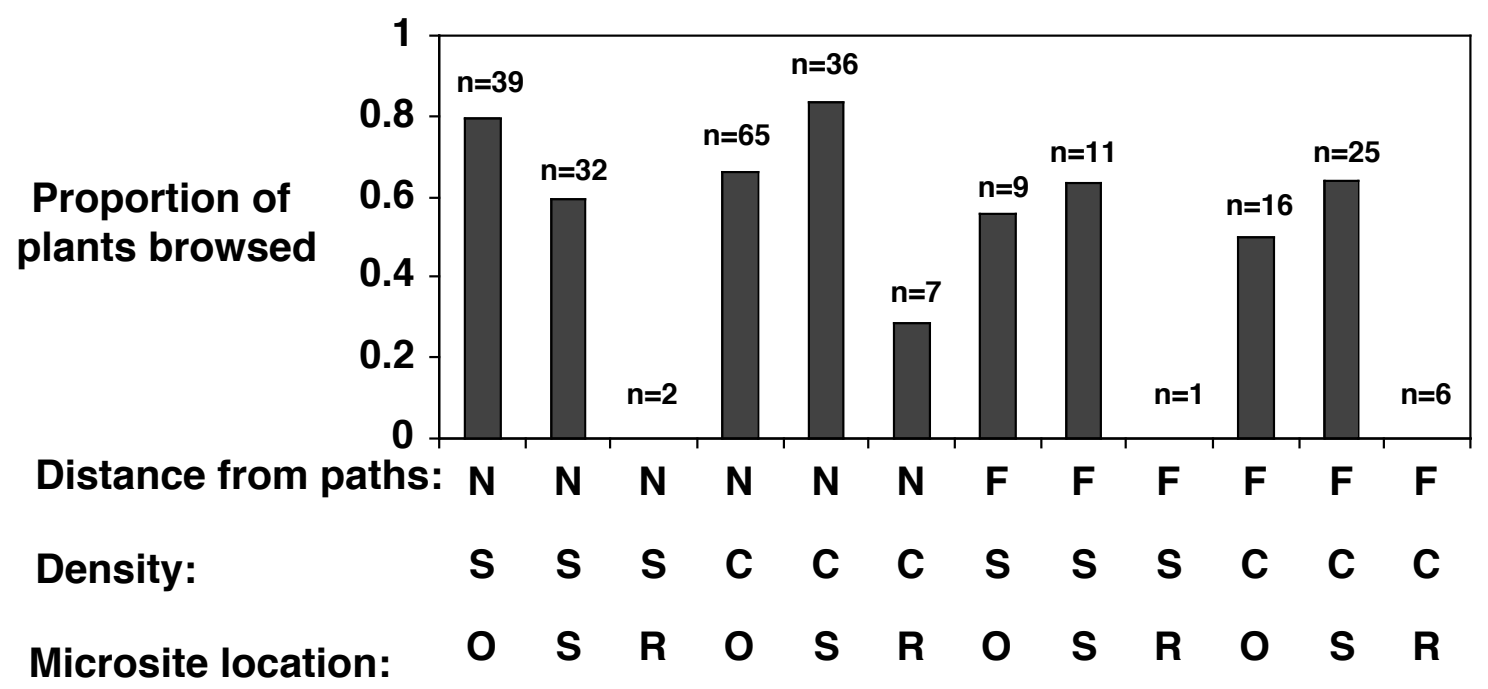




\section{Apparency in experimental populations}

In the experimental populations, whether or not a plant was browsed depended on the main effects of distance from deer paths and microsite location, with a trend towards density having a significant influence on browsing (Table 2.4). I found a relationship similar to that reported in W2 for the experimental populations. Plants located within $2 \mathrm{~m}$ of a deer path were browsed more than those farther away (Fig. 2.6a). The effect of microsite location in the experimental populations was comparable to that seen in population P4. Plants located in open areas experienced the highest proportion of browsed individuals compared to the other microsite locations (Fig. 2.6b).

In contrast to the results from the natural populations, I found a trend towards density influencing whether or not a plant was browsed in the experimental populations (Table 2.4). A slightly higher proportion of plants in clusters were browsed compared to single plants (Fig. 2.6c). 
Table 2.4. The effects of distance from a deer path, microsite location, and plant density on whether or not ginseng plants in two experimental populations are browsed by deer. The table includes the likelihood ratio chi-square values for each effect along with the associated $\mathrm{P}$ values in parentheses. 


\begin{tabular}{lcc}
\hline Effect & L-R Chi-Square & P value \\
\hline Distance & $4.946^{*}$ & $\mathbf{0 . 0 2 6}$ \\
Microsite & $23.870^{*}$ & $<\mathbf{0 . 0 0 1}$ \\
Density & $3.439 \dagger$ & 0.064 \\
Distance x microsite & 3.261 & 0.196 \\
Distance x density & 0.440 & 0.507 \\
Microsite x density & 0.550 & 0.760 \\
Distance x microsite x density & 0.318 & 0.853 \\
\hline
\end{tabular}

* denotes a significant effect if $\mathrm{P}<0.05$

$\dagger$ denotes a trend towards a significant effect if $0.1>\mathrm{P}>0.05$ 
Figure 2.6. The proportion of ginseng plants browsed in the experimental populations as a function of: (a) distance from deer paths, (b) microsite locations, and (c) plant density. 

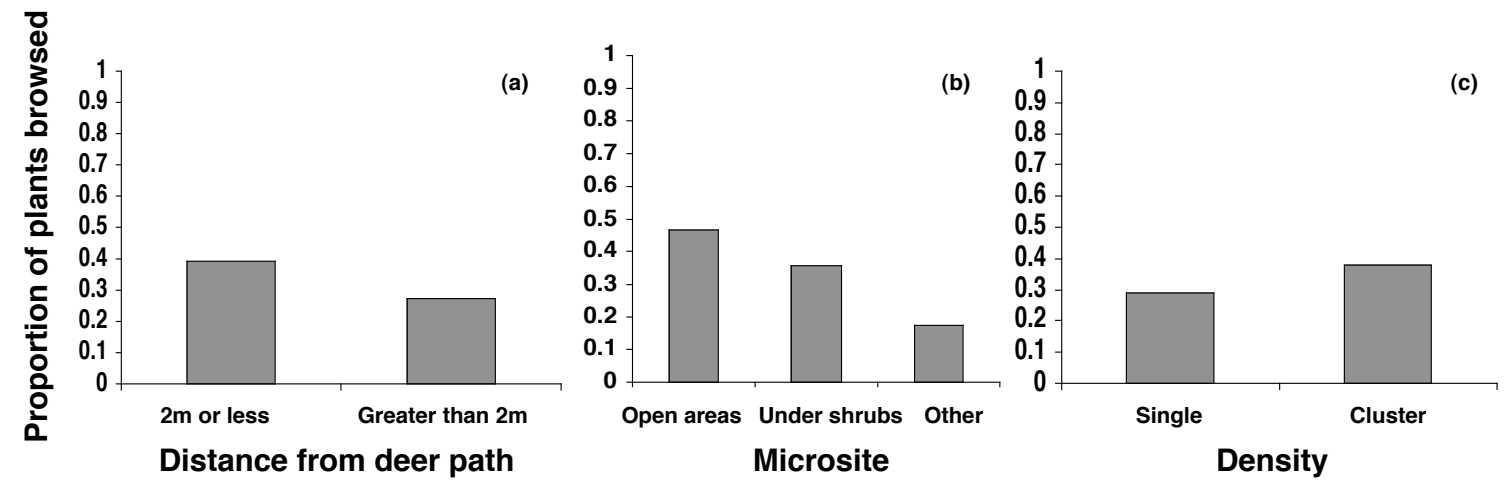


\section{Discussion}

In the natural populations, all plant traits contributed to the chance of being browsed in at least one population. With the exception of fruit number, the relationships were in the direction expected; larger, more conspicuous plants were browsed at higher rates. This is consistent with previous studies on ungulate food selection showing that larger plants are often chosen over smaller ones (Belovsky, 1981; Anderson, 1994; Ehrlen, 1995) and that reproductive structures (Edwards, 1985; Augustine and Frelich, 1998) and the presence of fruit (Sargent, 1990; Furedi and McGraw, 2004) bias food selection by deer. Other studies have reported that browsing preferences are density dependent (Edwards, 1985) and a function of accessibility (Rooney, 1997; Long et al., 1998).

In some populations (e.g., P4, P5), the expected size-browsing relationship was weak or nonexistent. This may be explained by considering the physiological effects of long-term browsing. In a concurrent study, I found that deer browsing in one year resulted in a decrease in height, leaf area, and reproductive potential of ginseng in the year following browse and that the negative effects were exacerbated with consecutive

years of browsing (Furedi, Chapter 3). Thus, proportions of a population susceptible to high rates of browsing may become less susceptible through phenotypic change. As suggested by Chew and Courtney (1991), the plastic response to herbivory can provide a potential "escape mechanism" from future episodes by shrinking size-associated characteristics.

Since plants were relatively uniform in the experimental populations, I was able to examine the accessibility issue as a function of microsite conditions independent of 
correlated size effects. Consistent with my findings from natural populations, distance from deer paths appeared to be a primary determinant of the chance of being browsed. Since deer usually travel along well-established paths, stopping periodically to browse (Marchinton and Hirth, 1984), plants adjacent to deer paths are more readily accessible to deer than those farther away.

My finding that browse rates were lower when plants were associated with a thick shrub layer and other forms of protection such as fallen logs or rocks suggests that these obstructions may serve as refugia. Others have found similar results. For example, Rooney (1997) found that large boulder tops served as refuge areas for Maianthemum canadense. Long et al. (1998) reported differences in the size and abundance of Tsuga canadensis on and off tip-up mounds and concluded that the mounds served as refugia from deer.

Although I did not find that plant density affected browsing in the natural populations, I examined density in the experimental populations because it was possible that long-term browsing in the natural populations had obscured true density effects. My results in the experimental populations showed that browse tendency was greater for plants in clusters than solitary plants. Again, this seems likely to be a real phenomenon, but one that could be masked over time in natural populations as clusters get browsed more heavily, ultimately leaving only isolated plants or clusters in protected microsites.

The overall findings show that characteristics associated with apparency do in fact influence browsing by deer both in the natural populations and my experimental ones. The findings also suggest that deer serve as agents of selection against plants that are highly visible. The strength of the influence of apparency-related traits may be weakened 
over time, as seen in the natural populations, due to browse selection of large plants in accessible areas and a reduction in size-related characteristics as a result of herbivory. Other studies have reported similar findings that long-term food choices made by deer result in changes in plant populations (see review by Russell et al., 2001; also see Rooney, 2001; Horsley et al., 2003; Rooney and Waller, 2003).

Although my study indicates that the weakened role of apparency in ginseng populations may be the consequence of long-term deer browsing, I cannot discount the effect that harvesting for the medicinal trade has played in altering these natural populations. Since humans are most likely governed by similar apparency-related characteristics when searching for harvestable plants, they too may have contributed to the masking of apparency effects in natural populations. Ginseng populations similar to my experimental ones may have once been the norm but increased deer browsing rates in combination with human harvesting have altered populations. Now in ginseng populations, once apparent plants have been either removed or have become less visible and large plants inherently more apparent, are found in less accessible areas within populations.

Knowledge of the variation in browsing rates as a function of microsite characteristics may be useful when devising best harvest practices or guiding restoration efforts. Since ginseng is a wild-harvested species, drawing unwanted attention to plants by using exclosures is not a viable means of protection. However, I found that browsing rates are lower for certain microsite conditions, thus using the natural features of the landscape as protection may be a suitable alternative. For example, in population P5 I saw that the best protective measure for new plants would be to place them farther from 
deer paths in well-protected areas, like large rocks and areas obscured by treefalls (Fig. 2.5).

Despite variation in the influence of apparency-related characteristics in the natural populations, I found that browsing rates were still substantial and positively related to deer densities. As a consequence of high deer densities, apparency-related alterations have not been effective in allowing ginseng plants to "escape" from deer browsing. Therefore, I can anticipate that further alterations of natural ginseng populations will occur with increasing deer densities. Unless management efforts are directed at effectively lowering excessive deer herds, valuable understory herbs like American ginseng may be lost. Those entrusted with the maintenance of forest ecosystems must consider the interactive effects of keystone species like white-tailed deer when designing and implementing management plans. Ultimately, the solution to the problems associated with deer browsing is the reduction of overabundant deer herds. 


\section{Literature Cited}

Alonson, C. and C. M. Herrera. 1996. Variation in herbivory within and among plants of Daphne laureola (Thymelaeaceae): correlation with plant size and architecture. Journal of Ecology 84: 495-502.

Anderson, R. C., J. S. Fralish, and J. E. Armstrong. 1993. The ecology and biology of Panax quinquefolium L. (Araliaceae) in Illinois. American Midland Naturalist 129: $357-372$.

Anderson, R. C. 1994. Height of white-flowered trillium (Trillium grandiflorum) as an index of deer browsing intensity. Ecological Applications 4: 104-109.

Augustine, D. J. and L. E. Frelich. 1998. Effects of white-tailed deer on populations of an understory forb in a fragmented deciduous forest. Conservation Biology 12: 995-1004.

Belovsky, G. E. 1981. Food plant selection by a generalist herbivore: the moose. Ecology 62: 1020-1030.

Belsky, A. J. 1986. Does herbivory benefit plants? a review of the evidence. The American Naturalist 127: 870-892. 
Carpenter, S. G. and G. Cottam. 1982. Growth and reproduction of American ginseng (Panax quinquefolius) in Wisconsin, U.S.A. Canadian Journal of Botany 60: 2692-2696.

Charron, D. and D. Gagnon. 1991. The demography of northern populations of Panax quinquefolium (American ginseng). Journal of Ecology 79: 431-445.

Chew, F. S. and S. P. Courtney. 1991. Plant apparency and evolutionary escape from insect herbivores. The American Naturalist 138: 729-750.

Crawley, M. J. 1989. Insect herbivores and plant population dynamics. Annual Review of Entomology 34: 531-564.

Davis, D. E. 1982. Calculations used in census methods, pp. 353-355. In: D. E. Davis [ed.]. CRC handbook of census methods for terrestrial vertebrates. CRC Press, Boca Raton, FL.

Eberhardt, L. and R. C. Van Etten. 1956. Evaluation of the pellet group count as a deer census method. Journal of Wildlife Management 20: 70-74.

Edwards, J. 1985. Effects of herbivory by moose on the flower and fruit production of Aralia nudicaulis. Journal of Ecology 73: 861-868. 
Ehrlen, J. 1995. Demography of the perennial herb Lathyrus vernus. I. Herbivory and individual performance. Journal of Ecology 83: 287-295.

Feeny, P. 1976. Plant apparency and chemical defenses, pp. 1-41. In: J. W. Wallace and R. L. Mansell [eds.]. Biochemical interactions between plants and insects. Plenum Press, New York, NY.

Furedi, M. and J. B. McGraw. 2004. White-tailed deer: dispersers or predators of American ginseng seeds. American Midland Naturalist 152: 268-276.

Horsley, S. B., S. L. Stout, and D. S. DeCalesta. 2003. White-tailed deer impact on the vegetation dynamics of a northern hardwood forest. Ecological Applications 13: 98-118.

Huntly, N. 1991. Herbivores and the dynamics of communities and ecosystems. Annual Review of Ecology and Systematics 22: 477-503.

Jenkins, S. H. 1980. A size-distance relation in food selection by beavers. Ecology 61: 740-746.

Lewis, W. H. and V. E. Zenger. 1982. Population dynamics of the American ginseng Panax quinquefolium (Araliaceae). American Journal of Botany 69: 1483-1490. 
Long, Z. T., W. P. Carson, and C. J. Peterson. 1998. Can disturbance create refugia from herbivores: an example with hemlock regeneration on treefall mounds. Journal of the Torrey Botanical Society 125: 165-168.

Longhurst, W. M. and G. E. Connolly. 1982. Deer pellet counts, pp. 247. In: D. E. Davis [ed.], CRC handbook of census methods for terrestrial vertebrates. CRC Press, Boca Raton, FL.

Marchinton, R. L. and D. H. Hirth. 1984. Behavior, pp 18. In: L. K. Halls [ed.], Whitetailed deer ecology and management. Stackpole Books, Harrisburg, PA.

Marquis, R. J. 1992. Selective impact of herbivores, pp. 301-325. In: R. S. Fritz and E. L. Simms [eds.], Plant resistance to herbivores and pathogens. Ecology, evolution, and genetics. University of Chicago Press, Chicago, IL.

McGraw, J. B., S. M. Sanders, and M. Van der Voort. 2003. Distribution and abundance of Hydrastis canadensis L. (Ranunculaceae) and Panax quinquefolius L. (Araliaceae) in the central Appalachian region. Journal of the Torrey Botanical Society 130: 62-69.

Miller, S. G., S. P. Bratton, and J. Hadidian. 1992. Impacts of white-tailed deer on endangered and threatened vascular plants. Natural Areas Journal 12: 67-74. 
Neff, D. J. 1968. The pellet-group count technique for big game trend, census, and distribution: a review. Journal of Wildlife Management 32: 597-614.

Robbins, C. T., T. A. Hanley, A. E. Hagerman, O. Hjeljord, D. L. Baker, C. C. Schwartz, and W. W. Mautz. 1987. Role of tannins in defending plants against ruminants: reduction in protein availability. Ecology 68: 98-107.

Rooney, T. P. 1997. Escaping herbivory: refuge effects on the morphology and shoot demography of the clonal forest herb Maianthemum canadense. Journal of the Torrey Botanical Society 124: 280-285.

Rooney, T. P. 2001. Deer impacts on forest ecosystems: a North American perspective. Forestry 74: 201-208.

Rooney, T. P. and D. M. Waller. 2003. Direct and indirect effects of white-tailed deer in forest ecosystems. Forest Ecology and Management 181: 165-176.

Russell, F. L., D. B. Zippin, and N. L. Fowler. 2001. Effects of white-tailed deer (Odocoileus virginianus) on plants, plant populations and communities: a review. American Midland Naturalist 146: 1-26.

Sargent, S. 1990. Neighborhood effect on fruit removal by birds: a field experiment with Viburnum dentatum (Caprifoliaceae). Ecology 71: 1289-1298. 
SAS, Institute. 2002. JMP. Version 5.0. SAS Institute, Cary, North Carolina.

Saunders, M. R. and K. J. Puettmann. 1999. Use of vegetational characteristics and browsing patterns to predict deer damage in eastern white pine (Pinus strobes) plantations. Northern Journal of Applied Forestry 16: 96-102.

Schädler, M., G. Jung, H. Auge, and R. Brandl. 2003. Palatability, decomposition and insect herbivory: patterns in a successional old-field plant community. Oikos 103: $121-132$.

Shipley, L. A., D. E. Spalinger, J. E. Gross, N. Thompson Hobbs, and B. A. Wunder. 1996. The dynamics and scaling of foraging velocity and encounter rate in mammalian herbivores. Functional Ecology 10: 234-244.

Spalinger, D. E., T. A. Hanley, and C. T. Robbins. 1988. Analysis of the functional response in foraging in the sitka black-tailed deer. Ecology 69: 1166-1175.

Van der Voort. M. E., B. Bailey, D. E. Samuel, and J. B. McGraw. 2003. Recovery of populations of goldenseal (Hydrastis canadensis L.) and American ginseng (Panax quinquefolius L.) following harvest. American Midland Naturalist 149: 282-292. 


\section{CHAPTER 3}

Effects of browsing by white-tailed deer (Odocoileus virginianus Zimm.) on growth, reproduction, and survival of American ginseng, (Panax quinquefolius L.) 


\begin{abstract}
Increases in abundance of white-tailed deer (Odocoileus virginianus Zimm.) have multiple negative effects on forest communities. One area remaining virtually unexplored is the effect of deer browsing on other managed species, such as American ginseng (Panax quinquefolius L.). I examined the effects of deer browsing on growth, reproduction, and survival of ginseng using a multi-yr experimental browse study in addition to monitoring plants in seven natural populations over four seasons. Complete browsing terminated growth and reproduction in the season that it occurred. Browsing had negative carryover effects on growth and reproduction the following yr, an effect enhanced with two consecutive yrs of browsing. Furthermore, severity of browse effects on subsequent-yr leaf area depended on browse timing. Early browsing had a greater negative effect on leaf area change than late season browsing. Mortality was more difficult to measure, but the greatest proportion of plants not emerging had experienced two consecutive prior yrs of browsing. These results show that deer browsing has a negative impact on individual plants that can contribute to population declines and increase vulnerability to extinction. This study demonstrates the need for better, more holistic management of both deer and ginseng populations.
\end{abstract}




\section{Introduction}

Management of natural populations that focuses exclusively on one key species can have unintended consequences. An often-cited example of this is the effects of overabundant white-tailed deer (Odocoileus virginianus Zimm.) on forest communities in the eastern United States. Populations of white-tailed deer have increased dramatically during the $20^{\text {th }}$ century, primarily due to the loss of native predators, land fragmentation resulting in more edge habitat, and effective game management (Russell et al., 2001). As keystone herbivores, large herd sizes can alter ecological communities (Alverson and Waller, 1997; Rooney, 2001; Rooney and Waller, 2003). The building body of evidence suggests that indeed deer are negatively impacting many aspects of the forest community. Studies have shown that deer browsing not only depresses the growth of valuable tree species (Russell et al., 2001; Horsley et al., 2003; Rooney and Waller, 2003) and several herbaceous species (Anderson, 1994; Rooney, 1997; Augustine and Frelich, 1998; Fletcher et al., 2001), but also decreases species richness and abundance (Hough, 1965; Horsley and Marquis, 1983; Van Deelen et al., 1996; Rooney and Dress, 1997; Russell et al., 2001; Horsley et al., 2003) and has contributed to the local extirpation of some rare plant species (Miller et al., 1992). In addition, overabundant deer populations have been associated with indirect negative impacts on bird (deCalesta, 1994; McShea and Rappole, 1997; Fuller, 2001) and small mammal populations (Flowerdew and Ellwood, 2001).

For plant species that are also managed but may be readily consumed by deer, it is important to understand the impact of deer browsing. American ginseng (Panax

quinquefolius L.) is one such species that may be negatively affected by deer browsing. American ginseng is a long-lived perennial understory herb found in the deciduous 
forests of the northeastern United States and southern Canada (Anderson et al., 1993; Robbins, 1998). Despite such a wide range, populations are small and scattered, an uncommon form of rarity (Rabinowitz, 1981). This rarity of ginseng prompted the listing of the species in Appendix II of the Convention on International Trade of Endangered Species of Wild Fauna and Flora (CITES). Because harvesting for the medicinal trade is thought to be one factor associated with the progressive disappearance of ginseng in North America (Charron and Gagnon, 1991), the U.S. Office of Scientific Authority is required to issue a "no-detriment" finding on a state-by-state basis each yr if harvesting is to continue.

In addition to harvesting by humans, deer browsing may be contributing to the decline of ginseng. Not only have I observed that deer actively consume ginseng, but that it is often browsed while known palatable species are not (Furedi, submitted). A study of size-related morphometric traits of American ginseng by McGraw (2001) implied that deer may be responsible in part for size declines over the past century seen in herbarium specimens. The time period over which the decline occurred corresponds roughly with the time when deer herds began to increase to densities large enough to be damaging to forest vegetation in the eastern United States (Porter, 1994). This correlative evidence suggests that deer could be negatively influencing the growth of ginseng, but no study has directly measured the effects of deer browsing on the size and fitness of individual ginseng plants.

To examine the effects of deer browsing on American ginseng, I considered both the time during the season when browsing occurred and if individuals had been previously browsed. Since ginseng exhibits determinate growth, early loss of 
aboveground biomass may result in much-reduced carbon storage, possibly reducing size and/or reproduction in the following yr, while late browse might be expected to have lesser effects. In addition, these negative effects could be compounded by consecutive yrs of browsing. I incorporated both observational and experimental studies to answer the following questions: (1) What are the effects of browsing on individuals in the yr that browsing occurs? (2) Are there carryover effects seen in the yr following the browsing event? (3) Does the severity of the carryover effects depend on the time when browsing occurred in the previous growing season? (4) Are carryover effects more pronounced in individuals that have been browsed for multiple yrs? 


\section{Methods}

\section{Study species}

American ginseng is found in the eastern deciduous forests of the United States and southern Canada. The emergence of American ginseng from winter dormancy is correlated with forest canopy closure (Lewis and Zenger, 1982). A single plant consists of an underground storage root and attached rhizome that gives rise to an aerial "stem" or sympodium. At the summit of the sympodium are the palmately compound leaves or "prongs" arranged in a whorled pattern. In most natural populations, plants range in leaf number from 1-leaf plants to 4-leaf plants although unusual cases have been reported of plants with more than 4 leaves (Furedi, personal observation). In adult plants, the umbel emerges at the summit of the sympodium. American ginseng is primarily selfpollinating, although cross-pollination does occur (Carpenter and Cottam, 1982; Lewis and Zenger, 1983; Schlessman, 1985; Hackney and McGraw, 2001). Flower maturation occurs in June and July. In late July through September, fruits containing one to three seeds are produced (Lewis and Zenger, 1982; Anderson et al., 1993) which are considered ripe when the exocarp turns from green to red.

\section{Study sites}

The eight natural populations used in this study were located in north-central West Virginia near the center of ginseng's natural range. One population was used for the simulated browse experiment while the other seven were monitored for natural browse occurrence and timing of browse. Exact locations are withheld for conservation reasons. All populations occurred in second growth stands, logged at the turn of the $20^{\text {th }}$ 
century. Although all populations were in forests dominated by sugar maple (Acer sacchrum L.) and tulip poplar (Liriodendron tulipifera Marsh.), they varied considerably in elevation, aspect, and dominant understory species (Table 3.1). This variation is typical of ginseng, which has been shown to occupy a relatively broad ecological niche (McGraw et al., 2003).

\section{Simulated browse experiment}

Beginning in May 2000, all plants in a natural population (identified as population TP) were tagged with engraved aluminum nails placed belowground at the base of each plant. If a plant was missing in the following $\mathrm{yr}$, the location of the tag could be determined with the aid of a metal detector. Enclosures were constructed from poultry fencing to protect plants from natural deer browsing without restricting plant growth. All plants were protected for the duration of the experiment (2000-2003).

Starting in May 2001, all plants were assigned to size categories based on the number of leaves per individual. The size categories were: 1-leaf plants, 2-leaf plants, and 3- and 4-leaf plants. The 3- and 4-leaf plants were placed into one category because so few 4-leaf plants were found in the population and both 3- and 4-leaf plants exhibited similar adult characteristics. Plants also were randomly assigned to one of three simulated browse treatments. Those treatments were as follows: (a) no browsing, (b) browsing in one yr (2002), and (c) browsing in two consecutive yrs (2001 and 2002). To mimic the pattern observed with natural browsing, browsing was simulated by clipping the aboveground biomass (Augustine and Frelich, 1998). Browse treatments were applied to plants in mid June of 2001 and 2002. This time period corresponded to our 
Table 3.1. Site characteristics of eight natural populations of American ginseng studied in north-central West Virginia, 2000-2003. 


\begin{tabular}{lccll}
\hline Population & $\begin{array}{c}\text { Elevation } \\
(\mathrm{m})\end{array}$ & $\begin{array}{c}\text { Aspect } \\
(\text { degrees })\end{array}$ & Dominant canopy species & Dominant shrub layer species \\
\hline BG & 722 & 146 & $\begin{array}{l}\text { Liriodendron tulipifera, Acer } \\
\text { saccharum, Fagus grandifolia }\end{array}$ & Fagus grandifolia \\
BN & 695 & 20 & Acer saccharum & Fagus grandifolia \\
CR & 616 & 54 & $\begin{array}{l}\text { Acer saccharum, Tilia } \\
\text { americana, Tsuga canadensis }\end{array}$ & No shrub layer \\
P4 & 475 & 24 & $\begin{array}{l}\text { Liriodendron tulipifera, Acer } \\
\text { saccharum }\end{array}$ & Lindera benzoin \\
P5 & 536 & 15 & $\begin{array}{l}\text { Liriodendron tulipifera, Acer } \\
\text { saccharum }\end{array}$ & Lindera benzoin \\
TP & 582 & 343 & $\begin{array}{l}\text { Liriodendron tulipifera, Acer } \\
\text { saccharum, Prunus serotina }\end{array}$ & Lindera benzoin \\
W2 & 810 & 3 & $\begin{array}{l}\text { Liriodendron tulipifera, Acer } \\
\text { saccharum, Prunus serotina }\end{array}$ & Acer pensylvanicum \\
W4 & 806 & 336 & $\begin{array}{l}\text { Liriodendron tulipifera, Acer } \\
\text { saccharum, Prunus serotina }\end{array}$ & Lindera benzoin \\
\hline
\end{tabular}


field observations made in 2000 , where a majority of the browsing events in several natural populations occurred before July.

Several measurements relating to fitness components were taken for each plant. Starting in May 2000, sympodium height, number of leaves, length (LL) and width (LW) of the longest leaflet per leaf, and reproductive status were recorded. In June 2000, the number of flower buds was recorded for each reproductive individual. Fruit number was noted in September 2000. These measurements were repeated in 2001, 2002, and 2003. The leaf dimensions were used to calculate leaf area based on the following regression equation determined by Furedi and McGraw (2004):

$\mathrm{LA}=4.03(\mathrm{LL})+5.17(\mathrm{LW})+1.38(\mathrm{LL} * \mathrm{LW})$.

The relative growth rate on a leaf area basis $\left(\mathrm{RGR}_{\mathrm{LA}}\right)$, on a sympodium height basis $\left(\mathrm{RGR}_{\mathrm{SY}}\right)$, and on a bud number basis $\left(\mathrm{RGR}_{\mathrm{BD}}\right)$ were calculated using the following equation (Bazzaz and Harper, 1977; McGraw and Garbutt, 1990):

$\mathrm{RGR}=\frac{\ln (\text { final measurement 2003) }-\ln (\text { initial measurement 2001) }}{2}$

The fate of each plant was determined in 2002 and 2003. Individuals were assigned to the following nominal classes: (A) alive (aboveground biomass present), (AD) alive and dormant (no aboveground biomass, but root present and no decay apparent), and (D) dead (decomposition of root or absence of aboveground biomass for two consecutive yrs). 


\section{Natural browsing occurrence}

Beginning in May 2000, all individuals in seven natural populations were tagged in a similar manner as previously described in the simulated herbivory experiment. In addition to tagging all individuals, the populations were mapped using a phototrail approach (Furedi and McGraw, 2004). All measurements taken in the seven populations and the time at which these measurements occurred were similar to those described in the simulated browsing experiment. In addition, I calculated the change in sympodium height and leaf area in 2000-2001, 2001-2002, and 2002-2003. These changes in plant fitness components were used to examine the effects of browsing as a function of the time during the growing season when browsing occurred. To identify these time intervals, each plant was checked for evidence of browse every three to four wks from May until October in each of the four seasons, 2000-2003. If a plant was browsed, the event was recorded along with the Julian d corresponding to the midpoint of the time interval during which browsing occurred.

\section{Statistical analyses of browsing effects}

To examine possible carryover effects of browsing, data from the experimental population and from the natural populations were analyzed in a similar manner. Since browsing resulted in the complete loss of aboveground biomass in the season when browsing occurred (either simulated or naturally occurring), these carryover effects were examined in the season(s) following the browsing event.

In order to compare the effects seen in the natural populations to those found in our simulated herbivory study, I created a subset from the $700+$ plants followed over the 
four-yr period. This subset was limited to plants that had not been browsed in the four-yr period, plants that had only been browsed in 2002, and plants that had been browsed in 2001 and 2002. The plants included in this subset had been browsed between late May and mid June. This time interval corresponded to the time when browsing treatments were applied in my experimental browse study.

The effects of size class and browsing on the $\mathrm{RGR}_{\mathrm{LA}}$ and $\mathrm{RGR}_{\mathrm{SY}}$ were examined by two-way ANOVA models with size class and browsing as fixed main effects. Since only the largest size class reproduced predictably, one-way ANOVA models with treatment as the fixed main effect were used to examine the effects of browsing (either simulated or naturally occurring) on the $\mathrm{RGR}_{\mathrm{BD}}$ and the number of fruits produced in 2003. A loglikelihood analysis was used to determine if browsing affected the reproductive status in 2003. The 1- and 2-leaf size classes were excluded from the statistical tests that dealt with reproductive effects since 1-leaf plants are nonreproductive and 2-leaf plants seldom produce fruits. A loglikelihood analysis was used to examine the effect of browsing on the fate (class $\mathrm{A}, \mathrm{AD}$, or $\mathrm{D}$ ) of plants with size classes and browsing as fixed main effects. When necessary, a post-hoc test, TukeyKramer HSD, was used to examine significant differences among treatment means.

\section{Statistical analysis of time-related effects}

To examine possible time-related effects of browsing on changes in sympodium height and leaf area measured over one-yr intervals (2000-2001, 2001-2002, 2002-2003), I used one-way ANCOVA models with Julian day as the fixed main effect and leaf area as a covariate. Since only a small proportion of plants were browsed during certain time 
intervals, I pooled data from all seven natural populations. I further excluded from the data analysis all plants that had been browsed in one yr, but either did not emerge in the following yr or were browsed again early in the following yr before plant measurements could be taken. When necessary, a log transformation was used to improve normality. To examine possible time-related effects of browsing on the number of buds produced in the yr following a browsing event (independent of the other size-related effects), I first created a data set from the pooled natural populations that contained only plants from the largest size class (3-/4-leaf) that had been browsed in the previous yr. I then regressed bud number in the yr following a browsing event on leaf area in the yr when browsing occurred. The residuals from the regression were then included as the dependent variable in a one-way ANOVA model with timing of browse (Julian d) as a fixed main effect to determine whether timing could explain effects beyond those explained by size. 


\section{Results}

\section{Simulated browse experiment}

Since American ginseng exhibits determinate growth, complete browsing (whether simulated or naturally occurring) resulted in cessation of aboveground growth in the yr that browsing occurred. However, residual effects of browsing were seen in the 2-yr period following the browsing event. I found a significant effect of browse treatments on relative growth rate on a leaf area basis $\left(\mathrm{RGR}_{\mathrm{LA}}\right)$ (browse main effect; $p=$ 0.0003), in addition to differences among size classes (size class main effect; $p=0.0022$ ). Browsed plants (independent of size class) had a lower (more negative) mean $\mathrm{RGR}_{\mathrm{LA}}$ relative to unbrowsed plants (Fig. 3.1a). There was no differential response of the size classes to browsing treatments (browse $\mathrm{x}$ size class interaction; $p=0.1924$ ).

There was a similar significant effect of browsing on plant height $\left(\mathrm{RGR}_{\mathrm{SY}}\right)$ in the 2-yr period following treatments (browsing main effect; $p=0.0082$ ). Browsing resulted in a significant reduction in mean $\mathrm{RGR}_{\mathrm{SY}}$ of plants experiencing two yrs of browse relative to the control group (Fig. 3.1b). There was no differential response of size classes to browsing treatments (browse $\mathrm{x}$ size class interaction; $p=0.5585$ ).

I hypothesized that browsing would have a negative effect on reproduction and, indeed, complete browsing (whether simulated or naturally occurring) terminated reproduction in the season that browsing occurred since complete browsing typically resulted in the loss of the inflorescence along with the plant foliage. Browsing (whether for one yr or two) did not affect whether plants flowered in the yr following browse 
Figure 3.1. Comparisons of the mean relative growth rates of ginseng plants in the simulated browse experiment exposed to three browse treatments (a) on a leaf area basis, and (b) on a sympodium height basis (means $\pm 1 \mathrm{SE}$ ). Means with the same letters are not significantly different. 

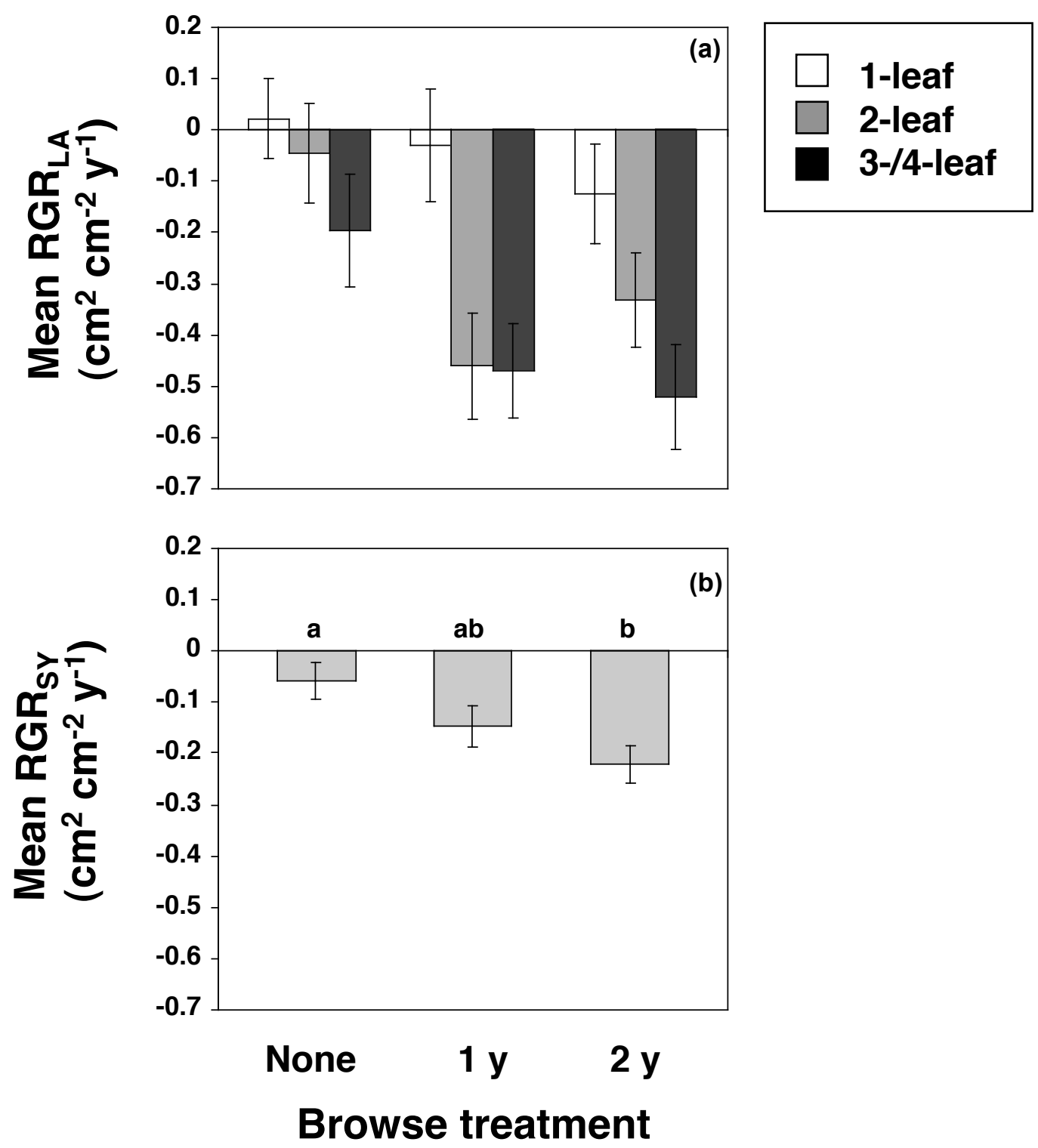
(Loglikelihood test; $p=0.1616$ ), primarily because nearly $100 \%$ of adult plants produced an inflorescence. However, I did find a significant reduction in the relative growth rate on a bud number basis $\left(\mathrm{RGR}_{\mathrm{BD}}\right)$ of browsed plants compared to unbrowsed plants (browse main effect; $p=0.019$ ) (Fig. 3.2). As expected, 3- and 4-leaf plants exposed to two yrs of browsing had an even greater decline in bud number (Fig. 3.2). There was no significant effect of browse treatments on fruit production (browse main effect; $p=$ 0.4456) primarily due to low and variable fruit production among all 3-/4-leaf plants. Only four of the 17 reproductive individuals in this size class produced fruit.

Mortality was difficult to measure since it was possible for a plant to remain dormant in one yr and return aboveground in the following yr (Carpenter and Cottam, 1982; Lewis and Zenger, 1982; Charron and Gagnon, 1991). In the time frame of this study, I was only able to confirm the death of one plant due to erosion. However, by $2003,20.4 \%$ of the plants were 'missing' (either dead or dormant) in early spring. Loglikelihood analysis showed that there was no effect of size class $(p=0.9930)$, browse treatment $(p=0.9876)$, or their interaction $(p=0.7081)$ on plant fate.

\section{Browsing patterns in natural populations}

Out of the 700+ plants followed during the four-yr duration of this study, overall browsing in the seven natural populations ranged from $15 \%$ (in 2000) to $42 \%$ (in 2002) (Table 2). Individual populations experienced browsing rates ranging from 9\% (CR, 2000) to $83 \%$ (CR, 2002) (Table 3.2). Although browsing rates differed among populations (Loglikelihood; $p<0.0001$ ) and yrs (Loglikelihood; $p<0.0001$ ), we found 
Figure 3.2. Comparison of the mean relative growth rate on a bud number basis of 3and 4-leaf plants in the simulated browse experiment exposed to three browse treatments (means $\pm 1 \mathrm{SE}$ ). Means with the same letters are not significantly different. 


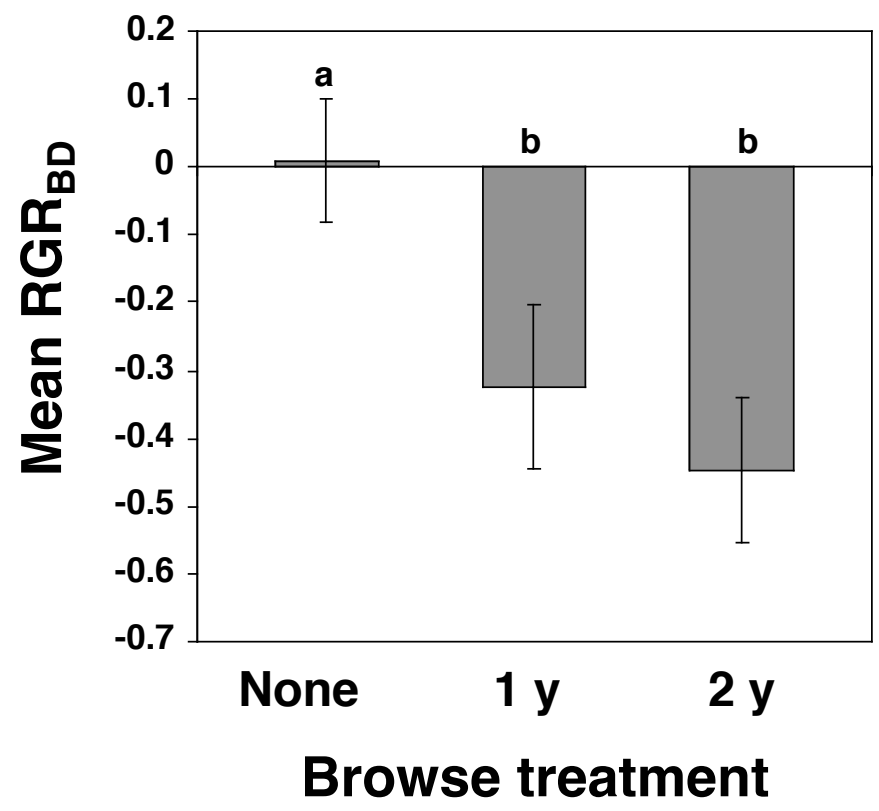


Table 3.2. Proportion of ginseng plants browsed in seven natural populations showing the overall browse rates for 2000-2003 and the proportion of plants browsed in each size class. (No data are available for W4 in 2000. Censusing of this population began in 2001.) 


\begin{tabular}{|c|c|c|c|c|c|c|c|c|c|c|c|c|c|c|c|c|}
\hline \multirow[b]{2}{*}{ Population } & \multicolumn{4}{|c|}{2000} & \multicolumn{4}{|c|}{2001} & \multicolumn{4}{|c|}{2002} & \multicolumn{4}{|c|}{2003} \\
\hline & $1-$ & $2-$ & $3-/ 4-$ & Overall & $1-$ & $2-$ & $3-/ 4-$ & Overall & $1-$ & $2-$ & $3-/ 4-$ & Overall & $1-$ & $2-$ & $3-/ 4-$ & Overall \\
\hline BG & 0.00 & 0.10 & 0.26 & 0.18 & 0.00 & 0.29 & 0.23 & 0.23 & 0.00 & 0.32 & 0.13 & 0.17 & 0.00 & 0.07 & 0.10 & 0.07 \\
\hline $\mathrm{BN}$ & 0.00 & 0.25 & 0.93 & 0.40 & 0.00 & 0.31 & 1.00 & 0.40 & 0.25 & 0.41 & 0.82 & 0.45 & 0.09 & 0.06 & 0.14 & 0.09 \\
\hline CR & 0.00 & 0.20 & 0.00 & 0.09 & 0.43 & 1.0 & 1.00 & 0.56 & 0.50 & 1.00 & 1.00 & 0.83 & 0.00 & 0.40 & 0.00 & 0.18 \\
\hline P4 & 0.00 & 0.17 & 0.19 & 0.10 & 0.15 & 0.14 & 0.32 & 0.19 & 0.04 & 0.64 & 0.57 & 0.37 & 0.09 & 0.30 & 0.36 & 0.22 \\
\hline P5 & 0.02 & 0.17 & 0.20 & 0.13 & 0.02 & 0.25 & 0.34 & 0.22 & 0.10 & 0.63 & 0.69 & 0.49 & 0.02 & 0.29 & 0.38 & 0.22 \\
\hline W2 & 0.15 & 0.12 & 0.38 & 0.19 & 0.09 & 0.28 & 0.29 & 0.20 & 0.11 & 0.50 & 0.76 & 0.43 & 0.04 & 0.47 & 0.65 & 0.42 \\
\hline W4 & -- & -- & -- & -- & 0.00 & 0.39 & 0.00 & 0.19 & 0.00 & 0.10 & 0.44 & 0.16 & 0.00 & 0.14 & 0.30 & 0.17 \\
\hline All & & & & 0.15 & & & & 0.23 & & & & 0.42 & & & & 0.22 \\
\hline populations & & & & & & & & & & & & & & & & \\
\hline
\end{tabular}


that browsing was focused on plants in the 2-, 3-/4-leaf size classes. These plants were larger, which increases their apparency to deer (Furedi, submitted).

The effects of natural browsing on size-related relative growth rates $\left(\mathrm{RGR}_{\mathrm{LA}}\right.$ and $\mathrm{RGR}_{\mathrm{SY}}$ ) corresponded to those reported in the experimental browse study, in that browsing significantly reduced the $\mathrm{RGR}_{\mathrm{LA}}$ and $\mathrm{RGR}_{\mathrm{SY}}$, an effect that was even more pronounced with two yrs of deer damage (browse main effect; $p<0.0001$ for $\mathrm{RGR}_{\mathrm{LA}}, p=$ 0.0015 for $\mathrm{RGR}_{\mathrm{SY}}$; Fig. 3.3a,b). The general effects of natural browsing were consistent with those found in the experimental study. Browsing resulted in a reduction in $\mathrm{RGR}_{\mathrm{LA}}$ and $\mathrm{RGR}_{\mathrm{SY}}$ in the yr after browsing occurred, which was further exacerbated by two consecutive yrs of browsing (with the exception of the $\mathrm{RGR}_{\mathrm{LA}}$ of 2-leaf plants after two yrs of browsing). There was a significant difference among size classes for both $\mathrm{RGR}_{\mathrm{LA}}$ $(p=0.0198)$ and $\operatorname{RGR}_{\mathrm{SY}}(p=0.0003)$. Three and 4-leaf plants experienced the greatest reduction in $\mathrm{RGR}_{\mathrm{LA}}$ (Fig. 3.3a). In contrast, 1-leaf plants experienced the greatest reduction in $\mathrm{RGR}_{\mathrm{SY}}$ (Fig. 3.3b). There was no differential response of size classes to browsing treatments for either $\mathrm{RGR}_{\mathrm{LA}}(p=0.4545)$ or $\mathrm{RGR}_{\mathrm{SY}}(p=0.6604)$.

Unlike the results reported for the experimental study, browsing had a significant effect on whether or not a plant was reproductive in the following yr (Loglikelihood test; $p=0.0046$ ). In 2003, all 3-/4-leaf unbrowsed plants produced flowers, while only $86 \%$ were reproductive after experiencing one yr of browsing and $77 \%$ were reproductive after two yrs of browsing. In addition to influencing the reproductive status of 3-/4-leaf plants, we also found that there was a trend towards browsing having a negative effect on the relative growth rate on a bud number basis $\left(\mathrm{RGR}_{\mathrm{BD}}\right)$ (browse main effect; $p=0.0712$ ). Similar to the experimental study, two yrs of browsing resulted in a significant reduction 
Figure 3.3. Comparisons of the mean relative growth rates of ginseng plants exposed to three levels of natural deer browsing (a) on a leaf area basis, and (b) on a sympodium height basis (means $\pm 1 \mathrm{SE}$ ). 

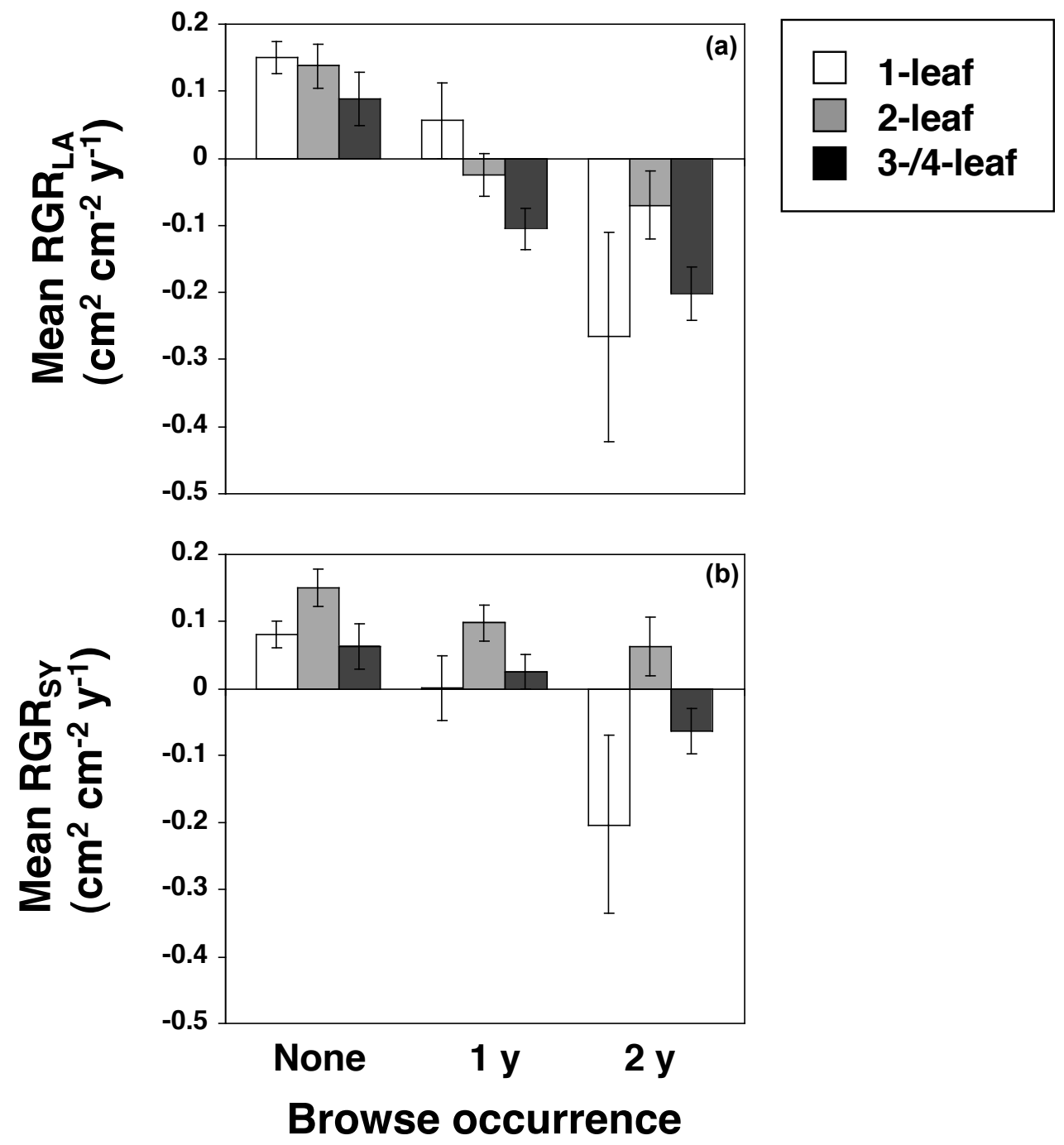
in $\mathrm{RGR}_{\mathrm{BD}}$ compared to unbrowsed plants (Fig. 3.4). Also similar to the experimental study, fruit production was not affected by browsing (browse main effect; $p=0.5227$ ). Fruit production was low and variable regardless of whether or not plants had experienced previous browsing episodes.

Contrary to the results in the experimental browse study, I found that both occurrence of browse $(p=0.0019)$ and size class $(p=0.0072)$ had a significant effect on plant fate (whether or not a plant was present in 2003). The greatest proportion of plants not emerging in 2003 had experienced two yrs of deer browsing (Fig. 3.5). One-leaf plants comprised the majority of plants not emerging in 2003 (Fig. 3.5). Since 1-leaf plants are usually young plants with little carbon reserve in the root, it was not surprising to find that $60 \%$ of the browsed 1-leaf plants were absent in 2003 . There was no differential response of size classes to browse occurrence in terms of plant fate ( $p=$ $0.6400)$.

\section{Timing of browse in natural populations}

Overall, there were differences in the proportion of plants browsed at different time intervals in the seven natural populations during the four-yr duration of the study (2000-2003). For all populations in 2000 (with the exceptions of BN and W2), the proportion of browsed plants was greatest before mid-June (Julian day 175) and gradually declined as the season progressed (Fig. 3.6a). Similar to the other populations, populations $\mathrm{BN}$ and $\mathrm{W} 2$ also experienced a high proportion of browsed plants before mid-June but continued to experience somewhat higher rates of browse throughout the growing season (Fig. 3.6a). In 2001, again, the greatest proportion of plants was browsed 
Figure 3.4. Comparisons of the mean relative growth rate on a bud number basis of 3and 4-leaf plants experiencing natural rates of deer browsing (means $\pm 1 \mathrm{SE}$ ). Means with the same letters are not significantly different. 


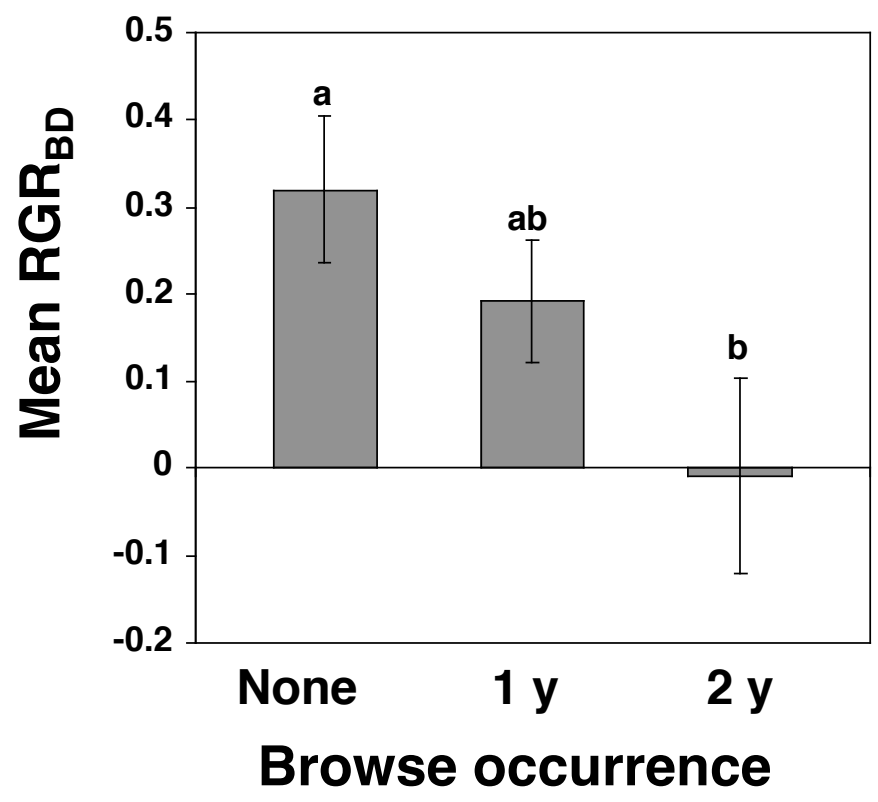


Figure 3.5. Proportion of browsed ginseng plants not emerging in the spring census 2003 as a function of browse occurrence. 


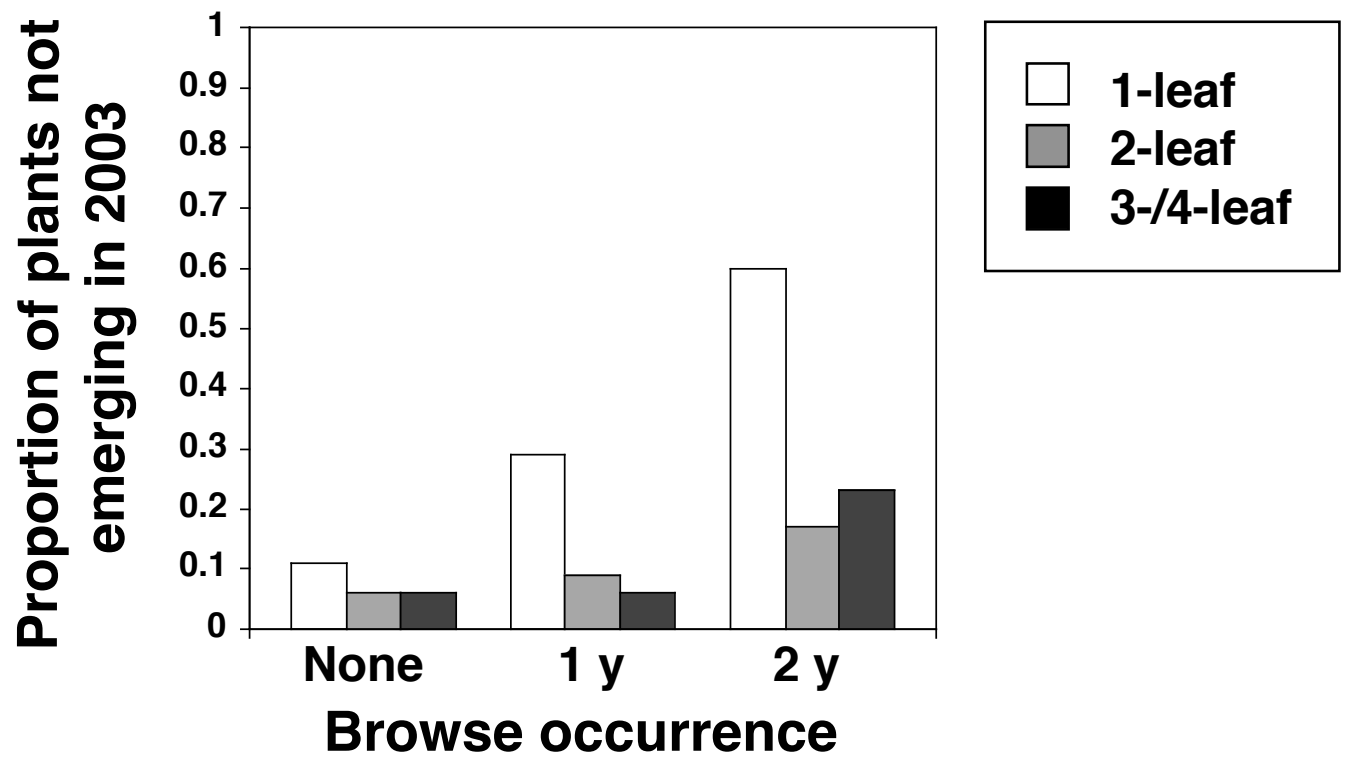


Figure 3.6. Proportion of browsed ginseng plants in the natural populations as a function of the time interval when browsing occurred (Julian day) in: (a) 2000, (b) 2001, (c) 2002, and (d) 2003. 

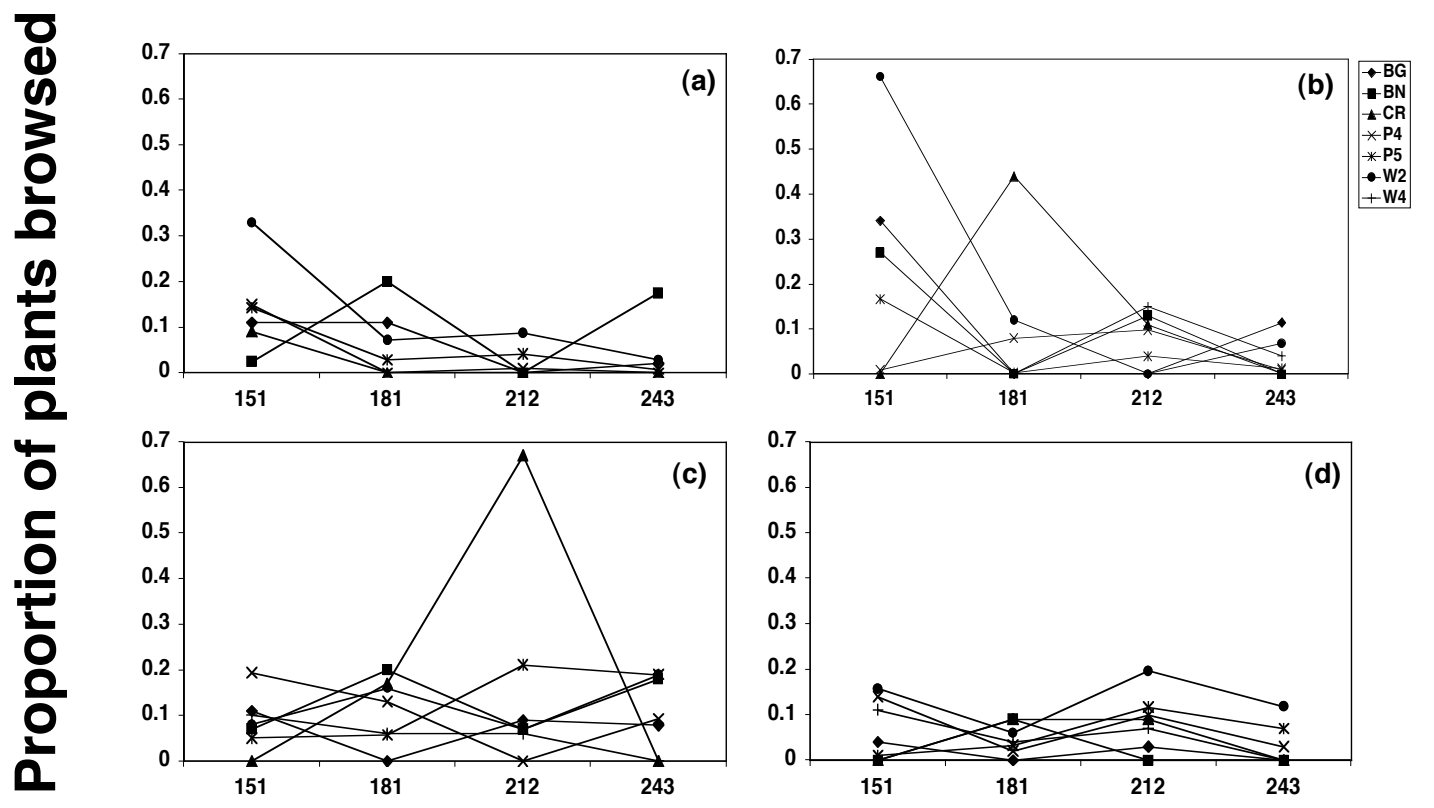

Timing of browse (Julian day) 
before mid-June (Fig. 3.6b). However, as the season progressed, some populations showed gradual declines in browsing (BG, BN, and CR) while others (P4, P5, W2, and W4) showed a more variable pattern (Fig. 3.6b). During the 2002 growing season, the largest proportion of plants was browsed in June (Julian day 152) and July (Julian day 212) although the proportion of browsed plants differed among populations (Fig. 3.6c). In 2003, browsing rates were low and mostly uniform throughout the growing season (Fig. 3.6d).

The time interval when browsing occurred (Julian d) did not affect the change in sympodium height seen over three one-yr intervals (Table 3.3). However, change in leaf area (2002-2001 and 2003-2002) was affected by the timing of browse (Table 3.3). For both intervals, a significantly greater decrease in leaf area was seen for plants browsed early in the season than for those individuals that had experienced late season browsing (Fig. 3.7a, 3.7b).

In the experimental study and in the natural populations, browsing resulted in a reduction in the relative growth rate on a bud number basis in the yr following browse. However, browse timing within a season did not alter this effect (Table 3.3). 
Table 3.3. The effect of the time interval when browsing occurred (Julian day) on the change in sympodium height, change in leaf area, and bud number over three oneyear intervals (200-2001, 2001-2002, and 2002-2003). The table includes F-values and their associated $p$-values in parentheses. 


\begin{tabular}{|c|c|c|c|c|c|c|c|c|c|}
\hline & \multicolumn{3}{|c|}{ Change in sympodium height $(\mathrm{cm})$} & \multicolumn{3}{|c|}{ Change in leaf area $\left(\mathrm{cm}^{2}\right)$} & \multicolumn{3}{|c|}{ Bud number } \\
\hline & $2000-01$ & 2001-02 & $2002-03$ & $2000-01$ & 2001-02 & $2002-2003$ & 2000-01 & 2001-02 & $2002-03$ \\
\hline Julian & 0.1970 & 1.5420 & 0.0889 & 0.8257 & $4.4393^{*}$ & $9.2020^{*}$ & 0.4385 & 0.2875 & 0.1432 \\
\hline
\end{tabular}

* denotes a significant effect if $p<0.05$ 
Figure 3.7. Mean change in leaf area occurring from (a) 2001 to 2002, and (b) 2002 to 2003 as a function of the time interval when browsing occurred (Julian day). 


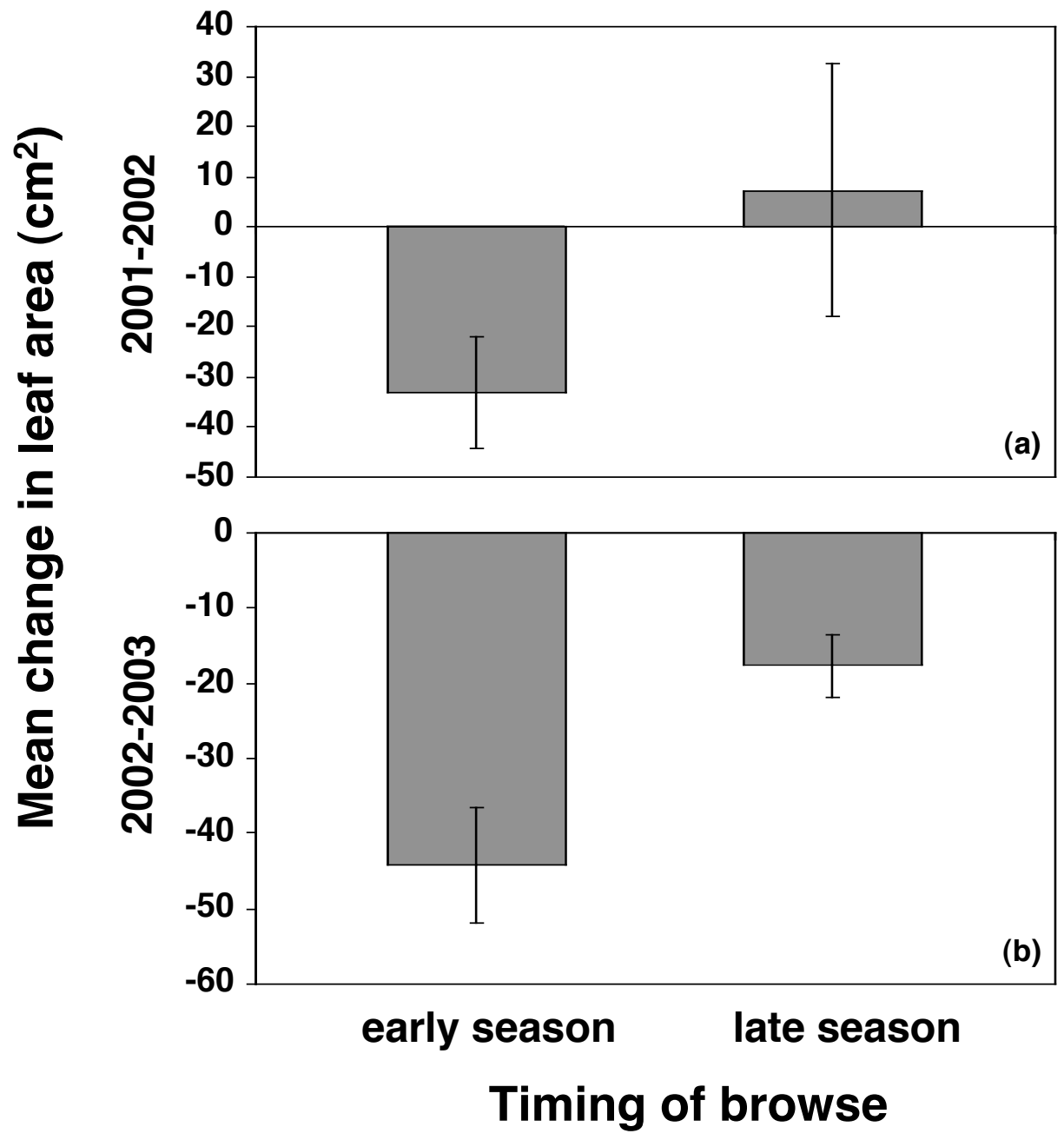




\section{Discussion}

Overall, the results from the experimental browse study and the natural browse study supported the hypothesis that deer browsing would have a negative effect on both the growth and reproduction of ginseng. Not only did complete browsing result in the loss of aboveground biomass and reproductive structures in the season that browsing occurred, but these negative effects were carried over into the following yr. Furthermore, for plants that experienced multiple yrs of deer damage, the carryover effects were compounded. In addition, timing of browse occurrence affected the severity of carryover effects on leaf area. Other studies on the effects of ungulate herbivory reported similar carryover effects in the $y r(s)$ following browsing (Edwards, 1985; Anderson, 1994; Ehrlen, 1995; Augustine and Frelich, 1998).

The reduction in growth and reproductive potential (inflorescence presence and bud number) observed in this study is mostly likely the result of carbon limitations brought on by the loss of all aboveground biomass to browsing. For plants such as ginseng that exhibit determinate growth, browsing not only affects current yr carbon storage but also future growth potential. Plant parts that are damaged or lost in a growing season are not replaced in that yr, thus halting carbon gain for the season, although belowground stem and root respiration continue. The resulting carbon deficit reduces plant size and reproductive potential. In addition, since current yr growth is dependent on stored carbon from previous yrs, each yr that browsing occurs results in less accumulated carbon. Cumulative yrs of browsing often resulted in an even greater reduction in sizerelated and reproductive traits than a single browse episode. 
Plants were often browsed in May and June (Figures 3.6a-3.6d), before they could reaccumulate carbon allocated to emergence, elongation, and inflorescence production. Since carbon storages decline when growth is rapid and recovers when growth stops or senescence begins (Chapin et al., 1990), early season browsing was expected to be more severe than late season browsing effects. This hypothesis was supported by the findings of a greater effect of early than late season browse on leaf area changes.

Effects on individuals can be translated into negative effects on population growth via increased mortality and reduced reproduction. Although mortality rates were not measured directly due to the difficulty of distinguishing dormant from dead plants, browsing was associated with non-emergence in the $\mathrm{yr}(\mathrm{s})$ following browsing. Some of these non-emerging plants may be dead. With nearly $20 \%$ of the plants missing in 2003 , ginseng populations can experience substantial declines if browsing results in the death of some individuals.

Reproduction is affected directly in the season that browsing occurs since complete browsing terminates reproduction that season. Even if fruits are present when a plant is browsed, the effects on reproduction are negative. Previous work demonstrated that deer are seed predators of American ginseng (Furedi and McGraw, 2004). If fruits are consumed with the foliage, they are lost. The results of this study showed that browsing can also alter the reproductive status of plants in the $\mathrm{yr}(\mathrm{s})$ following browse. For some yrs, populations exposed to deer pressures may have few reproductive individuals, resulting in a reduced contribution to the seed bank and hence reduced recruitment. 
A reduction in plant size can also have compounding negative effects on reproduction. Plants with reduced stature produce fewer buds per plant regardless of when plants were browsed. Reduced inflorescence size can indirectly alter population growth by affecting pollinators. Because small plants are less apparent to pollinators, this reduction could lower encounter and visitation rates of insects (Schemske, 1980; Sih and Baltus, 1987; Jennersten, 1988). Lewis and Zenger (1983) reported that pollinators showed a preference for ginseng plants with many open flowers suggesting that pollinators are affected by inflorescence size. Reduced visitation rates can then in turn lower the transfer rate of pollen (Kunin, 1993). Since American ginseng exhibits a mixed breeding system capable of both selfing and outcrossing with the aid of pollinators (Carpenter and Cottam, 1982; Lewis and Zenger, 1983; Schlessman, 1985), pollinator limitations can alter fertility. Hackney and McGraw (2001) provided evidence for this at a population level (i.e., an Allee effect) in experimental populations of ginseng.

While most effects of browsing on individual traits would seem to contribute to a decline in populations, there may be some short-term advantages for plants that are less apparent due to browse-related size reductions. In a previous study, I found that larger, reproductive plants are more apparent to deer than smaller, non-reproductive ones and thus, more susceptible to browsing (Furedi, Chapter 2). Plants that have been dwarfed by repeated browsing may ultimately get browsed at lower rates. Similarly, smaller plants may be less obvious to harvesters. The reduction in plant size may in fact serve indirectly as a protective response to browsing and harvesting, although it is doubtful whether the added protection outweighs the loss in reproductive potential associated with browsing. 
Although browsing may 'hide' ginseng from deer and harvesters by reducing size-related traits and reproductive structures, my results suggest that the additional pressures associated with browsing such as reductive losses may be more detrimental than beneficial to natural ginseng populations. Demographic studies of American ginseng by Nantel et al. (1996) showed that even small annual harvest rates of less than $10 \%$ could cause large populations to drop below their minimum viable population size in less than 100 years. These analyses did not consider the additional pressures of deer browsing. In order to more clearly understand the impact of both harvest and deer, it is important to: (a) census populations early in the season before browsing occurs to obtain an accurate account of population size and (b) incorporate both harvest and browse scenarios into demographic studies and population viability analyses.

Since ginseng is sensitive to browsing, it may be a useful species to use as an indicator of deer browsing intensity. Other studies have suggested using herbaceous species to gauge the impacts of deer abundances on forest plant communities (Anderson, 1994; Ballgooyen and Waller, 1995; Williams et al., 2000; Webster et al., 2001). Data collected from the monitoring of natural populations of ginseng (as suggested in the management program for the species; Robbins 2000) also may provide additional information on deer impacts.

My findings, in combination with a building body of evidence, show that deer are impacting forest plant populations, communities, and ecosystems (see Flowerdew and Ellwood, 2001; Fuller, 2001; Gill and Beardall, 2001; Russell et al., 2001; Rooney, 2001; Horsley et al., 2003; Rooney and Waller, 2003). Decades of single-species management, in addition to loss of top predators and landscape changes (Russell et al., 2001), have 
resulted in an overabundance of deer that is likely to negatively impact other valuable managed species, such as ginseng, as well as less "charismatic" and less economically valuable understory plants. A multi-species view of ecosystem management is clearly required in natural systems, particularly where overabundance of one species detrimentally affects others. By international law (CITES), ginseng populations must be protected from detrimental harvesting effects. Based on my findings, it seems likely that ginseng would be more vulnerable to lowered population viability due to persistent stress imposed by deer browsing (McGraw and Furedi, submitted). Furthermore, the viability of the ginseng trade itself (a minimum estimated annual value of \$18 million to states with ginseng programs) (Robbins, 2000) is threatened by white-tailed deer. 


\section{Literature Cited}

Alverson, W. S. and D. M. Waller. 1997. Deer populations and the widespread failure of hemlock regeneration in northern forests. In W. McShea and J. Rappole [eds.], The science of overabundance: deer ecology and population management, 280297. Smithsonian Institution Press, Washington, DC, USA.

Anderson, R. C., J. S. Fralish, J. E. Armstrong, and P. K. Benjamin. 1993. The ecology and biology of Panax quinquefolium L. (Araliaceae) in Illinois. American Midland Naturalist 129: 357-372.

Anderson, R. C. 1994. Height of white-flowered trillium (Trillium grandiflorum) as an index of deer browsing intensity. Ecological Applications 4: 104-109.

Augustine, D. J. and L. E. Frelich. 1998. Effects of white-tailed deer on populations of an understory forb in fragmented deciduous forests. Conservation Biology 12: 995-1004.

Balgooyen, C. P. and D. M. Waller. 1995. The use of Clintonia borealis and other indicators to gauge impacts of white-tailed deer on plant communities in northern Wisconsin, USA. Natural Areas Journal 15: 308-318.

Bazzaz, F. A. and J. L. Harper. 1977. Demographic analysis of the growth of Linum usitatissimum. New Phytologist 78: 193-208. 
Carpenter, S. G. and G. Cottam. 1982. Growth and reproduction of American ginseng (Panax quinquefolius) in Wisconsin, USA. Canadian Journal of Botany 60: 2692-2696.

Chapin, F. S. III, Schulze E.-D., and H. A. Mooney. 1990. The ecology and economics of storage in plants. Annual Review of Ecology and Systematics 21: 423-447.

Charron, D. and D. Gagnon. 1991. The demography of northern populations of Panax quinquefolium (American ginseng). Journal of Ecology 79: 431-445.

deCalesta, D. S. 1994. Effect of white-tailed deer on songbirds within managed forests in Pennsylvania. Journal of Wildlife Management 58: 711-718.

Edwards, J. 1985. Effects of herbivory by moose on flower and fruit production of Aralia nudicaulis. Journal of Ecology 73: 861-868.

Ehrlen, J. 1995. Demography of the perennial herb Lathyrus vernus I. Herbivory and individual performance. Journal of Ecology 83: 287-295.

Fletcher, J. D., L. A. Shipley, W. J. McShea, and D. L. Shumway. 2001. Wildlife herbivory and rare plants: the effects of white-tailed deer, rodents, and insects on growth and survival of Turk's cap lily. Biological Conservation 101: 229-238. 
Flowerdew, J. R. and S. A. Ellwood. 2001. Impacts of woodland deer on small mammal ecology. Forestry 74: 277-287.

Fuller, R. J. 2001. Responses of woodland birds to increasing numbers of deer: a review of evidence and mechanisms. Forestry 74: 289-298.

Furedi, M. and J. B. McGraw. 2004. White-tailed deer: dispersers or predators of American ginseng seeds. American Midland Naturalist 152: 268-276.

Gill, R. M. A. and V. Beardall. 2001. The impact of deer on woodlands: the effects of browsing and seed dispersal on vegetation structure and composition. Forestry 74: $209-218$.

Hackney, E. E. and J. B. McGraw. 2001. Experimental demonstration of an Allee effect in American ginseng. Conservation Biology 15: 129-136.

Horsley, S. B. and B. A. Marquis. 1983. Interference by weeds and deer with Allegheny hardwood reproduction. Canadian Journal of Forestry and Reclamation 13: 6169.

Horsley, S. B., S. L. Stout, and D. S. deCalesta. 2003. White-tailed deer impact on the vegetation dynamics of a northern hardwood forest. Ecological Applications 13: 98-118. 
Hough, A. F. 1965. A twenty-year record of the understory vegetational change in a virgin Pennsylvania forest. Ecology 46: 370-373.

Jennersten, O. 1988. Pollination in Dianthus deltoids (Caryophyllaceae): effects of habitat fragmentation on visitation and seed set. Conservation Biology 2: 359366.

Kunin, W. E. 1993. Sex and the single mustard: population density and pollinator behavior effects on seed-set. Ecology 74: 2145-2160.

Lewis, W. H. and V. E. Zenger. 1982. Population dynamics of the American ginseng Panax quinquefolium (Araliaceae). American Journal of Botany 69: 1483-1490.

Lewis, W. H. and V. E. Zenger. 1983. Breeding systems and fecundity in the American ginseng, Panax quinquefolium (Araliaceae). American Journal of Botany 70: 466-468.

McGraw, J. B. and K. Garbutt. 1990. Demographic growth analysis. Ecology 71: 11992004.

McGraw, J. B. 2001. Evidence for decline in stature of American ginseng plants from herbarium specimens. Biological Conservation 98: 25-32. 
McGraw, J. B., S. M. Sanders, and M. Van der Voort. 2003. Distribution and abundance of Hydrastis canadensis L. (Ranunculaceae) and Panax quinquefolius L. (Araliaceae) in the central Appalachian region. Journal of the Torrey Botanical Society 130: 62-69.

McShea, W. J. and J. H. Rappole. 1997. Herbivores and the ecology of forest understory birds. In W. McShea and J. Rappole [eds.], The science of overabundance: deer ecology and population management, 298-309. Smithsonian Institution Press, Washington, DC, USA.

Miller, S. G., S. P. Bratton, and J. Hadidian. 1992. Impacts of white-tailed deer on endangered and threatened vascular plants. Natural Areas Journal 12: 67-74.

Nantel, P., D. Gagnon, and A. Nault. 1996. Population viability analysis of American ginseng and wild leek harvested in stochastic environments. Conservation Biology 10: 608-621.

Porter, W. F. 1994. Burgeoning ungulate populations in national parks: is intervention warranted? In D. R. McCullough and R. H. Barrett [eds.], 304-312. Wildlife 2001: populations. Elsevier, New York, New York, USA.

Rabinowitz, D. 1981. Seven forms of rarity. In H. Synge [ed.], The biological aspects of rare plant conservation. Wiley, New York, New York, USA. 
Robbins, C. S. 1998. American ginseng: the root of North America's medicinal herb trade. TRAFFIC North America Report, Number B347, Washington, D.C., USA.

Robbins, C. S. 2000. Comparative analysis of management regimes and medicinal plant trade monitoring mechanisms for American ginseng and goldenseal. Conservation Biology 14: 1422-1434.

Rooney, T. P. 1997. Escaping herbivory: refuge effects on the morphology and shoot demography of the clonal forest herb Maianthemum canadense. Journal of the Torrey Botanical Society 124: 280-285.

Rooney, T. P. and W. J. Dress. 1997. Species loss over sixty-six years in the groundlayer vegetation of Heart's Content, an old-growth forest in Pennsylvania, USA. Natural Areas Journal 17: 297-305.

Rooney, T. P. 2001. Deer impacts on forest ecosystems: a North American perspective. Forestry 74: 201-208.

Rooney, T. P. and D. M. Waller. 2003. Direct and indirect effects of white-tailed deer in forest ecosystems. Forest Ecology and Management 181: 165-176. 
Russell, F. L., D. B. Zippin, and N. L. Fowler. 2001. Effects of white-tailed deer (Odocoileus virginianus) on plants, plant populations and communities: a review. American Midland Naturalist 146: 1-26.

Schemske, D. W. 1980. Floral ecology and hummingbird pollination of Combretum farinosum in Costa Rica. Biotropica 12: 169-181.

Schlessman, M. A. 1985. Floral biology of American ginseng (Panax quinquefolium). Bulletin of the Torrey Botanical Club 112: 129-133.

Sih, A. and M. Baltus. 1987. Patch size, pollinator behavior, and pollinator limitation in catnip. Ecology 68: 1679-1690.

Van Deelen, T. R., K. S. Pregitzer, and J. B. Haufler. 1996. A comparison of presettlement and present-day forests in two northern Michigan deer yards. American Midland Naturalist 135: 181-194.

Webster, C. R., M. A. Jenkins and G. R. Parker. 2001. A field test of herbaceous plant indicators of deer browsing intensity in mesic hardwood forests of Indiana, USA. Natural Areas Journal 21: 149-158. 
Williams, C. E., E. V. Mosbacher, and W. J. Moriarity. 2000. Use of turtlehead

(Chelone glabra L.) and other herbaceous plants to assess intensity of white-tailed deer browsing on Allegheny Plateau riparian forests, USA. Biological

Conservation 92: 207-215. 


\section{CHAPTER 4}

White-tailed deer: Dispersers or predators of American ginseng seeds? 


\begin{abstract}
As a result of game management practices and alterations in habitat, white-tailed deer populations (Odocoileus virginianus Z.) have increased to all time highs within the last century. Large herd numbers are having negative impacts at multiple levels in forest ecosystems, although there are many aspects that have not yet been investigated. One of the least understood impacts is the effect of deer browsing on the fate of valuable harvested understory species such as American ginseng (Panax quinquefolius L.). The objectives of this study were to quantify the natural frequency at which fruit-bearing ginseng plants are browsed by deer, to determine the amount of ginseng seeds consumed by deer, and with feeding trials, to determine if white-tailed deer are seed dispersers or seed predators of American ginseng. My results showed that fruits are frequently browsed in natural populations and that browsed seeds are most likely destroyed during the digestive process. The loss of ginseng seeds to deer browsing can negatively impact the seed bank and ultimately affect long-term population growth and viability. Although white-tailed deer and American ginseng are managed species, effective growth of deer populations is adversely affecting ginseng, as well as other valuable forest species.
\end{abstract}




\section{Introduction}

The loss of large carnivores and the fragmentation of the landscape, coupled with effective game management practices, have led to a sharp increase in white-tailed deer (Odocoileus virginianus) populations. As keystone herbivores in the eastern deciduous forests, large deer herds can alter biotic communities within forest ecosystems (Waller and Alverson, 1997). Research on the effects of this overabundant species show that white-tailed deer are having a negative impact on multiple trophic levels of the forest community including trees and shrubs (see review Russell et al., 2001), herbaceous plants (see review Miller et al., 1992; Anderson, 1994; Balgooyen and Waller, 1995; Rooney and Dress, 1997; Augustine and Frelich, 1998; Rooney and Waller, 2001) and even birds (deCalesta, 1994; McShea et al., 1995; McShea and Rappole, 1997) and other small mammals (Ostfeld et al., 1996; Flowerdew and Ellwood, 2001). Many studies have demonstrated negative effects of deer browsing on regeneration, growth and survival of valuable tree species (Alverson et al., 1988; Rooney, 2001; see also review Russell et al., 2001). Fewer studies have assessed the impact of deer browsing on herbaceous species although those studies again have demonstrated dramatic reductions in growth, survival, and abundance due to deer browsing (Anderson, 1994; Rooney and Dress, 1997; Augustine and Frelich, 1998; Rooney and Waller, 2001). The potential effects of deer on less understood plant processes like seed dispersal have rarely been studied (but see Welch, 1985; Dinerstein, 1989; Malo and Suarez, 1995; Gill and Beardall, 2001; Vellend et al., 2003).

Large herbivores such as white-tailed deer can serve as dispersal agents in two ways. First, seeds may disperse passively as hitch-hikers attached to fur (Stiles, 1992; 
Chambers and MacMahon, 1994). This is probably rare for seeds surrounded by a fleshy exocarp and certainly not a major mode of dispersal for many fruit producing woodland species. Second, white-tailed deer may eat fruit and seeds outright as a source of autumn forage (Gee et al., 1991). Fruit and seed consumption may also occur incidentally as a consequence of browsing the foliage of the plant (Chambers and MacMahon, 1994). In the latter situation, seed dispersal is the consequence of serendipitous mixing of the animal's forage with seed and subsequent fortuitous survival of the hazardous trip through the digestive process (Janzen, 1984). Regardless of whether ingestion is deliberate, if seeds survive, deer can help perform the two major functions of seed dispersal: (1) removal of seeds from the parent shadow and (2) colonization of a new, potentially better, site (Janzen, 1971). The newly deposited seed might have an environmental advantage over its undigested counterparts by being deposited in fertile, fecal material (Stiles, 1992). Plants that most likely benefit from deer browsing are those plants which produce small, hard seeds that are located within close proximity to the foliage. Deer have been shown to serve as dispersal agents for many grasses as well as members of the Leguminosae, Scrophulariaceae, and Amaranthaceae families (Stiles, 1992). Malo and Suarez (1995) and Welch (1985) showed that many grasses and legumes are successfully dispersed by red deer (Cervus elaphus) and fallow deer (Dama dama). Vellend et al. (2003) recovered viable seeds of Trillium grandiflorum Michx. from deer pellets.

Deer may be seed predators for some plant species. Seed predation can occur when seeds are directly destroyed during mastication or broken down in the gut during digestion. Larger seeds with soft coats are more susceptible to chewing and digestive 
damage. Several studies have reported evidence of seed predation by deer. Sargent (1990) noted that although the fruits of Viburnum dentatum L. were consumed by whitetailed deer, intact seeds were not recovered from deer pellets collected at the study sites. Dinerstein (1989) found that seeds were destroyed instead of dispersed in his examination of over 40,000 deer pellets from four Asian deer.

For rare plants that are often preferred browse species by white-tailed deer, it is important to understand the impact of deer consumption on seed fates. The focus of this study is American ginseng (Panax quinquefolius L.), which is considered rare due in part to harvesting of the root by humans for medicinal sales on the Asian market and due to loss of suitable habitat (Charron and Gagnon, 1991). American ginseng is often browsed by white-tailed deer though it is unclear how often ginseng seeds are consumed and whether seeds remain viable after being ingested. Although the timing of browse varies among years, browsing occurs late in the growing season when fruits are still present on the plants (M.A. Furedi, personal observation). In some wild populations in West Virginia, browsing rates are so intense that nearly all fruiting plants are defoliated. A priori it is not easy to predict whether ginseng seeds will successfully survive the chewing and digestive processes of deer. On the other hand, at ca. $3 \mathrm{~mm}$ (Lewis and Zenger, 1982), the seeds are relatively large. However, the seed coat is relatively hard and resistant at the time of dispersal, probably to protect the embryo through the $18+$ month dormancy period.

In this study I addressed three key questions regarding the role of deer as possible dispersal agents of American ginseng seeds: First, in seven wild populations, I asked what is the frequency of browsing of leaves and/or fruits of fruit-bearing plants by white- 
tailed deer? Second, of the plants browsed by deer, what fraction had fruits (and seeds) consumed? Third, after ingestion, what is the fate of these seeds? In summary, do deer act as dispersers or predators when consuming ginseng seeds? 


\section{Study species and methods}

\section{Study species}

American ginseng is a long-lived, perennial herb that can live for more than 20 years once established as a seedling (Charron and Gagnon, 1991). Ginseng is found in the understory community of deciduous forests in the eastern United States and southern Canada. The range of American ginseng extends from southern Quebec to northern Georgia and from the East Coast states to Missouri (Anderson et al., 1993; Robbins, 1998). In the central Appalachian region, American ginseng is often associated with rich, north-facing, coves although McGraw et al. (2003) found that ginseng occupies a broader niche than previously thought.

The seasonal phenological progression of American ginseng begins each spring after the tree canopy has partially or fully developed (Lewis and Zenger, 1982). Plants emerge from winter dormancy in late April to early May (Hackney and McGraw, 2001). Anthesis is reached in mid-May and continues until late July. Berry development and maturation begins in late June and ends by October (Carpenter and Cottam, 1982). Fruit maturation is marked by the bright red color of the exocarp. Mature berries contain from one to three seeds (Lewis and Zenger, 1982; Anderson et al., 1993).

\section{Natural rates of deer frugivory}

In order to understand the frequency with which American ginseng seeds are ingested by white-tailed deer, I followed the fate of all fruit-bearing plants found in seven natural populations of American ginseng. The seven populations were located in northcentral West Virginia in mid-successional mixed Allegheny hardwood stands dominated 
by oak species (Quercus spp.), yellow-poplar (Liriodendron tulipifera L.), red maple (Acer rubrum L.), sugar maple (Acer saccharum Marsh), and black cherry (Prunus serotina Ehrh.). All stands shared a common history of logging that occurred around the turn of the $20^{\text {th }}$ century. The populations represented a wide range of sizes (6 to 379) in a variety of aspects (north to northwest and south to southeast) and elevations (580.4 $\mathrm{m}$ to $805.6 \mathrm{~m}$ ) (Table 4.1). Precise locations are withheld for conservation reasons.

Beginning in May 2001, all plants within each population were located and cryptically marked with an identification number engraved on the flat head of a $6.4 \mathrm{~cm}$ aluminum nail. Each engraved nail was carefully placed belowground at the base of the sympodium so as not to damage the root but to obscure the nail head from view. In the event of complete deer browsing, the identification tag could be relocated using a metal detector. New plants discovered in 2002 and 2003 were marked and added to the study. All plants were censused in mid-July to determine which plants would produce fruit. After fruiting individuals were identified, the number of seeds produced per plant was recorded. All fruiting individuals were then monitored every three weeks to determine whether or not the plants had been browsed by deer. Damage due to deer browsing results in the partial or almost complete loss of aboveground plant biomass and is identified by the rough cut of the sympodium or petiole (Augustine and Frelich, 1998). Deer browsing sometimes results in a fraction of plant biomass being removed. In other instances, the entire plant is completely browsed, including the fruit cluster. For plants that were deer browsed, I recorded whether or not the fruits were consumed with the foliage. If a plant was completely browsed, the area around the plant was inspected for 
Table 4.1. The population size, number of reproductive individuals, and the deer browsing rates of reproductive plants found in seven natural populations of American ginseng from 2001-2003. 


\begin{tabular}{lccccccccc}
\hline & \multicolumn{3}{c}{ Population size } & \multicolumn{3}{c}{$\begin{array}{c}\text { Number of reproductive } \\
\text { individuals }\end{array}$} & \multicolumn{3}{c}{$\begin{array}{c}\text { Browsing rates of } \\
\text { reproductive plants(\%) }\end{array}$} \\
Population & 2001 & 2002 & 2003 & 2001 & 2002 & 2003 & 2001 & 2002 & 2003 \\
\hline BG & 44 & 64 & 75 & 22 & 26 & 22 & 27.3 & 23.1 & 13.6 \\
BN & 45 & 44 & 34 & 7 & 6 & 2 & 100 & 100 & 50 \\
CR & 9 & 6 & 11 & 1 & 2 & 0 & 0 & 100 & 0 \\
P4 & 102 & 129 & 121 & 27 & 18 & 14 & 57.1 & 61.1 & 88.9 \\
P5 & 317 & 365 & 379 & 51 & 62 & 73 & 41.1 & 83.9 & 45.2 \\
W2 & 59 & 112 & 102 & 5 & 17 & 24 & 50 & 75 & 28.6 \\
W4 & 26 & 31 & 28 & 8 & 4 & 7 & 60 & 23.5 & 62.5 \\
\hline
\end{tabular}


fruits that may have fallen during the browsing episode. If no fruits or remnants of seed coats were found on the ground, I assumed that all fruits had been consumed by deer. This monitoring of all fruiting plants continued until October when most of the fruits had been dispersed and plants had begun to senesce. The natural rates of frugivory were monitored for three growing seasons, 2001-2003. From these data, I was able to determine the percentage of fruiting plants browsed by deer, the percentage of browsing resulting in loss of fruit to deer consumption, and the overall percentage of seeds consumed by deer. Log-likelihood analyses were used to test for differences in deer frugivory with population and year as the main effects (SAS JMP, V.5.0, SAS, Inc., 2002). The CR population was excluded from the analyses because no data existed for 2001 and 2003 since all reproductive individuals in that population were browsed prior to fruit set in 2001 and no fruits were produced in 2003.

\section{Feeding Trials}

Since fruit production in natural populations is low, cultivated fruits were substituted for natural ones to obtain a sufficient sample size. Ripe ginseng fruits for the feeding trials were collected from 'wild simulated' plants grown by a ginseng cultivator in Preston County, West Virginia. Fruits were collected 23 August 2001 and stored at 24 ${ }^{\circ} \mathrm{C}$ in plastic bags until their use in the feeding trials.

Feeding trials began 28 August 2001 at the West Virginia Wildlife Center located in French Creek, WV. The selection of individuals to be used in the feeding trials was based on availability of resident deer at the wildlife center. Eight individuals were used for the feeding trials, four yearlings, two does, and two bucks. These animals were kept 
in separate enclosures adjacent to a larger enclosure where the deer were normally maintained. All deer were placed in their new enclosure for four days prior to the start of the feeding trials to allow for acclimation to the new surroundings.

Feeding trials were conducted for a period of three weeks. On a daily basis, fruits were fed to captive white-tailed deer by adding 100 intact fruits to their usual feed of corn and grain. During the 21-day period, a total of 16,800 fruits were fed to the deer. Those fruits not consumed from the previous day were removed and replaced with fresh ones each morning.

Along with the feeding trials, all fecal pellets were collected on a daily basis for a period of five weeks. This provided a sufficient time period for all consumed fruit to pass through the digestive tract of each deer. After collection, all fecal pellets were dissolved in water and filtered through a \#30 standard testing sieve to retain any undigested matter. The material retrieved from the sieve was then inspected for intact seeds using a dissecting microscope. 


\section{Results}

\section{Natural rates of herbivory and frugivory}

The difference among populations in herbivory of reproductive plants depended on the year $\left(\chi^{2}=24.286, P=0.0069\right)$. Although the proportion of fruit-bearing plants browsed was variable among populations and years, a general pattern emerged for some populations (Table 4.1)(Fig. 4.1a). For example, the BG population had the lowest proportion of browsed fruit-bearing individuals compared to the other populations $(27.3 \%, 23.1 \%$, and $13.6 \%$ in 2001,2002 , and 2003 , respectively) and this browsing proportion decreased over the three years (Fig. 4.1a). Similarly, the BN population experienced a decrease in the proportion of fruit-bearing plants browsed in $2003(50 \%)$ although browsing occurred at a constant and greater proportion in 2001 and 2002 (100\% for both years). In contrast, the P4 population experienced a gradual increase in the proportion of browsed fruit bearing individuals during the three-year duration of this study (Fig. 4.1a). Browsing of reproductive plants differed among populations $\left(\chi^{2}=\right.$ 25.491, $\mathrm{P}<0.0001)$ but not among years $\left(\chi^{2}=0.172, \mathrm{P}=0.9178\right)$. During the three-year census period, I found that the browsing frequency of fruit-bearing plants ranged from $13.6 \%$ to $100 \%$ with the exception of the CR population (Fig. 4.1a). In 2001, all reproductive individuals in the $\mathrm{CR}$ population were completely browsed prior to fruit production. In 2003, no fruits were produced.

When fruiting plants were browsed, the fruits themselves were not always consumed. Therefore, I separately analyzed the incidence of frugivory in browsed plants. Differences among populations in the proportion of browsed plants experiencing 
Figure 4.1. Browsing effects in seven natural populations of American ginseng over three growing seasons, including: (a) the proportion of fruiting plants that were either partially or completely browsed by deer, (b) the proportion fruiting plants whose fruits were consumed by deer, and (c) the proportion of all forming or ripe seeds that were consumed by deer. 

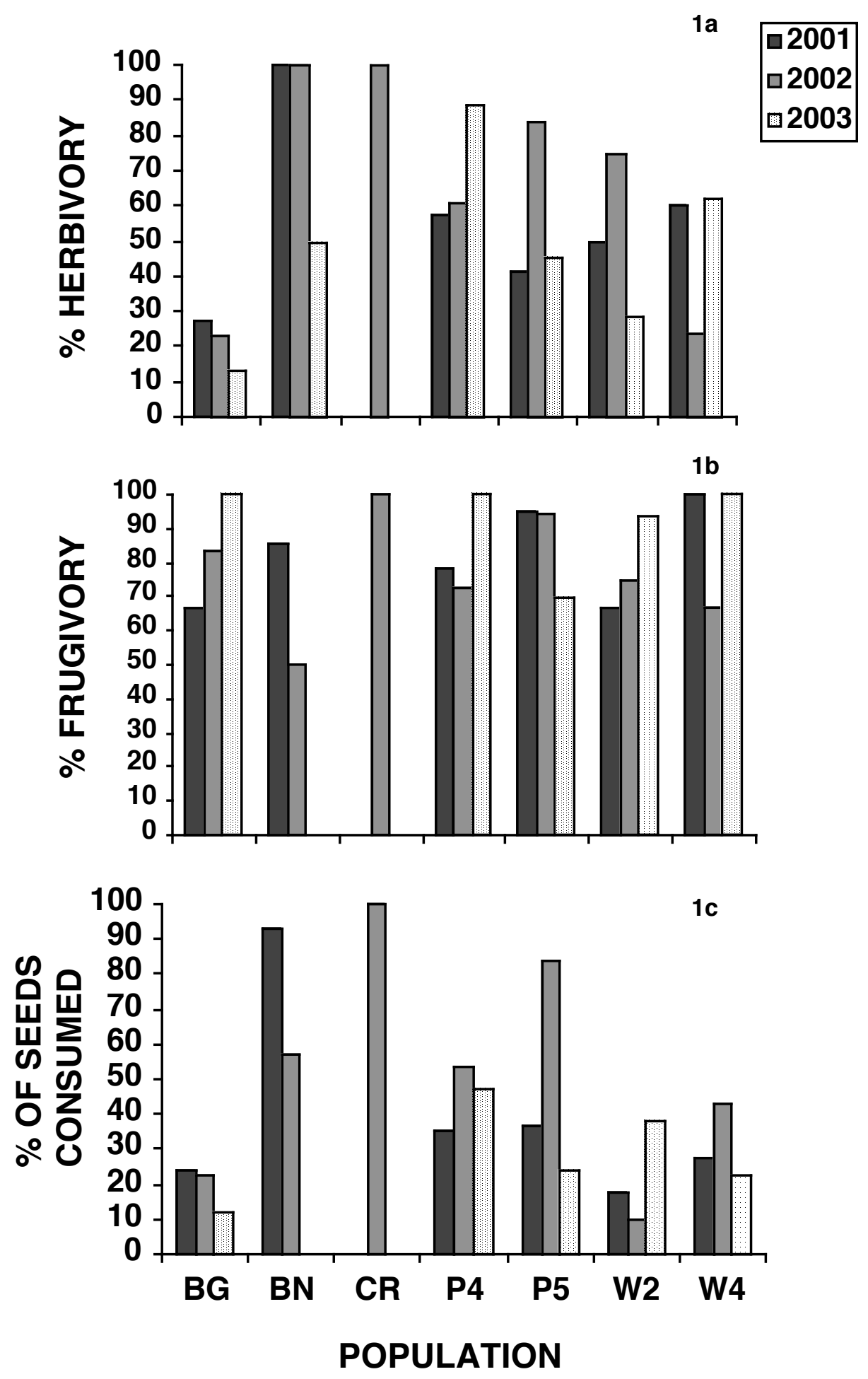
frugivory depended on the census year $\left(\chi^{2} 28.736, P=0.0014\right)$ (Fig. 4.1b). Both the BG and W2 populations exhibited a similar pattern of increasing frugivory in the three years, although the BG population experienced a greater proportion in 2002 and 2003 (83.3\% and 100\% respectively) (Fig. 4.1b). In contrast, the P5 and BN populations both showed a decrease in frugivory as the three years progressed (Fig. 4.1b), and the decrease was more pronounced in the $\mathrm{BN}$ population. Frugivory differed significantly among populations $\left(\chi^{2}=21.150, \mathrm{P}=0.0008\right)$, but not among years $\left(\chi^{2}=0.132, \mathrm{P}=0.9360\right)$. I found that the proportion of fruiting plants experiencing complete deer browsing ranged from $0 \%$ where plants had been partially browsed and fruits not consumed (BN, 2003) to $100 \%$, where all fruit bearing plants were completely browsed in several populations/years (Fig. 4.1b).

To describe the net effect of deer browsing on seed production, I estimated the proportion of seeds (not just fruit) consumed by deer. Seed consumption patterns across years differed among populations $\left(\chi^{2}=83.774, \mathrm{P}<0.0001\right)$. P5, P4, and W4 had comparable patterns of seed consumption over the three years with the greatest rate being seen in 2002 (Fig. 4.1c). In contrast, W2 experienced the least amount of seed consumption (10\%) by deer in 2002 (Fig. 4.1c). Although the proportion of seeds ingested by deer did not differ among years $\left(\chi^{2}=2.511, P=0.2849\right)$, the overall rate of seed consumption did vary among populations $\left(\chi^{2}=80.382, \mathrm{P}<0.0001\right)$. The proportion of seeds consumed by deer ranged from $0 \%$ (BN, 2003) where plants had been partially browsed but fruits remained, to $100 \%$ (CR, 2002) where all seeds were consumed by deer (Fig. 4.1c). 


\section{Fates of ingested seeds}

The deer used in the feeding trials consumed all of the fruits added to their daily feed. I observed that the fruits were often selectively removed from the corn and grain mixture and were consumed first. No intact seeds were recovered from the fecal pellets although one partial seed coat was identified. 


\section{Discussion}

Although the frequency of browsing of fruit-bearing plants, complete consumption of all plant parts including fruits, and the proportion of seeds consumed by deer varied among populations and years, this variability is not unexpected since large differences in local deer densities, vegetation, and accessibility can exist from one location to the next and from one season to another. While I did not find significant differences among years, the year-to-year variation in environmental conditions such as precipitation can also influence deer browsing patterns, more so in some populations than others.

To my surprise, for a majority of the populations followed in this study, deer completely browsed $50 \%$ or more of the fruit-bearing plants. In some populations, deer consumed a substantial proportion (47.4\% to $100 \%)$ of the seeds produced in that season. Although I have seen evidence that seeds can be predated upon by small rodents, I was careful to look for the remains of seed coats under plants when determining if in fact deer had consumed the seeds. For small populations with few reproductive individuals such as the CR population, consumption of even a small number of seeds can significantly decrease input into the seed bank. In 2001, the single reproductive plant in the small CR population was browsed before seed set. In 2002, the only two reproductive plants were completely browsed and in 2003, no fruits were produced. For this particular population, this means that no seeds were produced in three years. The results from this study not only provided clear evidence that white-tailed deer actively consume American ginseng fruit but also have the potential to strongly impact the yearly seed rain of American ginseng. This study focused solely on those fruit-bearing plants that were browsed, but 
the impact on seed contribution may actually be greater than this. Reproductive plants are often browsed prior to fruit production as seen in the CR population in 2001 (Fig. 4.1b).

Since my data showed that white-tailed deer could consume a large majority of seeds produced in a population, it is essential to further understand seed fate after consumption. The results of the feeding trials suggest that white-tailed deer are seed predators of American ginseng, not seed dispersers. The destruction of all 16,800 seeds may have been facilitated by the mastication process deer employed while consuming the corn and grain diet. In their natural environments, depending on the season, their diet would contain more roughage, which could result in less destructive chewing of fruits. However, an inspection of deer pellets collected from each population revealed no evidence of ginseng seeds nor any other seeds successfully passing through the gut. My findings are supported by other studies that have examined the fate of large seeds consumed by deer (Dinerstein, 1989; Sargent 1990; but also see Vellend et al., 2003). Thus, I feel it is reasonable to conclude that deer are primarily seed predators of American ginseng.

These results may seem illogical, given the location and coloration of ginseng fruits that suggests adaptation to animal dispersal. The fruits of American ginseng are located on an elevated peduncle at the juncture of the leaves and the sympodium, thus making them apparent to potential dispersers. The seeds of American ginseng are surrounded by a fleshy exocarp that turns bright red when the fruit is ripe. Fruit coloration is considered a primary cue to attract dispersers (Stiles, 1992) and white-tailed deer can distinguish longer wavelengths of color such as orange and red (VerCauteren 
and Pipas, 2003). The color of ginseng fruits may in fact serve as a cue for potential avian and mammalian dispersers, but incidentally also attract deer, which are not effective dispersal agents. Other woodland species such as jack-in-the-pulpit (Arisaema triphyllum L.) and spicebush (Lindera benzoin L.) have bright colored fruits similar to ginseng and are dispersed and predated upon by fruit-eating birds, rodents, etc. (Bierzychudek, 1982).

The high frequency of fruit consumption by deer, coupled with the subsequent possible destruction of consumed seeds during the digestive process, can have a direct negative impact on contributions to the seed bank and ultimately the recruitment rates of American ginseng. Reduced seed bank size may be particularly important for population recovery from harvest. Lewis (1988) found that the recovery of a harvested population of American ginseng in Missouri was due mostly to an accumulation of viable seeds in the seed bank. Van der Voort et al. (2003) reported a similar dependence on viable propagules in the seed bank to aid in the partial recovery of a harvested West Virginia population of American ginseng. Indeed, the reduced seed bank caused by deer browsing may be adequate to explain why the seed rain was insufficient to allow full population recovery after harvest in the populations reported by Lewis (1988) and Van der Voort et al. (2003). Although Charron and Gagnon (1991) found that population growth of ginseng populations was more sensitive to a decrease in the survival of plants in larger size classes than a reduction in seed production, for small populations ( 6 of the 7 followed in this study), loss of even a slight proportion of seeds can dramatically influence population growth. This same pattern is likely to affect other understory species' ability to recover from disturbances as well. In the early stages of deer 
overpopulation, the negative effects may be largely reversible: a lowering of deer populations can be expected to allow full recovery and re-establishment of the seed bank. However, once deer browsing has continued for too long, extinction of species can be expected, as resistance to other disturbances is lost. It is important for wildlife and land managers to understand these collateral costs associated with the overabundance of white-tailed deer. 


\section{Acknowledgments}

Many thanks to W. Slagle for his generous donation of thousands of ginseng fruit, W. VanScoy and staff at the West Virginia Wildlife Center for their assistance with the deer, and R. Kenyon, N. Kota, S. Lightner, R. May, E. Mooney, and M. Olive for their help in the field. This research was supported by National Science Foundation grant DEB - 0212411. 


\section{Literature cited}

Alverson, W.S., D.M. Waller, and S.L. Solheim. 1988. Forest too deer: edge effects in Northern Wisconsin. Con. Bio., 2:348-358.

Anderson, R.C. 1994. Height of white-flowered trillium (Trillium grandiflorum) as an index of deer browsing intensity. Ecol. Appl., 4:104-109.

—, J. S. Fralish, J. E. Armstrong, and P. K. Benjamin. 1993. The ecology and biology of Panax quinquefolium L. (Araliaceae) in Illinois. Am. Midl. Nat., 129:357-372.

Augustine, D.J. and L.E. Frelich. 1998. Effects of white-tailed deer on populations of an understory forb in fragmented deciduous forests. Con. Bio., 12:995-1004.

Balgooyen, C.P. and D.M. Waller. 1995. The use of Clintonia borealis and other indicators to gauge impacts of white-tailed deer on plant communities in Northern Wisconsin, USA. Nat. Areas J., 15:308-318.

Bierzychudek, P. 1982. The demography of jack-in-the-pulpit, a forest perennial that changes sex. Ecol. Monographs., 52:335-351.

Carpenter, S. G. and G. Cottam. 1982. Growth and reproduction of American ginseng (Panax quinquefolius) in Wisconsin, U.S.A. Can. J. Bot., 60:2692-2696. 
Chambers, J.C. and J.A. MacMahon. 1994. A day in the life of a seed: movement and fates of seeds and their implications for natural and managed systems. Annual Review of Ecology and Systematics., 25:263-292.

Charron, D. and D. Gagnon. 1991. The demography of northern populations of Panax quinquefolium (American ginseng). J. Ecol.,79:431-445.

DeCalesta, D.S. 1994. Effects of white-tailed deer on songbirds within managed forests in Pennsylvania. J. Widl. Manage., 58:711-718.

Dinerstein, E. 1989. The foliage-as-fruit hypothesis and the feeding behavior of South Asian ungulates. Biotropica., 21:214-218.

Flowerdew, J.R. and S.A. Ellwood. 2001. Impacts of woodland deer on small mammal ecology. Forestry., 74:277-287.

Gee, K. L., M. D. Porter, S. Demarais, F. C. Bryant, and G. Van Vreede. 1991. Whitetailed deer: their foods and management in the cross timbers. A Samuel Roberts Noble Foundation Publication. Ardmore, Oklahoma. 8-9 p.

Gill, R. M. A. and V. Beardall. 2001. The impact of deer on woodlands: the effects of browsing and seed dispersal on vegetation structure and composition. Forestry., 74:209-218. 
Hackney, E. E. and J. B. McGraw. 2001. Experimental demonstration of an Allee effect in American ginseng. Con. Bio.,15:129-136.

Janzen, D. H. 1971. Escape of Cassia grandis beans from predators in time and space. Ecology., 52:964-979.

-. 1984. Dispersal of small seeds by big herbivores: foliage is the fruit. Am. Nat., 123:338-353.

Lewis, W. H. 1988. Regrowth of a decimated population of Panax quinquefolium in a Missouri climax forest. Rhodora., 90:1-5.

- and V. E. Zenger. 1982. Population dynamics of the American ginseng Panax quinquefolium (Araliaceae). Am. J. Bot., 69:1483-1490.

Malo, J. E. and F. Suarez. 1995. Herbivorous mammals as seed dispersers in a Mediterranean dehesa. Oecologia., 104:246-255.

McGraw, J. B., S. M. Sanders, and M. Van der Voort. 2003. Distribution and abundance of Hydrastis canadensis L. (Ranunculaceae) and Panax quinquefolius L. (Araliaceae) in the central Appalachian region. J. Torr. Bot. Soc., 130:62-69. 
McShea, W.J., M.V. McDonald, E.S. Morton, M. Rose, and J.H. Rappole. 1995. Longterm trends in habitat selection by Kentucky warblers. Auk, 112: 375-381.

— and J. H. Rappole. 1997. Herbivores and the ecology of forest understory birds. In The Science of Overabundance: Deer Ecology and Population Management. W.J. McShea, H.B. Underwood and J.H. Rappole (eds). Smithsonian Press, Washington, DC. 298-309 pp.

Miller, S. G., S. P. Bratton, and J. Hadidian. 1992. Impacts of white-tailed deer on endangered and threatened vascular plants. Nat. Areas J., 12:67-74.

Ostfeld, R.S., C.G. Jones, and J.O. Wolf. 1996. Of mice and mast. Bioscience., 46:232330.

Robbins, C. S. 1998. American ginseng: the root of North America's medicinal herb trade. TRAFFIC North America. Washington, DC. 94 p.

Rooney, T.P. 2001. Deer impacts on forest ecosystems: a North American perspective. Forestry. 74:201-208.

- and W.J. Dress. 1997. Species loss over sixty-six years in the ground-layer vegetation of Heart's Content, an old growth forest in Pennsylvania, USA. Nat. Areas J., 17:297-305. 
— and D.M. Waller. 2001. How experimental defoliation and leaf height affect growth and reproduction in Trillium grandiflorum. J. Torrey Bot. Soc., 128:393-399.

Russell, F. L., D. B. Zippin, and N. L. Fowler. 2001. Effects of white-tailed deer (Odocoileus virginianus) on plants, plant populations, and communities: a review. Am. Midl. Nat., 146:1-26.

Sargent, S. 1990. Neighborhood effect on fruit removal by birds: a field experiment with Viburnum dentatum (Caprifoliaceae). Ecology., 71:1289-1298.

SAS, Institute. 2002. JMP. Version 5.0. SAS Institute, Cary, North Carolina.

Stiles, E. W. 1992. Animals as seed dispersers. In seeds: the ecology of regeneration in plant communities, M. Fenner (ed.), Wallingford, UK. CAB. 105-156 p.

Van der Voort, M. E., B. Bailey, D. E. Samuel, and J. B. McGraw. 2003. Recovery of populations of goldenseal (Hydrastis canadensis L.) and American ginseng (Panax quenquefolius L.) following harvest. Am. Midl. Nat., 149:282-292.

Vellend, M., J. a. Myers, S. Gardescu, and P.L. Marks. 2003. Dispersal of Trillium seeds by deer: implications for long-distance migration of forest herbs. Ecology., 84:1067-1072. 
VerCautern, K. C. and M. J. Pipas. 2003. A review of color vision in white-tailed deer. Wildlife Soc. Bul., 31:684-691.

Waller, D. M. and W. S. Alverson. 1997. The white-tailed deer: a keystone herbivore. Wildlife Soc. Bul., 25:217-226.

Welch, D. 1985. Studies in the grazing of heather moorland in north-east Scotland. IV. Seed dispersal and plant establishment in dung. J. App. Ecol., 22:461-472. 


\section{CHAPTER 5}

Demography of American ginseng: effects of herbivory by white-tailed deer 


\begin{abstract}
Previous demographic matrix modeling on American ginseng (Panax quinquefolius L.) in the northernmost part of its range has focused on the effect of harvesting by humans on population growth and viability. However, no demographic modeling has been done on populations in the range center where additional pressures such as browsing by whitetailed deer (Odocoileus virginianus Zimm.) may be impacting population growth. To examine the effects of deer browsing on population growth, two sets of matrix models, one including browsed plants and one without, were constructed from census data collected on seven natural populations in West Virginia over a five-year period (200004). Population growth rate $(\lambda)$ varied among populations and years. However, the general effect of deer browsing was a decline in $\lambda$. Results from the life table response experiment showed that large adults remaining large adults and several of the growth transitions contributed most to changes in $\lambda$ caused by herbivory. The sample influence function analysis showed that growing reproductive plants had the greatest positive effect on $\lambda$, an effect that was reduced by herbivory. The negative effect that deer have on $\lambda$ is most likely due to selective browsing of large reproductive plants, destruction of fruits, and carryover effects of browsing on future plant size. Under current deer pressures, the combined population from this study is projected to decline by $3.7 \%$ per year on average $(\lambda=0.963)$, indicating that if deer numbers are not reduced, natural populations of ginseng will not be able to support both deer browsing and harvesting.
\end{abstract}




\section{Introduction}

Matrix models have become a useful tool for assessing the status of threatened and endangered species. American ginseng (Panax quinquefolius L.) is one example of a federally listed species (Appendix II of the Convention on International Trade in Endangered Species of Wild Fauna and Flora) (Robbins 2000) that has been modeled using demographic data. Demographic matrix models were used to examine growth of four populations under different harvest simulations in southern Canada (Charron and Gagnon 1991). Further work included population viability analyses to assess potential harvest impacts in Quebec (Nantel et al. 1996). These studies provided valuable insight into the population dynamics and potential effects of harvesting by humans for the medicinal trade. However, they are based on limited data collected at the northern margin of ginseng's natural range. In central Appalachia, which is in the center of ginseng's range, formal demographic analyses of ginseng have not been carried out previously.

Ginseng populations in the center of the range are subject to a variety of environmental stressors in addition to harvest. Primary among these is browsing by white-tailed deer (Odocoileus virginianus Zimm.). Once hunted to near extinction in the late $19^{\text {th }}$ and early $20^{\text {th }}$ century, strict management efforts coupled with landscape alteration and loss of natural predators (Russel et al. 2001) have resulted in current deer densities estimated to be two to four times higher than pre-settlement densities in some areas of the United States (Alverson et al. 1988; Van Deelen et al. 1996). The building body of evidence indicates that overabundant deer herds are negatively impacting many elements of the forest community, including direct effects on valuable tree (Russell et al. 
2001; Rooney 2001; Horsley et al. 2003; Rooney and Waller 2003) and herbaceous plant species (Miller et al. 1992; Anderson 1994; Rooney 1997; Augustine and Frelich 1998; Fletcher et al. 2001; Rooney and Gross 2003; Knight 2004) as well as indirect negative effects on birds (deCalesta 1994; McShea and Rappole 1997; Fuller 2001) and small mammals (Flowerdew and Ellwood 2001). Several studies have employed demographic modeling to examine the effects of deer and other vertebrate grazers on population growth of Trillium grandiflorum (Rooney and Gross 2003; Knight 2004) and Lathyrus vernus (Ehrlen 1995).

The focus of this study was to examine the effects of deer browsing on population growth of American ginseng. Previous work on ginseng has shown that deer target larger reproductive plants in populations (Furedi Chapter 2), the same classes of plants found to have the greatest impact on population growth (Charron and Gagnon 1991). Deer browsing can result in a reduction in growth in the following growing season (Furedi Chapter 3). Furthermore, browsing of fruit-bearing plants results in the loss of seeds since deer are significant seed predators (Furedi and McGraw 2004). Collectively, these findings suggest that effects of deer browsing can potentially reduce population growth. Using extensive demographic data collected over a five-year period (2000-04), I constructed matrix models of seven natural populations of ginseng found in West Virginia. The specific objectives of this study were to: (1) examine the effects of deer browsing on population growth $(\lambda)$ of natural ginseng populations, (2) explore how changes in vital rates due to deer browsing affect $\lambda$, and (3) understand how the contribution of individuals to $\lambda$ is altered by deer browsing. 


\section{Methods}

\section{Study species}

American ginseng is a long-lived perennial herb found in the understory community of deciduous forests of the eastern United States and southern Canada (Lewis and Zenger 1982; Charron and Gagnon 1991, Anderson et al. 1993). The seasonal phenological progression of American ginseng begins in late April and May as plants emerge from winter dormancy and elongate (Hackney and McGraw 2001). Emergence and elongation are usually associated with partial closure of the tree canopy (Lewis and Zenger 1982). Anthesis occurs in June and July, followed closely by fruit development and maturation from July through September (Carpenter and Cottam 1982; McGraw et al. in press). Fruit dispersal occurs from August until late September and is thought to be mostly gravity mediated. Seed loss occurs via predation by deer (Furedi and McGraw 2004) and small rodents (M. Furedi personal observation). By October, most plants have senesced.

American ginseng progresses through a series of life history stages that are useful when assigning plants to classes for demographic purposes (see Charron and Gagnon 1991; Nantel et al. 1996). Newly emerged plants have one leaf with three leaflets. In subsequent years, a young plant may develop four or five leaflets and eventually two or more leaves (Lewis and Zenger 1982; Anderson et al. 1993). Flowering and fruit production occur when a plant has at least two leaves, but most 2-leaf plants do not produce fruit. Three- and 4-leaf plants typically produce flowers, although many individuals may produce no fruit in a given year. Plants may regress in size as a result of damage due to events such as herbivory (Furedi Chapter 3). 


\section{Study sites}

The seven naturally occurring populations of American ginseng followed in this study were located in north-central West Virginia. All populations were located in second growth mixed mesophytic forests with a history of clearcutting between 1880 and 1920. Although most populations were found in stands dominated by sugar maple (Acer saccharum Marsh.) and tulip poplar (Liriodendron tulipifera L.), they differed in aspect, elevation, and subcanopy species.

\section{Collection of demographic data}

In May 2000 (for six of the seven populations) and May 2001 (for population W4), all plants within seven natural populations of ginseng were located. Because of the need to preserve the anonymity of the populations, these plants were cryptically tagged with an engraved aluminum nail placed at the base of the plant but below the soil surface. If a plant was missing, the tag was then relocated using a metal detector. In addition, maps were constructed for each population using a 'photo-trail' approach. This method of mapping involved creating a 'path' from one plant to the next using digital photographs, distances, and compass bearings (Furedi and McGraw 2004). These methods of tagging and mapping the populations enabled me to inconspicuously relocate plants over the five-year duration of the study (2000-2004) with little disturbance to the surrounding understory.

Two censuses were required annually to collect the demographic data necessary for parameterizing the matrix models. The first census (spring census), measuring presence and size-related traits, was conducted between May 15 and June 1 each year. 
Censusing during this period was timed to minimize the loss of plants to deer browsing and ensure that all plants had emerged from winter dormancy and fully elongated. Data collected during the first census included the following measurements: leaf number, the length and width of the longest leaflet per leaf, and reproductive status. Leaflet length (LL) and width (LW) measurements were used to calculate leaf area (LA) based on the following regression equation $\left(\mathrm{r}^{2}=0.95, \mathrm{~N}=102\right)$ :

$\mathrm{LA}=4.03(\mathrm{LL})+5.17(\mathrm{LW})+1.38(\mathrm{LL} * \mathrm{LW})$.

This equation was derived from leaflet lengths, leaflet widths, and leaf areas (using a portable Li-Cor Model Li-3000A leaf area meter) of 102 randomly chosen leaves.

Along with size-related measurements, a $2 \mathrm{~m}$ radius around each reproductive individual was searched for new seedlings. Based on a large seed monitoring experiment involving ca. 16,000 seeds, $90 \%$ of seedlings dispersed $<2 \mathrm{~m}$ from where they were placed, therefore I assumed that $90 \%$ of the seeds were detected and adjusted my recruitment rates accordingly. New seedlings were identified based on the small, poorly established root, often with the seed coat still attached. New seedlings were tagged and added to the population in addition to other newly located plants.

The second census (fall census) recorded seed production and was conducted between August 1 and August 15 of each year. This time period occurred prior to the start of harvest season (fruit-bearing plants may be collected by harvesters) and before most fruits had begun to disperse but were mature enough to count seeds (fruits contain 1-3 seeds). In addition to the two annual censuses, plants were monitored every three weeks from June until October for evidence of deer browsing. Damage due to deer browsing was identified based on the partial or complete loss of aboveground biomass 
and the rough cut visible on the remaining portion of the petiole or sympodium (Augustine and Frelich 1998). In most cases, supplementary evidence such as deer tracks or nearby deer pellets corroborated the determination that deer caused the loss of aboveground plant parts.

To estimate seed survival rates and germination rates required for parameter estimation of the seed class in my matrix models, I embedded 6 seed cages in each population in August 2002. The cages were constructed from segments of PVC pipe (10 $\mathrm{cm}$ in length and $9 \mathrm{~cm}$ in diameter) with nylon mesh screening on the bottom. They were covered with plastic hardware cloth to prevent seed loss without inhibiting seed germination. Each cage contained native soil from that population in addition to 50 ripe fruits. Due to naturally low fruit production in my populations, fruits were obtained from a "wild-simulated" ginseng cultivator in West Virginia. Three cages were randomly collected from each population in May 2003 and sieved to recover all seeds. Seed viability was then determined using the tetrazolium test (Cottrell 1947; Baskin and Baskin 1998). Since ginseng seeds require at least an 18-month pre-germination period (Lewis and Zenger 1982; Charron and Gagnon 1991; Anderson et al. 1993), the number of viable seeds obtained from the cages removed in 2003 were used to estimate the proportion of seeds remaining viable in the seed bank from August to May $(p)$. A similar procedure that also included recording the number of germinated seeds per cage was repeated in May 2004. These values were used to estimate the proportion of seeds remaining in the seed bank $(v)$ and the proportion of seeds dying. 


\section{Matrix model construction}

Several steps were required to construct population transition matrices from the demographic data. First, discrete classes were created based on a mixture of stages and sizes that represented a compromise between adequate parameter estimation and real differences in vital rates. Each matrix contained the following five classes: seeds (class 1), 1-leaf plants (class 2), 2-leaf plants (class 3), small adults (class 4), and large adults (class 5) (Table 5.1). Although not shown directly in the model, a sixth class was created for those individuals that had died. Total leaf number was used to assign individuals to classes 2 and 3 (1-leaf plants in class 2 and 2-leaf plants in class 3). A combination of leaf area and leaf number was used to assign individuals to classes 4 and 5. Leaf area was calculated for all 3-leaf plants included in this study using the leaf area equation (see previous section). The median leaf area value of $250 \mathrm{~cm}^{2}$ was used to distinguish small adults from large adults ensuring the largest possible sample size in these two important classes. All 4-leaf plants were considered large adults.

Having established classes, every plant was then assigned to the appropriate classes for all five years of the study. Several class assignment assumptions were used to account for the fate of a small proportion of 'missing' plants $(0.5 \%-4 \%)$ each year. Plants may be absent from a population due to dormancy (Carpenter and Cottam 1982; Lewis and Zenger 1982; Charron and Gagnon 1991), harvest by humans, damage, or early deer browsing before the spring census. Since 1-leaf plants rarely experience 
Table 5.1. Transition matrix model (A) for American ginseng. Each matrix element $\left(a_{i j}\right)$ represents the probability that an individual of stage $i$ will be derived from an individual stage $j$ in one time interval. 


\begin{tabular}{|c|c|c|c|c|c|}
\hline From: & $\begin{array}{l}\text { Class } 1 \\
\text { (seeds) }\end{array}$ & $\begin{array}{l}\text { Class } 2 \\
\text { (1-leaf) }\end{array}$ & $\begin{array}{l}\text { Class } 3 \\
\text { (2-leaf) }\end{array}$ & $\begin{array}{c}\text { Class } 4 \\
\text { (sm. adult) }\end{array}$ & $\begin{array}{l}\text { Class } 5 \\
\text { (lg. adult) }\end{array}$ \\
\hline Class 1 & $a_{11}$ & 0 & $a_{13}$ & $a_{14}$ & $a_{15}$ \\
\hline Class 2 & $a_{21}$ & $a_{22}$ & $a_{23}$ & $a_{24}$ & 0 \\
\hline Class 3 & 0 & $a_{32}$ & $a_{33}$ & $a_{34}$ & $a_{35}$ \\
\hline Class 4 & 0 & 0 & $a_{43}$ & $a_{44}$ & $a_{45}$ \\
\hline Class 5 & 0 & 0 & 0 & $a_{54}$ & $a_{55}$ \\
\hline
\end{tabular}


dormancy (Furedi personal observation), these plants were considered dead (class 6) if missing for one year; numerous observations over multiple years confirmed that this determination was reliable. However, older plants can remain alive but dormant for one or more seasons (Carpenter and Cottam 1982; Lewis and Zenger 1982; Charron and Gagnon 1991). If a plant (>1-leaf) was missing for two years, it was considered dead in the first missed year (i.e., a plant present in one year but missing in years 2 and 3 would be considered dead in year 2). Because harvesting by humans results in the permanent removal of that individual from the population, harvested plants were considered dead. Assumptions were required when plants were either browsed before the first census or were not found in one year, but returned in the next. For these returning plants, in the year they were missing, I placed them in the same size class they were in prior to their disappearance (e.g., a 2-leaf plant present in year 1, missing in year 2, and returning as a 1-leaf plant in year 3 would be assigned to the 2-leaf class in year 2). Because assigning the fate of missing plants required three years of data on the individual, for the final interval (2003-04) I assigned fate based on probabilities developed from prior years of data.

After all individuals were classified, I used the demographic data to estimate vital rates (survival, growth, and reproduction) for each population for the four transition intervals (2000-01, 2001-02, 2002-03, 2003-04). Annual variation in population size occurred due to the addition of new seedlings and newly discovered plants each spring census. Growth and survival estimates for classes 2-5 came directly from the demographic data and included the following transitions: advance in size $\left(a_{i j}\right.$, where $\left.i>j\right)$, 
stasis $\left(a_{i i}\right)$, revert in size $\left(a_{i j}\right.$, where $\left.i<j\right)$, or die $\left(a_{6 j}\right.$; not in the matrix) (Table 1$)$. The fertility estimates for reproductive classes $(j=3,4$, and 5) were calculated as follows:

$a_{1 j}=\frac{p S_{j}}{n_{j}}$

where $S_{j}$ is the total number of seeds produced by class $j$ in year $1, n_{j}$ is the number of individuals in class $j$ in year 1 , and $p$ is the proportion of seeds remaining viable in the soil from August until May as determined from the seed cage study. I assumed a delayed dormancy of at least 18 months. Therefore, seeds produced in August could not germinate until one year after their first spring. The proportion of seeds germinating $\left(a_{21}\right)$ was calculated as follows:

$a_{21}=\frac{\left(\frac{R}{0.90}\right)}{p S_{0}}$

where $R$ is the number of observed new seedlings found in a population in year 2, 0.90 is the correction factor used to adjust for unaccounted seedlings beyond the $2 \mathrm{~m}$ search radius, and $S_{0}$ is the total number of seeds produced in August prior to year 1 . The proportion of seeds remaining dormant $\left(a_{11}\right)$ was calculated as:

$a_{11}=\frac{\frac{v p S_{0}}{0.90}-S_{g}}{p S_{0}}$

where $S_{\mathrm{g}}$ is the number of seeds germinating in year 2. Since the seven populations followed in this study are part of a long-term project, I had information on the number of seeds produced in 1999 to estimate seed fates in 2000 (Van der Voort, personal comm. 2004). 
After all class assignments were made for each one-year transition period (200001, 2001-02, 2002-03, and 2003-04), MATLAB (Mathworks, 1993) was used to assemble projection matrices (A). Separate matrices were constructed for each of the large populations where $\mathrm{n}>150(\mathrm{BG}, \mathrm{P} 4, \mathrm{P} 5, \mathrm{~W} 2)$. One combined matrix with all populations was constructed for each of the four transition intervals. The remaining three populations were too small for adequate parameter estimation. Following the approach of Knight (2004), each 1-year interval for every population was represented by two matrices. The "with herbivory" $(\mathrm{H})$ matrix contained the vital rates of both browsed and unbrowsed plants and the "without herbivory" $(\mathrm{NH})$ matrix contained the vital rates as determined by including only unbrowsed plants. In addition, two matrices ( $\mathrm{H}$ and $\mathrm{NH})$ were constructed containing means across years of the combined population matrix elements.

\section{Model analyses}

For each annual transition period, two population growth rates $(\lambda)$, one with herbivory $\left(\lambda_{H}\right)$ and one without herbivory $\left(\lambda_{\mathrm{NH}}\right)$, were calculated for individual populations and for the combined populations. For the large populations (P5, W2, and the combined populations) whose matrices were well parameterized, I used the conventional approach to calculating $\lambda$, where population growth rate was simply the dominant eigenvalue of the projection matrix. For the small populations $(\mathrm{BN}, \mathrm{CR}, \mathrm{W} 4)$ with poor parameter estimates due to small sample sizes, I used a new approach to estimating $\lambda$. I first estimated 'pseudovalues' $\left(\phi_{i}\right)$ of $\lambda$ for each individual in the data set comprising all populations (Sokal and Rohlf 1995). This is done by subtracting one 
individual (i) from the population and recalculating $\lambda$ for the dataset minus that individual $\left(\lambda_{-i}\right)$. The pseudovalue of $\lambda$ is then calculated as follows:

$\phi_{i}=n \lambda_{\text {all }}-\left[(n-1) \lambda_{i}\right]$

This process is then repeated for every individual in the population. From the pseudovalues of each individual in a population, an estimate of $\lambda\left(\overline{\phi_{s m}}\right)$ is then calculated using the following equation:

$\overline{\phi_{s m}}=\frac{\sum_{i=\alpha}^{\Omega} \phi_{i}}{n_{s m}}$

where $\alpha$ and $\Omega$ are the first and last individuals in the entered data set for the small population and $n_{s m}=\Omega-\alpha$. Populations were considered stable if $\lambda=1$, growing if $\lambda>$ 1 , and declining if $\lambda<1$. A three-way ANOVA was used to examine differences in $\lambda$ among years, populations, and whether or not browsed plants were included in the calculation of $\lambda$ (browse status). The three-way interaction (years $\mathrm{x}$ populations $\mathrm{x}$ browse status) was not included in the model due to the single estimate of $\lambda$ for each populationyear-browse level. The jackknife procedure was used to produce standard errors for $\lambda$ (Sokal and Rohlf 1995; Caswell 2001).

Next, I used prospective analyses (sensitivity and elasticity) to examine the absolute and relative proportional contribution of each vital rate to $\lambda$ in the presence and absence of deer browsing (Caswell 2001). Sensitivities $\left(s_{i j}\right)$ and elasticities $\left(e_{i j}\right)$ were calculated for the mean matrix (H and NH) using MATLAB (Caswell 2001) as follows and qualitatively compared:

$S_{i j}=\frac{\delta \lambda}{\delta a_{i j}}=\frac{v_{i} w_{j}}{\langle w, v\rangle}$ 
$e_{i j}=\frac{a_{i j}}{\lambda} * \frac{\delta \lambda}{\delta a_{i j}}=\frac{\delta(\log \lambda)}{\delta\left(\log a_{i j}\right)}$

Sensitivities and elasticities were calculated for the mean matrix (with and without herbivory) using MATLAB (Caswell 2001) and qualitatively compared.

To further understand the underlying sources of variation in vital rates caused by deer browsing, I used life table response experiments, LTRE (Caswell 2001). This method decomposes differences between $\lambda_{N H}$ and $\lambda_{H}$ into its components. As detailed by Caswell (2001), the mean $\mathrm{A}_{N H}$ (projection matrix) was used as a baseline against which the mean across years $\mathrm{A}_{H}$ was compared. The difference in $\lambda$ due to herbivory $\left(\lambda_{N H}-\lambda_{H}\right)$ can be attributed to two multiplicative components, the difference in matrix parameters caused by deer browsing $\left(a_{i j, \mathrm{NH}}-a_{i j, \mathrm{H}}\right)$ and the sensitivity of $\lambda$ to that vital rate $\left(s_{i j}\right)$. The summed terms give an indication of the relative contribution of to each parameter $\lambda_{N H^{-}}$ $\lambda_{H}$

$\lambda_{N H}-\lambda_{H} \cong \sum_{i j}\left(a_{i j, N H}-a_{i j, H}\right) s_{i j}$

(the sensitivities of each vital rate are from the average matrix of $\mathrm{A}_{N H}$ and $\mathrm{A}_{H}$ ). The contribution of each term on the right side of the equation was non-zero matrix elements.

The sample influence function (SIF) analysis is another retrospective analysis that provides a LTRE at the individual level (McGraw 1989; Vavrek et al. 1996; Vavrek et al. 1997). $\mathrm{SIF}_{i}$ quantifies the relative effect of individual $i$ on population growth and is calculated as follows:

$S I F_{i}=\phi_{i}-\bar{\phi}$ 
A negative SIF showed that individual $i$ was having a negative effect on $\lambda$ and vice versa for a positive SIF. To compare $\operatorname{SIF}_{i}$ among individuals, the mean $\operatorname{SIF}_{i}$ associated with each possible individual fate over the four 1-year intervals was calculated for individuals in the $\mathrm{H}$ data set and for those in the $\mathrm{NH}$ data set. To examine the $\mathrm{SIF}_{i}$ of reproductive individuals producing varying amounts of seeds, a weighted analysis of covariance (ANCOVA) with seed number and herbivory status as main effects (including the interaction) was used to determine if the effect of seed number on $\mathrm{SIF}_{i}$ depended on whether or not plants were browsed. Separate regressions of $\operatorname{SIF}_{i}$ on seed number were used to illustrate the importance of individual seed production to $\lambda$. Residuals around the regression line for " $\mathrm{H}$ " were compared for individual adults with contrasting fates (regressing, stasis, and growing). 


\section{Results}

\section{Frequency of deer browsing}

Overall browsing in the seven natural populations of ginseng ranged from $19 \%$ in 2000 to $42 \%$ in 2002 (Table 5.2). Individual populations experienced browsing rates ranging from $8 \%$ (CR in 2003) to $63 \%$ (CR in 2002). Although browsing rates differed significantly among years (Loglikelihood; $\mathrm{p}=0.0433$ ) they did not differ significantly among populations (Loglikelihood; $\mathrm{p}=0.2949$ ). In general, a greater proportion of plants in large size classes were consumed (2-leaf, small adults, and large adults) than smaller 1leaf plants (Table 5.2). 
Table 5.2. Proportion of ginseng plants deer browsed in seven natural populations showing the proportion of plants browsed in each size class and the total browse rate per population for 2000-2003. (No data is available for W4 in 2000. Monitoring of this population began in 2001.) 


\begin{tabular}{|c|c|c|c|c|c|c|c|c|c|c|c|c|c|c|c|c|c|c|c|c|}
\hline \multirow[b]{2}{*}{ Population } & \multicolumn{5}{|c|}{2000} & \multicolumn{5}{|c|}{2001} & \multicolumn{5}{|c|}{2002} & \multicolumn{5}{|c|}{2003} \\
\hline & $\mathrm{C} 2$ & $\mathrm{C} 3$ & $\mathrm{C} 4$ & $\mathrm{C} 5$ & Tot & $\mathrm{C} 2$ & $\mathrm{C} 3$ & $\mathrm{C} 4$ & C5 & Tot & $\mathrm{C} 2$ & $\mathrm{C} 3$ & $\mathrm{C} 4$ & $\mathrm{C} 5$ & Tot & $\mathrm{C} 2$ & $\mathrm{C} 3$ & $\mathrm{C} 4$ & $\mathrm{C} 5$ & Tot \\
\hline BG & 0 & 0.31 & 0.57 & 0.14 & 0.29 & 0 & 0.14 & 0.41 & 0.17 & 0.24 & 0 & 0.26 & 0.30 & 0.24 & 0.21 & 0 & 0.12 & 0.11 & 0.17 & 0.10 \\
\hline $\mathrm{BN}$ & 0.22 & 0.44 & 0.83 & 1.00 & 0.49 & 0 & 0.15 & 1.00 & 1.00 & 0.37 & 0.28 & 0.41 & 0.75 & 1.00 & 0.48 & 0.08 & 0.12 & 0.43 & 1.00 & 0.21 \\
\hline CR & 0.25 & 0.33 & 0 & 0 & 0.29 & 0.29 & 1.00 & 0 & 1.00 & 0.50 & 0.33 & 0.75 & 1.00 & 0 & 0.63 & 0 & 0.20 & 0 & 0 & 0.08 \\
\hline P4 & 0 & 0.24 & 0.56 & 0.19 & 0.16 & 0.22 & 0.44 & 0.75 & 0.59 & 0.39 & 0.03 & 0.64 & 0.55 & 0.87 & 0.40 & 0.09 & 0.35 & 0.52 & 0.57 & 0.29 \\
\hline P5 & 0 & 0.17 & 0.25 & 0.19 & 0.13 & 0.03 & 0.27 & 0.41 & 0.40 & 0.26 & 0.09 & 0.60 & 0.61 & 0.77 & 0.48 & 0.02 & 0.24 & 0.33 & 0.29 & 0.21 \\
\hline W2 & 0.23 & 0.13 & 0.44 & 0.50 & 0.25 & 0 & 0.44 & 0.92 & 0.80 & 0.40 & 0.03 & 0.43 & 0.72 & 1.00 & 0.39 & 0.04 & 0.49 & 0.68 & 0.71 & 0.45 \\
\hline W4 & NA & NA & NA & NA & NA & 0 & 0.38 & 0 & 0 & 0.19 & 0 & 0.22 & 0.17 & 0.50 & 0.15 & 0 & 0.14 & 0.29 & 0.50 & 0.18 \\
\hline Overall & & & & & 0.19 & & & & & 0.30 & & & & & 0.42 & & & & & 0.24 \\
\hline
\end{tabular}




\section{Effects of deer browsing on demography}

A qualitative assessment of the mean life cycle diagram showing transitions when the population included browsed individuals (H) (Fig. 5.1a) vs. changes in transitions when browsed individuals were subtracted (NH) (Fig. 5.1b) revealed important effects of deer browsing. Although deer browsing caused small changes in several transitions, the largest change was seen for two large adult transitions. Browsing reduced the proportion of large adults remaining large adults (a 6.9\% decrease) (Fig. 5.1a, 5.1b). Additional notable reductions due to deer browsing were in the proportion of 2-leaf plants growing to small adults (a 3.4\% decrease) and small adults becoming large adults (a $4.1 \%$ decrease) (Fig. 5.1a, 5.1b). Fertilities also declined for all three reproductive classes (large adults declined by $30.6 \%$, small adults by $14.0 \%$, and 2 -leaf plants by $32.0 \%$ ).

\section{Effects on population growth}

Over the four year time frame, $\lambda$, from the average matrix, showed that the overall population was declining in the presence of herbivory $(\lambda=0.963)$, but this same overall population would have increased slightly without the browsed plants $(\lambda=1.011)$ (Fig. 5.2a). Averaged over the four intervals, there was substantial population to population variation in $\lambda$ (Fig. 5.2a). Four of the seven populations were declining $(\lambda<1)$ regardless of deer browsing effects and three of the seven were growing $(\lambda>1)$, again regardless of herbivory (Fig. 5.2a). However, in each case, browsing clearly lowered $\lambda(1.6 \%$ to $7.5 \%$ decrease). On an annual basis, the effect of herbivory on $\lambda$ varied among populations ( $\mathrm{p}$ $\leq 0.0001)$, years $(\mathrm{p}=0.0002)$, and browse status $(\mathrm{p}=0.0118)$ There also was a 
Figure 5.1. Life cycle diagram of American ginseng showing the five classes (seeds, 1leaf plants, 2-leaf plants, small adults, and large adults) and all possible transitions between the classes (s) when all plants were included in the calculation of the mean matrix $\left(\mathbf{A}_{\mathbf{H}}\right)$ and (b) when only unbrowsed plants were included in the calculation of the mean matrix $\left(\mathbf{A}_{\mathbf{N H}}\right)$. The mean probabilities of transitioning from one class to another $\left(a_{i j}\right)$ are indicated with numbers above each arrow. The dotted arrows below each class represent the proportion of plants that died. 

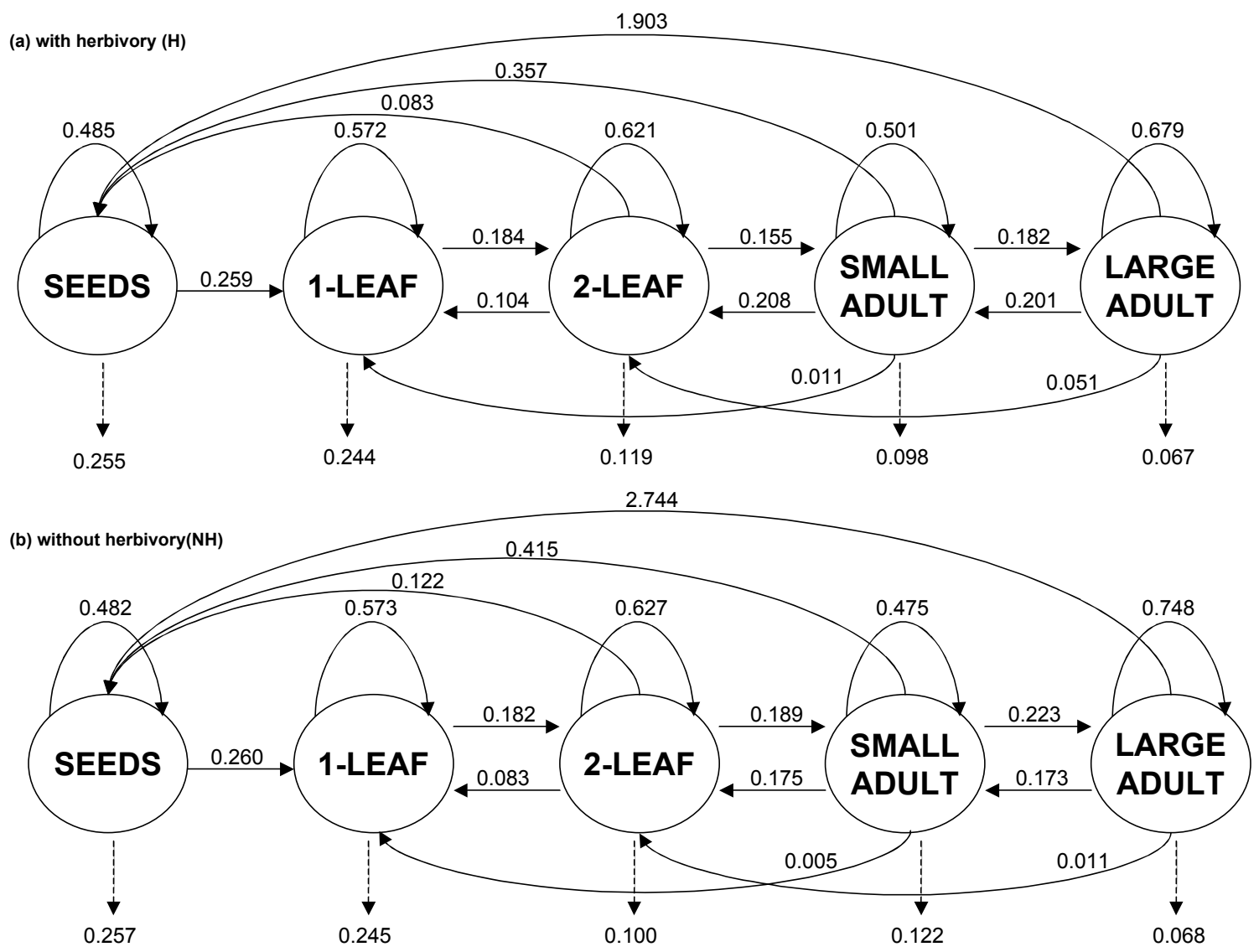
Figure 5.2. The population growth rate $(\lambda)$ of seven natural populations of American ginseng and the combined populations for the following one-year intervals: (a) the mean $\lambda$ for each population, (b) 2000-01, (c) 2001-02, (d) 2002-03, and (e) 2003-04 (includes $\pm 1 \mathrm{SE}$ ). 


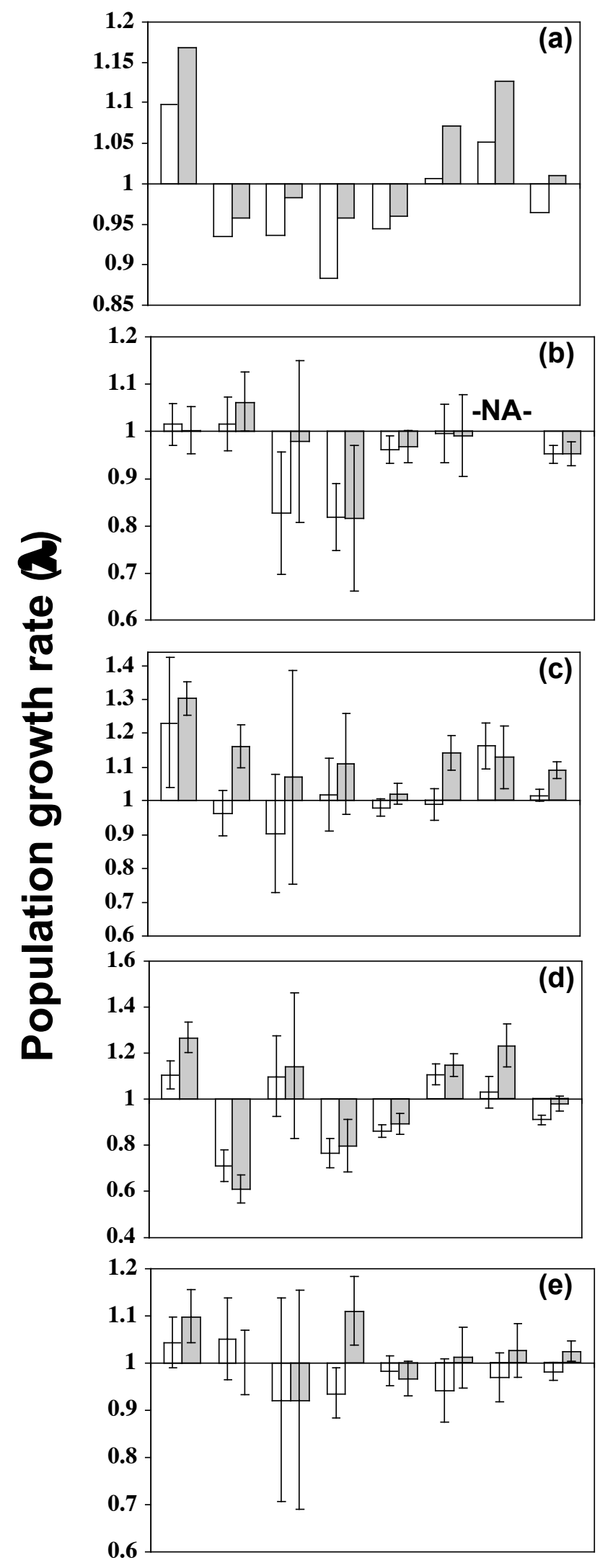

BG BN CR P4 P5 W2 W4 ALL 
differential response of $\lambda$ to year depending on the population $(\mathrm{p} \leq 0.0001)$. Browsing usually had a negative effect on $\lambda$ (Fig. 5.2b-5.2e).

Elasticity analyses of the $A_{H}$ matrix for all populations combined revealed that those matrix elements relating to stasis contributed most to $\lambda$ (Table 5.3). Two-leaf plants remaining 2-leaf plants $\left(a_{33}\right)$ and large adults remaining large adults $\left(a_{55}\right)$ contributed nearly equally (17\% each) to $\lambda$ (Table 5.3). Small adults remaining small adults $\left(a_{44}\right)$, and 1-leaf plants remaining 1-leaf plants $\left(a_{22}\right)$ also contributed substantially (Table 5.3). By comparing the $\mathrm{A}_{\mathrm{H}}$ matrix to the $\mathrm{A}_{\mathrm{NH}}$ matrix, I was able to determine how contributions of matrix elements to $\lambda$ changed when browsed individuals were subtracted. Although the stasis matrix elements $\left(a_{i i}\right)$ continued to contribute most to $\lambda$, their proportional contribution was altered. The fate of large adults $\left(a_{i 5}\right)$ took on added importance to $\lambda$ in the absence of browsed plants. The fate of 2-leaf plants $\left(a_{i 3}\right)$ had a diminished influence (Table 5.3).

The results of the LTRE revealed that the reduction in $a_{55}$ (large adults remaining large adults) caused by herbivory had the greatest contribution to the change in $\lambda$, followed by the decrease in $a_{54}$ (small adults becoming large adults), decrease in $a_{43}$ (2leaf plants becoming small adults), and decrease in $a_{15}$ (large adults producing seeds) (Table 5.4). Although elasticity analyses showed that those matrix elements associated with stasis contributed most to $\lambda$ (Table 5.3), the LTRE showed that changes in the $a_{i i}$ were not responsible for the effects of browsing on the change in $\lambda$ (with the exception of large adults remaining large adults) (Table 5.4). 
Table 5.3. Elasticities $\left(e_{i j}\right)$ corresponding to the mean herbivory matrix $\left(\mathrm{A}_{\mathrm{H}}\right)$ and the mean no herbivory matrix $\left(\mathrm{A}_{\mathrm{NH}}\right)$. The matrix elements having the greatest effect on $\lambda$ are in bold. 


\begin{tabular}{llllll}
\hline & \multicolumn{5}{l}{ Size at time $\mathrm{t}$} \\
\cline { 2 - 6 } Size at time $\mathrm{t}+1$ & Class 1 & Class 2 & Class 3 & Class 4 & Class 5 \\
\hline Herbivory & & & & & \\
Class 1 & 0.0522 & - & 0.0066 & 0.0113 & 0.0336 \\
Class 2 & 0.0514 & $\mathbf{0 . 0 9 5 4}$ & 0.0130 & 0.0007 & - \\
Class 3 & - & 0.0652 & $\mathbf{0 . 1 7 2 0}$ & 0.0268 & 0.0038 \\
Class 4 & - & - & 0.0761 & $\mathbf{0 . 1 2 7 6}$ & 0.0292 \\
Class 5 & - & - & - & 0.0665 & $\mathbf{0 . 1 6 8 9}$ \\
No herbivory & & & & & \\
Class 1 & 0.0641 & - & 0.0055 & 0.0087 & 0.0458 \\
Class 2 & 0.0601 & $\mathbf{0 . 0 8 8 5}$ & 0.0298 & 0.0008 & - \\
Class 3 & - & 0.06768 & $\mathbf{0 . 1 4 2 4}$ & 0.0167 & 0.0010 \\
Class 4 & - & - & 0.0723 & $\mathbf{0 . 0 9 8 1}$ & 0.0265 \\
Class 5 & - & - & - & 0.0732 & $\mathbf{0 . 2 2 1 9}$ \\
\hline
\end{tabular}


Table 5.4. Results of a life table response experiment (LTRE) for American ginseng showing how the two components responsible for changing $\lambda\left(\Delta a_{i j}\right.$ and $\left.s_{i j}\right)$ varied among the possible life-stage transitions observed. Those transitions with the greatest contributions are shown in bold. The $a_{i j}$ values are from the mean no herbivory matrix $\left(\mathrm{A}_{\mathrm{NH}}\right)$ and the mean herbivory matrix $\left(\mathrm{A}_{\mathrm{H}}\right)$. The $s_{i j}$ values of each matrix element are from the average matrix of $A_{N H}$ and $A_{H}$. 


\begin{tabular}{cccc}
\hline $\begin{array}{c}\text { Life cycle } \\
\text { transitions }(j-i)\end{array}$ & $a_{i j, \mathrm{NH}}-a_{i j, \mathrm{H}}$ & $s_{i j}$ & Contribution to $\Delta \lambda$ \\
\hline C1-C1 & -0.0024 & 0.1073 & -0.0003 \\
C1-C2 & 0.0005 & 0.2138 & 0.0001 \\
C2-C2 & 0.0004 & 0.1543 & 0.00006 \\
C2-C3 & -0.0016 & 0.3626 & -0.0006 \\
C3-C1 & 0.0391 & 0.0549 & 0.002 \\
C3-C2 & -0.0213 & 0.1095 & -0.002 \\
C3-C3 & 0.0060 & 0.2573 & 0.002 \\
C3-C4 & 0.0342 & 0.4725 & $\mathbf{0 . 0 1 6}$ \\
C4-C1 & 0.0580 & 0.0247 & 0.001 \\
C4-C2 & -0.0059 & 0.0493 & -0.0003 \\
C4-C3 & -0.0329 & 0.1159 & -0.004 \\
C4-C4 & -0.0260 & 0.2128 & -0.006 \\
C4-C5 & 0.0408 & 0.3809 & $\mathbf{0 . 0 1 6}$ \\
C5-C1 & 0.8420 & 0.0174 & $\mathbf{0 . 0 1 5}$ \\
C5-C3 & -0.1929 & 0.0816 & -0.016 \\
C5-C4 & -0.0288 & 0.1499 & -0.004 \\
C5-C5 & 0.0681 & 0.2684 & $\mathbf{0 . 0 1 8}$ \\
\hline
\end{tabular}


The mean SIF of individuals in all possible class transitions showed how reproduction and growth contributed to $\lambda$. For the non-reproductive individuals, similar patterns emerged regardless of herbivory status (Fig. 5.3a-5.3e). As expected, nonreproductive dying individuals had the largest negative impact on population growth. Plants that transitioned downward (shrank in size) also contributed negatively to $\lambda$, although not as much as dying. Non-reproductive plants remaining within their size class had little effect on $\lambda$ while individuals experiencing upward growth transitions had a large positive effect even though they produced no offspring. The positive contribution of those growing individuals increased as classes increased (Fig. 5.3a-5.3e). For example, small adults becoming large adults (C4-C5) contributed more to $\lambda$ than 2-leaf plants becoming small adults (C3-C4). The effect of browsing on an individual's influence on $\lambda$ was most evident for large adults where each dying or shrinking adult had a greater negative effect on $\lambda$ in the absence of herbivory (Fig. 5.3e).

For the reproductive individuals, two general patterns emerged. First, as expected, a plant's contribution to $\lambda$ (SIF) increased as the number of seeds produced increased, regardless of whether a plant shrank, stayed the same, or grew (Fig. 5.4a). Second, static and growing individuals in classes 3 and 4 had SIF values greater than those predicted by the regression equation (Fig. 5.4b). Although reproductive individuals in class 5 had lower SIF values relative to the predicted, they still had a positive influence on $\lambda$ (Fig. 5.4b). There was no differential response of SIF to seed number in the combined $(\mathrm{H})$ data set and in the unbrowsed $(\mathrm{NH})$ dataset $(\mathrm{p}=0.1962)$. 
Figure 5.3. The sample influence function (SIF) of individuals in the combined population with herbivory $(\mathrm{H})$ and in the combined population without herbivory (NH) undergoing all possible transitions within (a) class 1, (b) class 2, (c) class 3, (d) class 4, and (e) class 5. The class transitions represent a plant going from one class to another in a one-year interval $\left(a_{i j}\right)$. Plants transitioning from class $j$ to class 6 have died. 


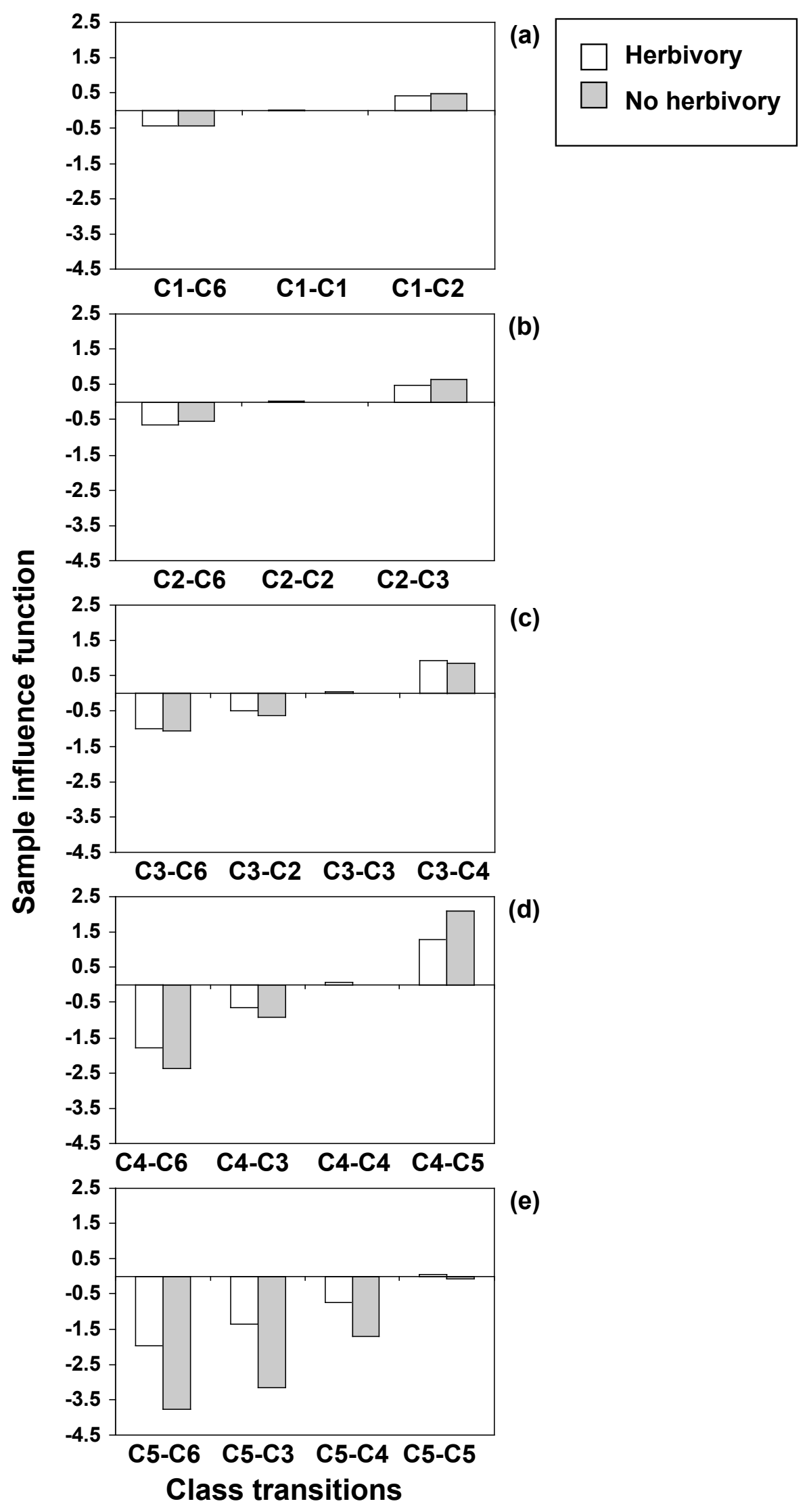


Figure 5.4. (a) The relationship between the mean sample influence function (SIF) of individuals and the number of seeds produced in all possible reproductive transitions both when deer browsing is included and when it is excluded. The dotted regression line represents the relationship when deer browsing is included. The solid line represents the relationship when browsing is excluded. (b) The mean residuals around the deer browsing regression line for each reproductive class transition (includes $\pm 1 \mathrm{SE}$ ). 


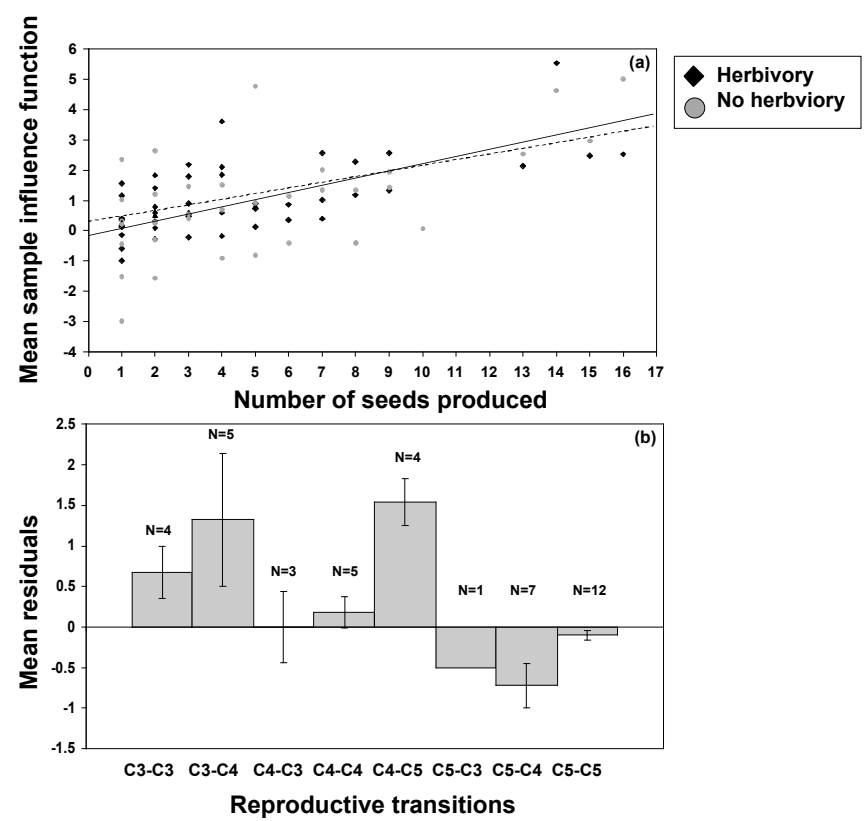




\section{Discussion}

The construction of the demographic model for this study differed in several ways from prior ginseng demography work (see Charron and Gagnon 1991; Nantel et al. 1996). Following the example of Kalisz and McPeek (1992), I used seed cage data combined with census data to incorporate more realistic seed parameter estimates into the model. The use of seed cage data to estimate initial seed survival in the soil also allowed a more realistic estimate of fertility. The model differed in both the number and designation of classes. No new seedling class was included due to low seedling recruitment in all populations, which otherwise would have resulted in poor parameter estimates in the model. Instead, new seedlings were pooled with their older 1-leaf counterparts in Class 2. Larger plants (3- and 4-leaf plants) were partitioned into small and large adults based on leaf area rather than leaf number due to the rarity of 4-leaf plants in many populations.

Despite differences in the details of model construction, several similarities were observed between populations in the range center and those studied at the northern margin (Charron and Gagnon 1991; Nantel et al. 1996). Particularly striking was the prevalence of annual variation in $\lambda$. A population could increase in one year and decline in the next. This variation was even more so when browsed plants were excluded from the calculation of $\lambda$. Another similarity was seen in the elasticity analyses. The elasticity analyses revealed that larger plants contribute most to $\lambda$ if they remain in the same size class rather than grow to the next one.

Previous demographic work emphasized the potential effect of harvest for the herbal trade (Charron and Gagnon 1991; Nantel et al. 1996). This present study has 
shown that natural ginseng populations in the range center are threatened by another pressure, browsing by white-tailed deer. Although browsing rates varied among years, there were some years when at least $50 \%$ of the small and large adults were browsed. The classes most susceptible to browse are those classes that are usually reproductive (Furedi Chapters 2 and 3) and contribute most to $\lambda$ as shown with the SIF analysis. Other studies also have documented high rates of deer browsing on specific species (Miller 1992 et al. 1992; Balgooyen and Waller 1995; Rooney 1997; Williams et al. 2000; Russell et al. 2001)

The net effect of deer browsing in all years produced two alarming patterns. First, under current conditions of deer browsing, the projection from the combined population matrix was a declining $\mathrm{N}$ of $3.7 \%$ per year on average $(\lambda=0.963)$, although these populations would have grown by $1.1 \%$ annually in the absence of the browsing effect ( $\lambda$ $=1.011)$. Similar declines in $\lambda$ due to deer browsing were reported for populations of Trillium grandiflorum (Rooney and Gross 2003; Knight 2004). Second, four populations were declining even when browsed plants were excluded. For populations BN and CR, in addition to deer browsing, the underlying cause of this continual decline in $\lambda$ is most likely a combination of small population size, low recruitment, and location. Population $\mathrm{CR}$ has less than 15 individuals, no seed production (the few reproductive plants in the population were always browsed before seed set) and no new seedlings in the last five years. Population $\mathrm{BN}$ ranged in size from 42 to 69 individuals and experienced near total loss of all fruits due to intense deer browsing of reproductive individuals. Both populations are located on steep banks of streams prone to erosion. Reproductive limitations due to an Allee effect (Hackney and McGraw 2001), high browse pressures, 
zero to low recruitment, and soil erosion are likely leading to imminent extinction of these small populations. Although populations P4 and P5 are two of the larger populations included in the study $(\mathrm{N}>120)$, they have been subjected to illegal harvest activity such as harvesting plants with less than 3 leaves and harvesting out of season. Higher mortality rates in combination with low seedling recruitment in these populations may explain why $\mathrm{N}$ was projected to decline even without the deer effect. The added pressures of deer browsing may be pushing these populations towards extinction.

For a few populations, $\lambda$ decreased when browsed plants were removed from the population. This effect could be due to several possibilities. First, a majority of reproductive individuals were partially browsed late in the season (fruits left intact), but still have positive effects on $\lambda$ due to seed contributions. The exclusion of these plants would then result in a lower $\lambda$ then if they were included due to their positive SIF (i.e., population P5, 2003-04). Second, nearly all reproductive individuals may have been browsed, therefore exclusion of almost an entire class would have a negative effect on $\lambda$ (i.e., population BN, 2002-03). Third, browsing was concentrated on the largest individuals within the larger classes, regardless of the reproductive status so again removal of these plants results in a decrease in $\lambda$ (population BG, 2000-01).

Given that deer browsing suppresses population growth, how does deer browsing act to decrease $\lambda$ ? Previous studies examining the effects of deer browsing have reported that plant size and presence of fruits and flowers influence browsing (Sargent 1990; Anderson 1994; Augustine and Frelich 1995; Knight 2004; Furedi and McGraw 2004). I found similar results that both size and reproductive status influenced whether or not ginseng plants were browsed (Furedi Chapter 3). Small and large adults were consumed 
at higher proportions than 1- and 2-leaf plants and reproductive individuals were more likely to be browsed than their non-reproductive counterparts (Furedi Chapters 2 and 3). The results from the sample influence function (SIF) analysis suggest that these preferentially browsed plants (large, reproductive plants) are also positive contributors to population growth. The life table response experiment (LTRE) showed that large and small adults contribute most to the change in $\lambda$ brought about by browsing. Similarly, Ehrlen (1995) and Knight (2004) both reported that individuals in the largest size classes contributed most to changes in population growth.

Consumption of ginseng fruits by deer is another way $\lambda$ is negatively affected. I found that fruit consumption occurred at high frequencies in some ginseng populations and all seeds are destroyed during the digestive process (Furedi and McGraw 2004). The fact that deer are seed predators (Furedi and McGraw 2004) explains why the fertility components of the life cycle diagram generally increased when browsed individuals were subtracted from the dataset. Removal of deer resulted in a greater proportion of seeds entering the seed class. The LTRE showed that the seed contribution of large adults has a large effect on the change in $\lambda$ caused by browsing. As expected, the SIF associated with seed death (C1-C6) had a negative effect on $\lambda$.

An indirect effect of browsing, but one that has negative consequences for $\lambda$, is the carryover effect on plant growth and reproduction of being browsed. Browsing in one year resulted in a significant decline in leaf area and sympodium height and alteration of reproductive status (from reproductive to non-reproductive) in the season following the browsing event (Furedi Chapter 3). These carryover effects were even more pronounced for plants experiencing consecutive years of browse (Furedi Chapter 3). The 
manifestation of these effects at the population level is an increase in the proportion of plants shrinking to smaller classes $\left(\mathrm{a}_{\mathrm{ij}}, i<j\right)$. The SIF analysis showed that shrinking in size negatively contributes to $\lambda$, which is expected since smaller size classes have lower reproductive rates.

Since the 1973 Appendix II CITES listing of American ginseng as a species at risk (Robbins 2000), research has focused on the impact of harvesting on population growth (Charron and Gagnon 1991) and viability (Nantel et al. 1996) and recovery after harvest (Lewis 1988; Van der Voort et al. 2003). However, the results of this study show that deer browsing is an additional pressure of concern for natural populations in West Virginia and possibly much of the eastern United States where deer populations are overabundant. Although browsing differs from harvest in that browsing does not kill the plant outright and can potentially "hide" a plant from harvesters (deer browse the aboveground biomass leaving the root behind), I have shown that effects of deer on growth and reproduction are enough to negatively affect $\lambda$.

The results of this study in combination with the building body of evidence from research on the effects of overabundant white-tailed deer all indicate the need for population control of this keystone species. Some studies have already reported the loss of forest species due to deer browsing (see review by Russell et al. 2000; Rooney 2001; Horsley et al. 2003; Rooney and Waller 2003). The implications are far ranging for the potential loss of ginseng from its native range due to deer browsing. Ginseng is not only valued for its ecological worth as an understory species, but also has socioeconomic importance. American ginseng plays an integral role in traditional Chinese medicine as an aphrodisiac, tonic, and life-prolonging drug (Goldstein 1975; Pritts 1995). Since the 
United States supplies this demand for ginseng, reductions in natural populations due to deer browsing may result in a minimum annual loss of $\$ 18$ million to states with active ginseng programs (Robbins 1999; Robbins 2000). Not only does potential population decline affect state programs but also the harvesters themselves who often depend on the sale of ginseng as supplemental income (Bailey 1999). Within Appalachia, the harvest and sale of ginseng is commonly viewed as a cross-generational thread that unites families (Pritts 1995; Hufford 1997; Bailey 1999). Without intervention by land and wildlife managers, natural ginseng populations may not be able to support both deer browsing and human harvesting. The only plausible solution for promoting the growth of ginseng while still maintaining the traditions and economic success associated with the species is to reduce deer numbers. 


\section{Acknowledgements}

I thank the following assistants for their much appreciated assistance in the field:

G. Jochum, R. Kenyon, N. Kota, S. Lightner, R. May, E. Mooney, M. Olive, and C.

Packert. This research was made possible through National Science Foundation Grant DEB - 0212411 to J. B. McGraw. 


\section{Literature cited}

Alverson, W. S., D. M. Waller, and S. L. Solheim. 1988. Forest too edge: edge effects in northern Wisconsin. Conservation Biology 2: 348-358.

Anderson, R. C., J. S. Fralish, J. E. Armstrong, and P. K. Benjamin. 1993. The ecology and biology of Panax quinquefolium L. (Araliaceae) in Illinois. American Midland Naturalist 129: 357-372.

Anderson, R. C. 1994. Height of white-flowered Trillium (Trillium grandiflorum) as an index of deer browsing intensity. Ecological Applications 4: 104-109.

Augustine, D. J. and L. E. Frelich. 1998. Effects of white-tailed deer on populations of an understory forb in a fragmented deciduous forest. Conservation Biology 12: 995-1004.

Bailey, B. 1999. Social and economic impacts of wild harvested products. Dissertation. West Virginia University, Morgantown, West Virginia, USA.

Balgooyen, C. P. and D. M. Waller. 1995. The use of Clintonia borealis and other indicators to gauge impacts of white-tailed deer on plant communities in Northern Wisconsin, USA. Natural Areas Journal 15: 308-318. 
Baskin, C. C. and J. M. Baskin. 1998. Page 19 in Seeds: ecology, biogeography, and evolution of dormancy and germination. Academic Press, San Diego, California.

Caswell, H. 2001. Matrix population models: construction, analysis, and interpretation. Second edition. Sinauer, Sunderland, Massachusetts, USA.

Carpenter, S. G. and G. Cottam. 1982. Growth and reproduction of American ginseng (Panax quinquefolium) in Wisconsin. Canadian Journal of Botany 60: 26922696.

Charron, D. and D. Gagnon. 1991. The demography of northern populations of Panax quinquefolium (American ginseng). Journal of Ecology 79: 431-445.

Cottrell, H. J. 1947. Tetrazolium salt as a seed germination indicator. Nature 159: 748

deCalesta, D. S. 1994. Effects of white-tailed deer on songbirds within managed forests in Pennsylvania. Journal of Wildlife Management 58: 711-718.

Ehrlen, J. 1995. Demography of the perennial herb Lathyrus vernus II. Herbviory and population dynamics. Journal of Ecology 83: 297-308. 
Fletcher, J. D., L. A. Shipley, W. J. McShea, and D. L. Shumway. 2001. Wildlife herbivory and rare plants: the effects of white-tailed deer, rodents, and insects on growth and survival of Turk's cap lily. Biological Conservation 101: 229-238.

Flowerdew, J. R. and S. A. Ellwood. 2001. Impacts of woodland deer on small mammal ecology. Forestry 74: 277-287.

Furedi, M. and J. B. McGraw. 2004. White-tailed deer: dispersers or predators of American ginseng seeds? American Midland Naturalist 152 268-276.

Fuller, R. J. 2001. Responses of woodland birds to increasing numbers of deer: a review of evidence and mechanisms. Forestry 74: 290-298.

Goldstein, B. 1975. Ginseng: its history, dispersion, and folk traditions. American Journal of Chinese Medicine 3: 223-234.

Hackney, E. E. and J. B. McGraw. 2001. Experimental demonstration of an Allee effect in American ginseng. Conservation Biology 15: 129-136.

Horsley, S. B., S. L. Stout, and D. S. deCalesta. 2003. White-tailed deer impact on the vegetation dynamics of a northern hardwood forest. Ecological Applications 13: 98-118. 
Hufford, M. 1997. American ginseng and the idea of the commons. Folklife Center News 19: 3-18.

Kalisz, S. and M. A. McPeek. 1992. Demography of an age-structured annual: resampled projection matrices, elasticity analyses, and seed bank effects. Ecology 73: 1082-1093.

Knight, T. M. 2004. The effects of herbivory and pollen limitation on a declining population of Trillium grandiflorum. Ecological applications 14: 915-928.

Lewis, W. H. 1988. Regrowth of a decimated population of Panax quinquefolium in a Missouri climax forest. Rhodora 90: 1-5.

Lewis, W. H. and V. E. Zenger. 1982. Population dynamics of the American ginseng Panax quinquefolium (Araliaceae). American Journal of Botany 69: 1483-1490.

MATLAB. 1993. MATLAB. Version 4.0. MathWorks, Natick, Massachusetts, USA.

McGraw, J. B. 1989. Effects of age and size on life histories and population growth of Rhododendron maximum shoots. American Journal of Botany 76: 113-123. 
McGraw, J. B., M. Furedi, K. Maiers, C. Carroll, G. Kauffman, A. Lubbers, J. Wolf, R. C. Anderson, M. R. Anderson, B. Wilcox, D. Drees, M. E. Van der Voort, M. A. Albrecht, A. Nault, H. MacCulloch, and A. Gibbs. In press. Berry ripening and harvest season in wild American ginseng. Northeastern Naturalist.

McShea, W. J. and J. H. Rappole. 1997. Herbivores and the ecology of forest understory birds. In: W. J. McShea and J. H. Rappole (eds.), The science of overabundance: deer ecology and population management. Smithsonian Institution Press, Washington D. C., pp. 298-309.

Miller, S. G., S. P. Bratton, and J. Hadidian. 1992. Impacts of white-tailed deer on endangered and threatened vascular plants. Natural Areas Journal 12: 67-74.

Nantel, P., D. Gagnon, and A. Nault. 1996. Population viability analysis of American ginseng and wild leek harvested in stochastic environments. Conservation Biology 10: 608-621.

Pritts, K. D. 1995. Ginseng: how to find, grow, and use America’s forest gold. Stackpole Books, Mechanicsburg, Pennsylvania, USA.

Robbins, C. S. 1999. Ginseng dealers surveyed, conservation measures addressed. TRAFFIC Bulletin 18: 3-5. 
Robbins, C. S. 2000. Comparative analysis of management regimes and medicinal plant trade monitoring mechanisms for American ginseng and goldenseal. Conservation Biology 14: 1422-1434.

Rooney, T. P. 1997. Escaping herbivory: refuge effects on the morphology and shoot demography of the clonal forest herb Maianthemum canadense. Journal of the Torrey Botanical Society 124: 280-285.

Rooney, T. P. 2001. Deer impacts on forest ecosystems: a North American perspective. Forestry 74: 201-208.

Rooney, T. P. and K. Gross. 2003. A demographic study of deer browsing impacts on Trillium grandiflorum. Plant Ecology 168: 267-277.

Rooney, T. P. and D. M. Waller. 2003. Direct and indirect effects of white-tailed deer in forest ecosystems. Forest Ecology and Management 181: 165-176.

Russell, F. L., D. B. Zippin, and N. L. Fowler. 2001. Effects of white-tailed deer (Odocoileus virginianus) on plants, plant populations, and communities: a review. American Midland Naturalist 146: 1-26.

Sargent, S. 1990. Neighborhood effect on fruit removal by birds: a field experiment with Viburnum dentatum (Caprifoliaceae). Ecology 71: 1289-1298. 
Sokal, R. R. and F. J. Rohlf. 1995. Biometry: the principles and practice of statistics in biological research. Third edition. W. H. Freeman and Company, New York, USA.

Van Deelen, T. R., K. S. Pregitzer, and J. B. Haulfer. 1996. A comparison of presettlement and present-day forests in northern Michigan deer yards. American Midland Naturalist 135: 181-194.

Van der Voort, M. E., B. Bailey, D. E. Samuel, and J. B. McGraw. 2003. Recovery of populations of goldenseal (Hydrastis canadensis L.) and American ginseng (Panax quinquefolius L.) following harvest. American Midland Naturalist 149: $282-292$.

Vavrek, M. C., J. B. McGraw, and H. S. Yang. 1996. Within population variation in demography of Taraxacum officinale: maintenance of genetic diversity. Ecology 77: 2098-2107.

Vavrek, M. C., J. B. McGraw, and H. S. Yang. 1997. Within-population vaiation in demography of Taraxacum officinale: season- and size-dependent survival, growth, and reproduction. Journal of Ecology 85: 277-287. 
Williams, C. E., E. V. Mosbacher, and W. J. Moriarity. 2000. Use of turtlehead

(Chelone glabra L.) and other herbaceous plants to assess intensity of white-tailed deer browsing on Allegheny Plateau riparian forests, USA. Biological

Conservation 92: 207-215. 


\section{CHAPTER 6}

General Conclusions 
The unusual rarity of American ginseng (Panax quinquefolius L.), wide distribution but rare within its range (Rabinowitz 1981), has been previously attributed to: 1) harvesting of the ginseng root by humans for medicinal sales on the Asian market, and 2) habitat destruction/degradation due to altered land use and environmental changes (Charron and Gagnon 1991). However, the results from this dissertation work show that herbivory by white-tailed deer (Odocoileus virginianus Zimm.) is an additional pressure contributing to the decline of populations within the range center. Under current deer pressures, the combined population growth rate $(\lambda)$ of plants followed over the last five years (2000-04) indicate a decline by $3.7 \%$ per year on average.

Selective browsing is one way deer negatively affect ginseng populations (Chapter 2). Consistent with previous work on ungulate food selection (Belovsky 1981; Edwards 1985; Anderson 1994; Ehrlen 1995; Augustine and Frelich 1998), I found that characteristics associated with apparency influenced browsing by deer. In general, larger, reproductive plants were more susceptible to deer browsing than their smaller, nonreproductive counterparts. Susceptibility to browsing also was a function of spatial arrangement of plants within a population. Similar to what others have reported (Rooney 1997; Long et al. 1998), I found that certain microsite conditions served as refugia from browsing. Unfortunately, the same plants susceptible to deer browsing also are the individuals (or classes of individuals) contributing most to population growth $(\lambda)$ (Chapter 5). Over time, selection due to deer browsing can result in declines in $\lambda$. Carryover effects on individual plants due to deer browsing also contribute to population decline (Chapter 3). I found that not only did complete browsing result in the loss of aboveground biomass and reproductive structures in the season that browsing 
occurred, but these negative effects were carried over into the following year.

Furthermore, for plants that experienced multiple years of deer damage, the carryover effects were compounded. In addition, timing of browse occurrence affected the severity of carryover effects on leaf area. Other studies on the effects of ungulate herbivory reported similar carryover effects in the year(s) following browsing (Edwards, 1985; Anderson, 1994; Ehrlen, 1995; Augustine and Frelich, 1998). Negative carryover effects due to browsing not only alter population structure (populations with smaller plants) but also reduce seed contributions to the seed bank by reducing reproduction (both reproductive status and bud number). Moreover, frugivory by deer results in the destruction of ginseng seeds (Chapter 4) (Furedi and McGraw, 2004). For a species like ginseng with already naturally low seed production rates, loss of even a slight proportion of seeds can dramatically influence new recruitment. Ultimately, these carryover effects in combination with seed destruction due to deer browsing contribute to declines in $\lambda$ (Chapter 5).

The overall results from this series of research questions provide evidence that white-tailed deer are negatively impacting ginseng. Negative deer browsing effects were seen at both the individual plant level and the population level. In addition, this research showed that population growth is threatened by overabundant white-tailed deer alone even without considering the impact of human harvesting. Although browsing differs from harvest in that browsing does not kill a plant outright and can potentially "hide" a plant from harvesters (deer browse the aboveground portion and leave the root behind), the combined results suggest that selective browsing, carryover effects, and seed losses are enough to negatively affect $\lambda$. Under current deer pressures, natural ginseng 
populations may not be able to support both deer browsing and the long-standing Appalachian tradition of harvesting ginseng (Pritts 1995; Hufford 1997; Bailey 1999). Thus, the viability of the ginseng trade itself (a minimum estimated annual value of $\$ 18$ million to states where it grows naturally) (Robbins 2000) is threatened by white-tailed deer.

My findings, in combination with a building body of evidence, show that deer are impacting forest plant populations, communities, and ecosystems (see Flowerdew and Ellwood, 2001; Fuller, 2001; Gill and Beardall, 2001; Russell et al., 2001; Rooney, 2001; Horsley et al., 2003; Rooney and Waller, 2003). Decades of management focused at increasing deer numbers, in addition to other factors such as loss of top predators and creation of edge habitat caused by landscape fragmentation (Russell et al., 2001), have resulted in large deer herds that are negatively impacting valuable managed species such as ginseng, as well as less "charismatic" and economically valuable understory plants. A multi-species view of ecosystem management is clearly required in natural systems, particularly where overabundance of one species detrimentally affects others. Ultimately, the solution to the problems associated with deer browsing is the reduction in current deer numbers. 


\section{Literature cited}

Anderson, R. C. 1994. Height of white-flowered trillium (Trillium grandiflorum) as an index of deer browsing intensity. Ecological Applications 4: 104-109.

Augustine, D. J. and L. E. Frelich. 1998. Effects of white-tailed deer on populations of an understory forb in a fragmented deciduous forest. Conservation Biology 12: 995-1004.

Bailey, B. 1999. Social and economic impacts of wild harvested products. Dissertation. West Virginia University, Morgantown, West Virginia, USA.

Belovsky, G. E. 1981. Food selection by a generalist herbivore: the moose. Ecology 62: 1020-1030.

Charron, D., and D. Gagnon. 1991. The demography of northern populations of Panax quinquefolium (American ginseng). Journal of Ecology 79: 431-445.

Edwards, J. 1985. Effects of herbivory by moose on the flower and fruit production of Aralia nudicaulis. Journal of Ecology 73: 861-868.

Erlen, J. 1995. Demography of the perennial herb Lathyrus vernus. I. Herbivory and individual performance. Journal of Ecology 83: 287-295. 
Flowerdew, J. R. and S. A. Ellwood. 2001. Impacts of woodland deer on small mammal ecology. Forestry 74: 277-287.

Fuller, R. J. 2001. Responses of woodland birds to increasing numbers of deer: a review of evidence and mechanisms. Forestry 74: 289-298.

Furedi, M. and J. B. McGraw. 2004. White-tailed deer: dispersers or predators of American ginseng seeds. American Midland Naturalist 152: 268-276.

Gill, R. M. A. and V. Beardall. 2001. The impact of deer on woodlands: the effects of browsing and seed dispersal on vegetation structure and composition. Forestry 74: 209-218.

Horsley, S. B., S. L. Stout, and D. S. deCalesta. 2003. White-tailed deer impact on the vegetation dynamics of a northern hardwood forest. Ecological Applications 13: 98-118.

Hufford, M. 1997. American ginseng and the idea of the commons. Folklife Center News 19: 3-18.

Long, Z. T., W. P. Carson, and C. J. Peterson. 1998. Can disturbance create refugia from herbivores: an example with hemlock regeneration on treefall mounds. Journal of the Torrey Botanical Society 125: 165-168. 
Pritts, K. D. 1995. Ginseng: how to find, grow, and use America's forest gold. Stackpole Books, Mechanicsburg, Pennsylvania, USA.

Rabinowitz, D. 1981. Seven forms of rarity. In: H. Synge (ed.), The biological aspects of rare plant conservation. Wiley Press, New York, New York, USA.

Robbins, C. S. 2000. Comparative analysis of management regimes and medicinal plant trade monitoring mechanisms for American ginseng and goldenseal. Conservation Biology 14: 1422-1434.

Rooney, T. P. 1997. Escaping herbivory: refuge effects on the morphology and shoot demography of the clonal forest herb Maianthemum canadense. Journal of the Torrey Botanical Society 124: 280-285.

Rooney, T. P. 2001. Deer impacts on forest ecosystems: a North American perspective. Forestry 74: 201-208.

Rooney, T. P. and D. M. Waller. 2003. Direct and indirect effects of white-tailed deer in forest ecosystems. Forest Ecology and Management 181: 165-176.

Russell, F. L., D. B. Zippin, and N. L. Fowler. 2001. Effects of white-tailed deer (Odocoileus virginianus) on plants, plant populations and communities: a review. American Midland Naturalist 146: 1-26. 


\section{CURRICULUM VITAE}

MARY ANN FUREDI

RR1 Box 300A

Wapwallopen, PA 18660

(570) 868-6245

mafuredi@aol.com

\section{EDUCATION}

Ph.D. Environmental and Evolutionary Biology

West Virginia University, 2004.

Dissertation: The effects of herbivory by white-tailed deer (Odocoileus virginianus Zimm.) on the population ecology and conservation biology of American ginseng (Panax quinquefolius L.).

B.S. Biology

Fairleigh Dickinson University, 1994.

\section{POSITIONS HELD}

2004-2004 Lecturer, Department of Biology, West Virginia Wesleyan College

1999-2004 Teaching Assistant, Department of Biology, West Virginia University

2000-2003 Graduate Research Assistant, Department of Biology, West Virginia University

1995-1999 Pathology Assistant, Saint Barnabas Medical Center, Livingston, NJ

1996-1997 Research Assistant, Tissue Transplant Foundation, Somerset, NJ

1993-1997 Medical-Legal Death Investigator, Morris County and NJ State Medical Examiner's Office

\section{RESEARCH EXPERIENCE}

1999-present The effects of herbivory by white-tailed deer (Odocoileus virginianus Zimm.) on the population ecology and conservation biology of American ginseng (Panax quinquefolius L.). (Dissertation research) 
2000-2002 Evaluation of management options for wild American ginseng populations based on demographic consequences. (Research Assistant to J. B.

McGraw, WVU)

2002-2003 Effects of harvesting and white-tailed deer browsing on demography and population viability of American ginseng. (Research Assistant to J. B. McGraw, WVU)

1996-1997 Guide to organ transplantation. (Research Assistant to R. Suarez, Tissue Transplant Foundation)

\section{TEACHING EXPERIENCE}

2004 "Environmental Science Lecture" (BIOL 130, Lecturer at WVWC)

2004 "Environmental Science Lab" (BIOL 130L, Lab Instructor at WVWC)

2002-2003 "Wetland Ecology Lab" (BIOL 793J, Teaching Assistant at WVU)

2003 "Biometry" (BIOL 302, Teaching Assistant/Grader at WVU)

2000-2003 "Total Science Experience Lab" (BIOL 321, Teaching Assistant at WVU)

1999 "Principles of Biology Lab" (BIOL 115, Teaching Assistant at WVU)

\section{ACADEMIC SERVICE}

2003-2004 Co-coordinator of WVU Department of Biology Seminar Series

2002-2003 Student Coordinator of Graduate Student Recruitment Weekend

\section{PUBLICATIONS}

Furedi, M. and J. B. McGraw. 2004. White-tailed deer: dispersers or predators of American ginseng. American Midland Naturalist 152: 268-276.

\section{MANUSCRIPTS IN PRESS}

McGraw, J. B., M. Furedi, K. Maiers, C. Carroll, G. Kauffman, A. Lubbers, J. Wolf, R. C. Anderson, M. R. Anderson, B. Wilcox, D. Drees, M. E. Van Der Voort, M. A. Albrecht, A. Nault, H. MacCulloch, and A. Gibbs. Berry ripening and harvest season in wild American ginseng. For Northeastern Naturalist.

McGraw, J. B. and M. Furedi. Deer browsing and population viability of a forest understory plant. For Science. 


\section{SUBMITTED MANUSCRIPTS}

Furedi, M. and J. B. McGraw. Plant characteristics and microsite conditions affecting herbivory of American ginseng by white-tailed deer. For Journal of the Torrey Botanical Society.

Furedi, M. and J. B. McGraw. Effects of browsing by white-tailed deer on the survival, growth, and reproduction of American ginseng. For American Journal of Botany.

\section{MANUSCRIPTS IN PREPARATION}

Furedi, M. and J. B. McGraw. Demography of American ginseng (Panax quinquefolius L.): effects of herbivory by white-tailed deer (Odocoileus virginianus Z.). For Conservation Biology

\section{PRESENTATIONS}

Furedi, M. and J. B. McGraw. 2004. Causes and consequences of browsing by whitetailed deer on American ginseng. Poster presentation at Ecological Society of America Annual meeting in New York City.

Furedi, M. and J. B. McGraw. 2003. Deer browsing effects on American ginseng: better late than never? Oral presentation at $88^{\text {th }}$ ESA Annual Meeting in Savannah, Georgia.

McGraw, J. B. and M. Furedi. 2003. Demography of central populations of American ginseng. Oral presentation at $88^{\text {th }}$ ESA Annual Meeting in Savannah, Georgia.

Furedi, M. 2003. Biology of American ginseng and pressures affecting natural populations. Oral presentation at a sustainable forest products course for continuing education credits for West Virginia Foresters.

Furedi, M., M. E. Van der Voort, S. M. Spencer, and J. B. McGraw. 2002. Browsing effects on growth and reproduction in a natural population of American ginseng. Oral presentation at $87^{\text {th }}$ ESA Annual Meeting in Tucson, Arizona.

Furedi, M. and J. B. McGraw. 2001. The effects of browsing by white-tailed deer on wild ginseng populations in West Virginia. Oral presentation at the Conference for Appalachian Ethnobotany Studies. 
Furedi, M. and J. B. McGraw. 2001. The effects of browsing by white-tailed deer on ginseng populations. Poster presentation at the $2^{\text {nd }}$ annual WVU Eberly College of Arts and Science Graduate Program Forum.

Furedi, M. 2001. Crouching deer, hidden ginseng. Oral presentation for the D.C. Scientific Writers Association.

\section{GUEST LECTURES}

Furedi, M. 2004. Population structure, growth, and decline. Guest lecturer for BIOL 361 "Plant Ecology", West Virginia University, Department of Biology.

Furedi, M. 2004. Population growth equations. Guest lecturer for BIOL 221 "Ecology and Evolution”, West Virginia University, Department of Biology.

Furedi, M. 2003. Population dynamics. Guest lecturer for BIOL 221 "Ecology and Evolution", West Virginia University, Department of Biology.

Furedi, M. 2003. Two-way analysis of variance. Guest lecturer for BIOL 302

"Biometry", West Virginia University, Department of Biology.

Furedi. M. 2002. Use of Distance to determine relative abundance. Guest lecturer for WMAN 431 "Wildlife Habitat Techniques", West Virginia University, Department of Wildlife and Fisheries Resources.

\section{AWARDS AND GRANTS} Biology

Recipient of WVU Eberly College of Arts and Sciences Doctoral Travel Award

Recipient of WVU Eberly College of Arts and Sciences Doctoral Travel Award

2002

Outstanding Teaching Assistant, Department of Biology, Eberly College of Arts and Sciences, West Virginia University 


\section{PROFESSIONAL MEMBERSHIPS}

Botanical Society of America

Ecological Society of America

Society for Conservation Biology 